UNIVERSIDADE DE SÃO PAULO

FACULDADE DE ODONTOLOGIA DE RIBEIRÃO PRETO

SÉRGIO JORGE JAYME

EFEITO DE DIFERENTES TEMPOS DE ATIVAÇÃO SOBRE A ESTABILIDADE E RESPOSTA ÓSSEA AO REDOR DE IMPLANTES DENTÁRIOS. ESTUDO POR ANÁLISE DE FREQÜÊNCIA DE RESSONÂNCIA E HISTOMORFOMÉTRICO EM CÃES.

RIBEIRÃO PRETO 


\title{
EFEITO DE DIFERENTES TEMPOS DE ATIVAÇÃO SOBRE A ESTABILIDADE E RESPOSTA ÓSSEA AO REDOR DE IMPLANTES DENTÁRIOS. ESTUDO POR ANÁLISE DE FREQÜÊNCIA DE RESSONÂNCIA E HISTOMORFOMÉTRICO EM CÃES.
}

\begin{abstract}
Tese apresentada ao Curso de PósGraduação da Faculdade de Odontologia de Ribeirão Preto da Universidade de São Paulo para obtenção do título de Doutor em Odontologia, Área de concentração: Reabilitação Oral.
\end{abstract}

Orientador: Prof. Dr. Ricardo Faria Ribeiro

Co-orientador: Prof. Dr. Arthur Belém Novaes Jr.

RIBEIRÃO PRETO 
AUTORIZO A REPRODUÇÃO E DIVULGAÇÃO TOTAL OU PARCIAL DESTE TRABALHO, POR QUALQUER MEIO CONVENCIONAL OU ELETRÔNICO, PARA FINS DE ESTUDO E PESQUISA, DESDE QUE CITADA A FONTE.

Catalogação na publicação

Serviço de Documentação Odontológica

Faculdade de Odontologia de Ribeirão Preto da Universidade de São Paulo

Jayme, Sérgio Jorge

Efeito de diferentes tempos de ativação sobre a estabilidade e resposta óssea ao redor de implantes dentários. Estudo por análise de freqüência de ressonância e histomorfométrico em cães. Ribeirão Preto, 2009.

183p.; $30 \mathrm{~cm}$

Tese de doutorado, apresentada à Faculdade de Odontologia de Ribeirão Preto/USP. Área de concentração: Reabilitação Oral.

Orientador: Ribeiro, Ricardo Faria.

1. Implantes dentários 2. carga precoce 3. carga imediata 4. estabilidade primária 5.densidade óssea 6.contato osso-implante; osseointegração; estudos com animais 
FOLHA DE APROVAÇÃO

Sérgio Jorge Jayme

Título da tese: Efeito de diferentes tempos de ativação sobre a estabilidade e resposta óssea ao redor de implantes dentários. Estudo por análise de freqüência de ressonância e histomorfométrico em cães.

Tese apresentada ao Curso de Pós-Graduação da Faculdade de Odontologia de Ribeirão Preto da Universidade de São Paulo para obtenção do título de Doutor em Odontologia, Área de concentração Reabilitação Oral.

Aprovado em:

Banca Examinadora:

Prof. Dr.

Instituição:

Assinatura:

Prof. Dr.

Instituição:

Assinatura:

Prof. Dr.

Instituição:

Assinatura:

Prof. Dr.

Instituição:

Assinatura:

Prof. Dr.

Instituição:

Assinatura: 
DEDICATÓRIA 
Dedico e agradeço a concretização deste trabalho àqueles que mais amo.

À meu pai, Abraão Miguel Jayme (in memorian), que foi um pai amigo sempre me amparando; alegre compartilhando vitórias e emoções; adversário, quando teus cuidados fizeram algo me negar; apreensivo, quando “criei asas"para alçar vôos independentes; forte para me incentivar, quando sua vontade era chorar e fraco para me mostrar que às vezes caímos, mas o importante é ter forças para se levantar. Um ser humano sempre tentando me ensinar a acertar. Um grande e eterno amigo, onde quer que tu estejas...

À minha mãe, Lourdes Jorge Jayme, por suas histórias de sucesso na educação dos filhos, diante de todas as adversidades da vida e que em outras ocasiões, tive o privilégio de homenageá-la por seus méritos.

À Rose, minha esposa, todo o meu carinho e amor e meu reconhecimento pela compreensão nos momentos de ausência; foi a pessoa que me ensinou as coisas que são primordiais na vida.

Aos meus filhos, Eduardo e Letícia, que servem de estimulo em minha vida e dos quais me orgulho muito. A eles dedico os méritos deste trabalho. 
AGRADECIMENTOS ESPECIAIS 


\section{Prof. Dr. Ricardo Faria Ribeiro}

É com alegria que ao final de dois anos faço este agradecimento ao meu orientador que muito me ajudou e me ensinou a trilhar os caminhos da pesquisa, sempre me orientando e motivando.

Sua amizade, paciência e seus conhecimentos foram fundamentais para a execução deste trabalho. Meus mais sinceros agradecimentos pelas suas orientações e atenção.

\section{Prof. Dr. Arthur Belém Novaes Júnior}

Em especial ao meu grande amigo e co-orientador - Mestre de sempre por sua paciência, sensibilidade, visão, conhecimento e um dos pesquisadores mais diferenciados, por seu senso crítico, na Odontologia contemporânea.

Admiro sua dedicação à pesquisa e o prazer que você sempre demonstrou em orientar, ajudar e mostrar o caminho certo a ser seguido. 


\section{Prof. Dr. Valdir Muglia}

Meu grande amigo e incentivador, agradeço por sua atenção sempre marcada pela disposição e boa vontade em me ajudar na concretização deste trabalho.

Sinto-me honrado por poder contar com sua amizade e profundamente grato pela sua ajuda, orientação e pelas palavras de ânimo e conforto. Obrigado pela credibilidade.

\section{Prof. Dr. Julio Cezar Sá Ferreira}

Meus sinceros agradecimentos por todo apoio na minha formação profissional. Mais do que isso, agradeço sua amizade, a qual é de fundamental importância para mim.

Um amigo que despertou em mim o interesse pela Osseointegração e pela pesquisa.

Julio, você é o grande mestre! 
AGRADECIMENTOS 
Ao grande Arquiteto do Universo, pelo dom da vida, pela saúde, pela proteção, pela força e pelo conforto nas horas difíceis.

Aos professores da Pós-graduação em Reabilitação Oral da Faculdade de Odontologia de Ribeirão Preto - Universidade de São Paulo, pelos ensinamentos transmitidos.

Aos animais que participaram da pesquisa, aos quais o destino inexorável deu-lhes o poder e a grandeza de servir à humanidade que por eles passou indiferente.

Ao Sebastião Carlos Bianco agradeço toda a sua colaboração, boa vontade e disposição, sempre pronto a me ajudar.

Ao professor e amigo Raphael de Freitas Souza pelo auxílio e simpatia, colaborando com o presente trabalho.

À Nobel Biocare pelo fornecimento dos implantes e componentes protéticos, possibilitando a realização deste trabalho.

Ao meu grande amigo Marco Antonio Amorim Vasco, pela amizade sincera, sempre pronto em me ajudar nas cirurgias com os animais, nas fotografias fantásticas e nos ensinamentos de informática. Você tem um grande coração e um caráter invejável, eu desejo a você um sucesso imensurável.

Aos meus amigos Abílio Ricciardi Coppedê, Natércia Carreira Soriani e Gisseli Bertozzi Ávila,meus profundos agradecimentos, pelo convívio agradável durante todo o curso e pela amizade única, companheirismo e apoio. Muito obrigado pelo carinho que recebi de vocês. 


\section{À Isabel Cristina Galino Sola e Regiane Cristina Moi}

Sacilotto, da secretaria da Seção de Pós-Graduação da Faculdade de Odontologia de Ribeirão Preto-USP, pela atenção concedida durante todo o curso.

À Regiane de Cássia Tirado Damasceno e Ana Paula Xavier, do Departamento de Materiais Dentários e Prótese da Faculdade de Odontologia de Ribeirão Preto-USP, pela presteza durante todo o curso.

Aos meus irmãos, Marisia, Miguel e Marcelo, sempre prontos a apoiar as minhas decisões, me amparando quando estas não foram tão acertadas e compartilhando comigo aquelas bem sucedidas.

A toda equipe de funcionários e assistentes do IAP- Instituto Sérgio Jayme, aos meus amigos e a todos aqueles que diretamente ou indiretamente contribuíram para a realização deste trabalho obrigado pelo incentivo, apoio, carinho e acima de tudo, a paciência que tiveram comigo nos momentos de estresse.

À Nobel Biocare pela doação dos implantes e componentes.

À FAPESP - Fundação de Amparo à Pesquisa do Estado de São Paulo, pelo auxílio financeiro para a realização desta pesquisa (Processo $\mathrm{n}^{\circ}$ 06/04747-0). 


\section{SUMÁRIO}

\begin{tabular}{|c|c|}
\hline Resumo & 15 \\
\hline Abstract & 17 \\
\hline 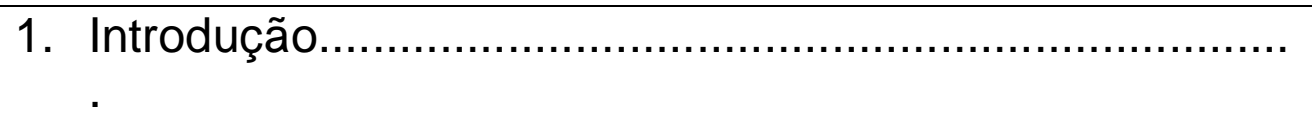 & 19 \\
\hline 2. Proposição.. & 24 \\
\hline 3. Materiais e Métodos.............. & 26 \\
\hline 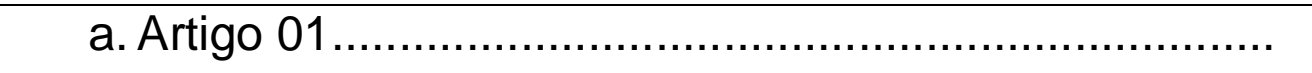 & 27 \\
\hline 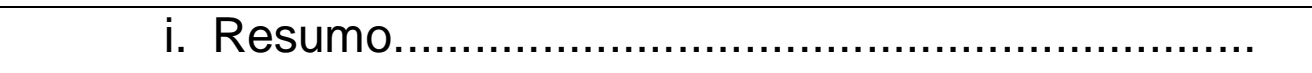 & 28 \\
\hline ii. Introdução............................ & 28 \\
\hline iii. Materiais e Métodos............................................... & 31 \\
\hline iv. Resultados.......................... & 34 \\
\hline v. Discussão......... & 36 \\
\hline 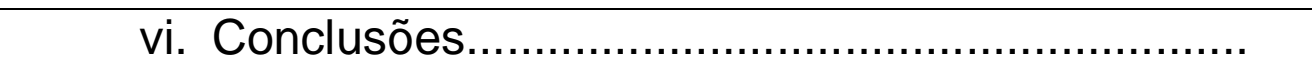 & 40 \\
\hline 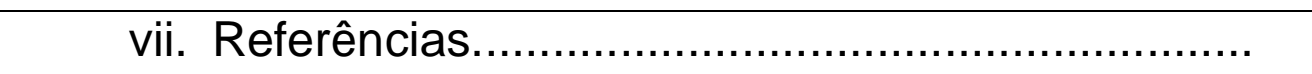 & 42 \\
\hline 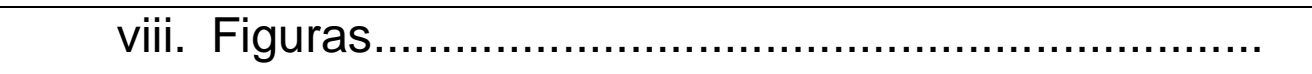 & 49 \\
\hline ix. Tabela. & 51 \\
\hline 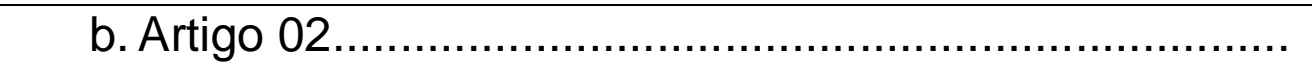 & 52 \\
\hline i. Resumo......... & 53 \\
\hline ii. Introdução..... & 53 \\
\hline 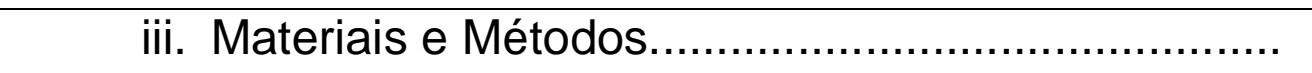 & 56 \\
\hline 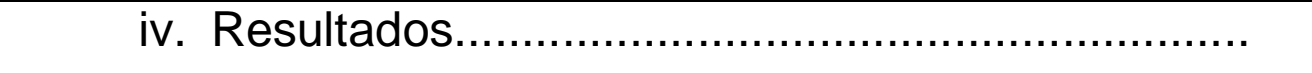 & 61 \\
\hline v. Discussão................................................. & 63 \\
\hline 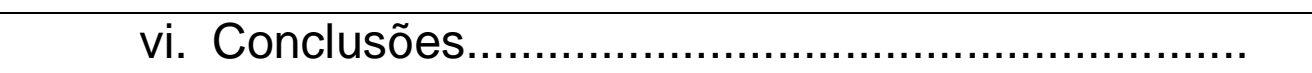 & 67 \\
\hline
\end{tabular}




\begin{tabular}{|c|c|}
\hline 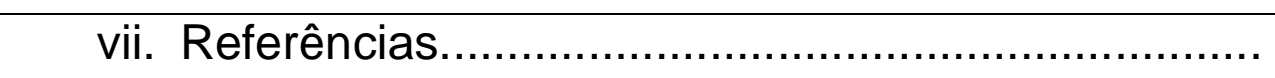 & 69 \\
\hline 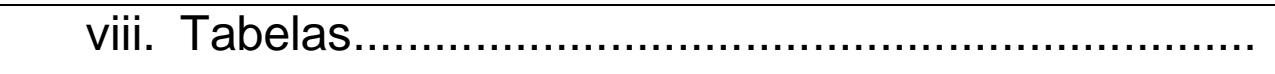 & 78 \\
\hline ix. Figuras. & 81 \\
\hline 4. Conclusão.... & 90 \\
\hline 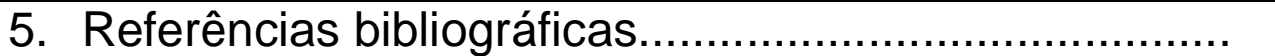 & 92 \\
\hline 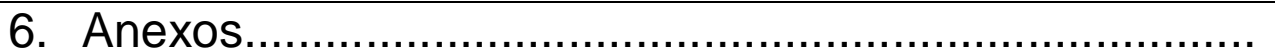 & 112 \\
\hline \multicolumn{2}{|l|}{ Anexo 1 - Aprovação do Comitê de Ética em Pesquisa } \\
\hline \multicolumn{2}{|l|}{ Anexo 2 - Artigo 01 em inglês } \\
\hline \multicolumn{2}{|l|}{ Anexo 3 - Artigo 02 em inglês } \\
\hline \multicolumn{2}{|l|}{ Anexo 4 - Normas de publicação - } \\
\hline The International Journal of Oral \& Maxillofacial Implant & \\
\hline
\end{tabular}




\section{RESUMO}

Jayme SJ. Efeito de diferentes tempos de ativação sobre a estabilidade e resposta óssea ao redor de implantes. Estudo por análise de freqüência de ressonância e histomorfométrico em cães. [Tese] Doutorado. Ribeirão Preto: Faculdade de Odontologia de Ribeirão Preto, Universidade de São Paulo, 2009.

Propósito: $\mathrm{O}$ objetivo deste estudo foi avaliar a estabilidade primária com análise de freqüência de ressonância e a resposta óssea por histomorfometria em implantes sob tratamento com carga imediata e carga precoce. Material e método: Foram colocados três implantes Replace Select (Nobel Biocare, Suécia) em cada lado da mandíbula de 8 cães, totalizando 48 implantes no estudo. Um par de implantes foi selecionado para o protocolo de carga imediata $(\mathrm{Cl})$. Após sete dias, o segundo par de implantes recebeu as próteses para o protocolo de carga precoce (CP). Catorze dias após a colocação dos implantes, o terceiro par de implantes recebeu as próteses para o protocolo de carga precoce tardia (CPT). Em cada período foi medida a estabilidade dos implantes por freqüência de ressonância. Após o período total de doze semanas da colocação das próteses os animais foram sacrificados e os espécimes foram preparados para análise histomorfométrica. As diferenças entre os tempos de carregamento para os seguintes parâmetros: estabilidade, contato ossoimplante (COI), densidade óssea (DO) e perda da crista óssea (PCO) foram avaliadas usando ANOVA. Resultados: Os valores iniciais de estabilidade (ISQ) dos implantes foram: 77,88 \pm 4,61 para $\mathrm{Cl}, 79,73 \pm 3,55$ para $\mathrm{CP}$ e $79,64 \pm 3,00$ para CPT, sem diferença estatisticamente significante $(p=0,30)$. Os valores finais de estabilidade foram $80,46 \pm 4,23$ para $\mathrm{Cl}$, 81,88 $\pm 3,55$ para CP e 81,88 \pm 3,42 para CPT, também sem diferença estatística $(p=0,47)$. Para avaliar a estabilidade dos implantes em função do tempo, foi realizada ANOVA para amostras repetidas e para cada grupo foi detectado aumento significativo da estabilidade ao final do experimento $(p=0,003)$. A 
interação método de carregamento versus tempo não foi significativa $(p=0,97)$. A porcentagem de $\mathrm{COI}$ para $\mathrm{Cl}$ foi $77,9 \pm 1,71 \%$, para $\mathrm{CP}$ foi 79,25 $\pm 2,11 \%$ e para CPT foi $79,42 \pm 1,49 \%$. A porcentagem de DO para $\mathrm{Cl}$ foi $69,97 \pm 3,81 \%$, para CP foi $69,23 \pm 5,68 \%$ e para CPT foi $69,19 \pm 2,90 \%$. A PCO para Cl foi $1,57 \pm 0,22 \mathrm{~mm}$, para CP foi $1,23 \pm 0,19 \mathrm{~mm}$ e para CPT foi $1,17 \pm 0,32 \mathrm{~mm}$. Não foi observada diferença estatística para nenhum dos parâmetros avaliados ( $p>0,05)$. Conclusão: Considerando a estabilidade primária, contato osso-implante, densidade óssea ao redor do implante e perda da crista óssea em cães, conclui-se que não existem diferenças estatisticamente significantes num prazo de até 12 semanas para implantes submetidos à ativação imediata, em 7 dias ou 14 dias após a cirurgia.

Palavras-chave: Implantes dentários; carga precoce; carga imediata; estabilidade primária; densidade óssea; contato osso-implante; osseointegração; estudos com animais. 


\section{ABSTRACT}

Jayme SJ. Effect of different loading time on the stabililty and boné response around dental implants. Resonance frequency analysis and histomorphometric study in dogs. [Thesis] Doctorate. Ribeirão Preto: Faculdade de Odontologia de Ribeirão Preto, Universidade de São Paulo, 2009.

Purpose: The aim of this study was to evaluate the implant stability through frequency resonance analysis and the effect that different loading time will have on the bone response around implants through a histomorphometric analysis. Material and Methods: Three Replace Select implants were placed on each side of the mandible in 8 dogs totaling 48 implants in the study. One pair of implants was selected for immediate loading protocol (IL). After seven days the second pair of implants received the prostheses for the early loading protocol (EL). In each period, the implant stability measurements were performed by means of resonance frequency. After 12 weeks, a new reading of the implant stability was performed. Fourteen days after the implant placement the third pair of implants received the prostheses for the advanced early loading (AEL). Following a period totaling twelve weeks of prosthetics, the animals were sacrificed and the specimens were prepared for histomorphometric analysis. The differences between loading time in the following parameters: bone-to-implant contact (BIC), bone density (BD) and crestal bone loss $(\mathrm{CBL})$ were evaluated through ANOVA. Results: The mean values of initial stability (ISQ) in different loading times were $77.88 \pm 4.61$ (IL), $79.73 \pm 3.55$ (EL) and $79.64 \pm 3.00$ (AEL). The data were subject to ANOVA and a significant difference was not detected $(p=0.30)$. The mean values of final stability in different loading times were $80.46 \pm 4.23$ (IL), 81.88 \pm 3.55 (EL) and $81.88 \pm 3.42$ (AEL). The data were subject to ANOVA and a significant difference was not detected $(p=0.47)$. To evaluate the implant stability in function of time, a variance analysis for repeated samples was performed, and there was significant difference $(p=0.003)$, indicating, for 
each group, a significant increase in stability at the end of the experiment. The time versus method interaction did not show significant difference $(p=$ 0.97 ), indicating that the variations are similar in the studied groups. The percentage of BIC for IL was $77.9 \pm 1.71 \%$, for EL was $79.25 \pm 2.11 \%$ and for AEL was $79.42 \pm 1.49 \%$. The percentage of BD for IL was $69.97 \pm 3.81 \%$, for EL was $69.23 \pm 5.68 \%$ and for AEL was $69.19 \pm 2.90 \%$. The CBL for IL was $1.57 \pm 0.22 \mathrm{~mm}$, for EL was $1.23 \pm 0.19 \mathrm{~mm}$ and for AEL was $1.17 \pm 0.32 \mathrm{~mm}$. There was no statistical difference for any of the parameters evaluated $(p>0.05)$. Conclusion: Considering primary stability, bone-to-implant contact, bone density around the implants and crestal bone loss, there are no significant differences until 12 weeks after surgery for the stability of immediate, 7 or 14 days after placement activated implants.

Key Words: dental implants; implant stability; early loading; immediate loading; bone density; bone-to-implant contact; osseointegration; animal studies. 
INTRODUÇÃO 
Com o advento dos implantes dentários a forma de resolução de diversos males bucais mudou radicalmente devido às possibilidades que esta forma de tratamento permite. Embora não haja como negar suas vantagens, há algumas limitações inerentes à técnica original. O primeiro protocolo cirúrgico para colocação de implantes em duas etapas advoga um período de cicatrização de 3 meses na mandíbula e 6 meses na maxila, e o implante deve estar recoberto por tecido mole e num ambiente de cargas mecânicas mínimas. As razões principais para este cuidado, segundo os autores, são reduzir o risco de infecções, prevenir a migração epitelial na interface osso-implante e minimizar o risco de carga precoce sobre o implante durante a remodelação óssea (BRANEMARK, HANSSON et al., 1977).

Por décadas este modo de tratamento se mostrou eficaz para terapia com implantes, demonstrando resultados satisfatórios em médio e longo prazo (MISCH, WANG et al., 2004). Entretanto, uma das maiores queixas apresentadas por profissionais e pacientes era o tempo de terapia e espera entre a fase cirúrgica e a protética, com conseqüente aumento do sofrimento do indivíduo sob tratamento. Esta limitação foi um dos principais motivos que levaram pesquisadores a procurar uma alternativa viável com menor tempo de duração do tratamento. Desta necessidade surgiram conceitos de 
colocação de implantes em carga imediata e carga precoce. Embora a definição varie de autor para autor, carga imediata seria a ativação do implante e sua exposição ao meio bucal concomitante com a colocação de próteses logo após a instalação dos implantes, e carga precoce em um período intermediário entre a colocação do implante e o intervalo de tempo proposto por Branemark (1977).

Pesquisadores começaram a avaliar o uso de implantes sob carga imediata inicialmente em pacientes totalmente desdentados e com overdentures. Babbush et al. (1986) relataram sobrevivência de 88\% de 1739 implantes após 8 anos. Outros pesquisadores obtiveram resultados semelhantes com carga imediata em overdentures (CHIAPASCO, ABATI et al., 2001; CHIAPASCO, GATTI et al., 1997; GATTI, HAEFLIGER et al., 2000). Em 1990, Schnitman et al. (1990) demonstraram resultados favoráveis em próteses totais fixas mandibulares em 10 pacientes. Posteriormente outros autores demonstraram resultados promissores tanto em mandíbula quanto em maxila (HENRY e ROSENBERG, 1994; SALAMA, ROSE et al., 1995), entretanto todos os resultados se limitavam a pacientes edêntulos.

As primeiras pesquisas com implantes em pacientes parcialmente desdentados datam do final da década de 90. Em 1998 Misch relatou 10 casos para pacientes parcialmente desdentados, incluindo até mesmo implante unitário. Também em 1998, Wohrle relatou 14 casos de implantes unitários. Todos estes trabalhos com reabilitações parciais tiveram taxas de 100\% de sobrevivência dos implantes, demonstrando a viabilidade do 
método de carga imediata para a reabilitação de desdentados parciais, além dos totais já mencionados. Diversos outros estudos têm analisado a carga precoce e a carga imediata revelando resultados promissores em curto e longo prazo em diversas situações clínicas e protéticas (GANELES, ROSENBERG et al., 2001; JAFFIN, KUMAR et al., 2000; MALO, RANGERT et al., 2000; MALO, RANGERT et al., 2005; NORDIN, NILSSON et al., 2004; OLSSON, URDE et al., 2003; RANDOW, ERICSSON et al., 1999; RASMUSSON, MEREDITH et al., 1999; SCHNITMAN, WOHRLE et al., 1997; TARNOW, EMTIAZ et al., 1997; VAN DEN BOGAERDE, PEDRETTI et al., 2002; WOLFINGER, BALSHI et al., 2003).

Porém, existem diferenças em relação às características de um tratamento com carga imediata e carga tardia. Ainda que a literatura demonstre o sucesso e viabilidade destas modalidades de tratamento, os benefícios e prejuízos referentes à técnica não são completamente esclarecidos. Isso fica parcialmente demonstrado pelas mudanças nos conceitos em todos estes anos de pesquisa, explicadas pelo melhor entendimento de suas características e implicações. Entretanto, estas particularidades não foram completamente elucidadas, tornando essenciais novas pesquisas.

Destas características, duas são de grande importância. A primeira é a estabilidade primária dos implantes, considerada um dos principais fatores para o sucesso do tratamento, evitando a micromovimentação e conseqüentemente formação de fibras na interface osso-implante. A segunda é o comportamento ósseo ao redor do implante, sobre uma 
interface ainda não osseointegrada e suas conseqüências em médio e longo prazo, especialmente se esta ativação antecipada trará conseqüências permanentes a um tratamento que, se realizado de modo convencional traria mais certeza quanto ao sucesso final.

Para aprofundar o conhecimento sobre o tema, estudos clínicos trazem informações valiosas. Entretanto, ao se avaliar o comportamento ósseo, diversas informações importantes para o entendimento da terapia não podem ser coletadas em estudos clínicos em humanos, mas apenas quando o conjunto osso-implante é removido e analisado em laboratório em condições técnicas específicas, o que torna imprescindíveis estudos em animais, para se obter informações que de outra forma seriam inviáveis.

Os dois artigos a seguir são resultado de pesquisas motivadas pela necessidade de esclarecer diversas lacunas de conhecimento sobre carga imediata, precoce e precoce tardia. 
PROPOSIÇÃO 
O objetivo deste trabalho é analisar, em cães, o impacto que diferentes tempos de ativação do implante acarretam, em médio prazo, sobre a:

- Estabilidade dos implantes, através da análise de freqüência de ressonância,

- Resposta óssea ao redor de implantes, através de análise histomorfométrica. 
MATERIAIS E MÉTODOS 
Análise comparativa da estabilidade primária de implantes submetidos a carga imediata, carga precoce e carga precoce tardia, por meio da análise de freqüência de ressonância em cães. 


\section{RESUMO}

Propósito: O propósito deste estudo foi avaliar em cachorros a estabilidade primária de implantes após carga imediata e precoce. Materiais e Métodos: Os pré-molares mandibulares de 8 cães foram extraídos bilateralmente; após 12 semanas de cicatrização cada cão recebeu 6 implantes (3 em cada hemimandíbula). Dois implantes (um de cada lado) foram ativados imediatamente após a colocação, dois outros implantes foram ativados uma semana depois, e os dois últimos implantes foram ativados duas semanas após a colocação. O método de análise de freqüência de ressonância foi utilizado para medir o quociente de estabilidade do implante (ISQ) no dia da ativação e 12 semanas após a colocação dos implantes. Resultados: O valor médio de estabilidade inicial nos diferentes tempos de ativação foram 77,88 \pm 4,61 (imediato), 79,73 \pm 3,55 (7 dias) e 79,64 \pm 3,0 (14 dias). Os dados foram submetidos à ANOVA e não foi encontrada diferença estatisticamente significante $(p=0,30)$. Os valores (média \pm desvio padrão) para a estabilidade final (12 semanas) foram 80,46 \pm 4,23 (imediata), 81,88 \pm 3,55 (7 dias) e $81,88 \pm 3,42$ (14 dias), sem diferenças estatisticamente significantes $(p=0,47)$. Para avaliar a estabilidade implantar funcional ao longo do tempo, uma análise de variância para amostras repetidas foi realizada, indicando aumento significativo em estabilidade para cada grupo $(p=0,003)$. A falta de interação entre estabilidade e tempo $(p=0,97)$ indica que as variações foram similares em todos os grupos. Conclusão: Em 12 semanas não existem diferenças estatisticamente significantes na estabilidade primária dos implantes ativados imediatamente, 7 ou 14 dias após a colocação.

Palavras- chave: Implantes dentários, Carga imediata, Carga tardia, análise de freqüência de ressonância, Estabilidade funcional dos implantes, estudos em animais.

\section{INTRODUÇÃO}

Implantes dentários são considerados um tratamento previsível para repor dentes perdidos. Na implantologia dental moderna, protocolos de tratamento avançado (exemplo: carga imediata ou precoce) são freqüentemente usados para reduzir o tempo de tratamento. A exigência cada vez maior dos pacientes em relação ao tratamento odontológico levou a aumento na procura de terapias rápidas e que gerem pouco ou nenhum sofrimento. Pesquisadores e profissionais procuram formas alternativas de 
tratamento com implantes dentários que não exijam o tempo de espera de 3 a 6 meses, preconizado inicialmente por Branemark ${ }^{1}$.

Isto levou à introdução de técnicas de implante dentário utilizando protocolos de carga imediata ou precoce, a fim de diminuir ou eliminar o tempo em que o paciente fica sem a prótese ou com uma prótese provisória removível. Isto beneficia o conforto, função mastigatória, fala, estabilidade, além de melhorar fatores psicológicos durante este período ${ }^{2,3}$.

Diversos estudos têm demonstrado o sucesso e a previsibilidade do método de carga imediata ou carga precoce nas reabilitações com implante ${ }^{4-}$ ${ }^{18}$. Entretanto, estes estudos não avaliaram se estes diferentes protocolos de tratamento causam diferenças na qualidade do tratamento em médio e longo prazo.

Embora existam diversas definições na literatura para os termos de carga imediata e precoce, segundo Ganeles \& Wismeijer ${ }^{19}$ carga ou restauração imediata foi definida como a conexão de uma restauração ao implante com ou sem contato oclusal direto até 48 horas da colocação cirúrgica dos implantes. Carga precoce de implantes dentários foi definida como a conexão de uma restauração ao implante com ou sem contato oclusal direto após 48 horas da colocação cirúrgica dos implantes, mas dentro de um período mais curto que o proposto convencionalmente.

Embora a princípio se possa pensar que qualquer espera na colocação de cargas propicia uma zona basal óssea mais adequada para a ativação do implante, o estudo da remodelação óssea demonstra o contrário. No dia de colocação do implante o osso ao redor do implante está mais 
forte, com a presença de osso lamelar. A partir da colocação do implante começa um processo de remodelação óssea, com a reabsorção deste osso lamelar, mais forte e resistente, e sua substituição por osso neoformado, mais fraco e desorganizado. Este osso neoformado somente será substituído por osso lamelar futuramente e o período para esta substituição do osso lamelar por osso neoformado, e a maturação em osso lamelar, é crítico, e constitui o período de maior risco de falha não infecciosa ${ }^{20-27}$. Segundo Strid $^{20}$ o osso perimplantar no dia de colocação do implante tem maior porção lamelar se comparado à mesma região após três meses.

Neste contexto pode-se perguntar se protocolos de carga imediata implicam diferenças em médio e longo prazo em relação a protocolos de carga precoce ou precoce tardia.

Uma forma de realizar esta avaliação seria com o uso de instrumentos que medem a estabilidade do implante através da análise de freqüência de ressonância (RFA) ${ }^{28-35}$. Foi sugerido que a estabilidade primária do implante é importante para haver sucesso na osseointegração ${ }^{36}$. Clinicamente resultados de análises de freqüência de ressonância têm sido correlacionados a mudanças na estabilidade do implante durante a cicatrização óssea e falhas na osseointegração ${ }^{33,34}$. Um aparelho que utiliza esta forma de análise em suas mensurações é o transdutor Osstell. Este é um aparelho utilizado para avaliação clínica da estabilidade de implantes dentários, sendo sensível a diferenças na dureza do osso perimplantar ${ }^{34,37}$. O resultado é um índice denominado "Quociente de Estabilidade do Implante" (ISQ) que vai de 1 a $100^{38}$. Com base neste quociente é possível 
estabelecer comparações entre diferentes tempos de tratamento. Existem evidências que um ISQ de 57 a 82 garante o sucesso do implante ${ }^{25}$.

O presente estudo foi realizado para avaliar a hipótese que não existem diferenças na estabilidade de implantes submetidos a protocolos de carga imediata ou de carga precoce após o período de cicatrização de 12 semanas utilizando análise de freqüência de ressonância em um modelo animal.

\section{MATERIAIS E MÉTODOS}

O protocolo de estudo foi aprovado pelo Comitê de Ética em Pesquisa em Animais (Processo 05.1.1318.53.1). Foram utilizados neste estudo oito cães adultos, machos, de raça indefinida $( \pm 25 \mathrm{Kg})$. Os animais apresentavam boas condições de saúde geral, incluindo maxilas e mandíbulas atraumáticas e ausência de lesões orais, virais ou fúngicas.

Na noite anterior, 12 horas antes da cirurgia, foi retirada a alimentação dos cachorros para evitar vômito. Eles receberam uma injeção intramuscular de pré-anestésico ( $2 \%$ cloridrato de xilazina, $0,8 \mathrm{~mL} / 10 \mathrm{~kg}$ ) e foram anestesiados com injeção intravenosa de thiopental $(1 \mathrm{~mL} / \mathrm{kg} ; 20 \mathrm{mg} / \mathrm{kg}$ diluídos em $50 \mathrm{~mL}$ de soro fisiológico). Um retalho total foi levantado na região dos quatro dentes pré-molares mandibulares (P1, P2, P3 e P4) e estes foram seccionados na direção buco-lingual e extraídos com forceps. Os retalhos foram reposicionados e suturados com fios absorvíveis 4-0.

Foi estabelecido um intervalo cicatricial de 12 semanas para então começar a segunda fase. Os cães receberam 20000 UI de penicilina e 1,0 
g/10 kg de estreptomicina na noite anterior à cirurgia. Esta dose provê cobertura antibiótica por 4 dias. Outra dose foi dada 4 dias depois, garantindo cobertura por 8 dias. Este antibiótico de amplo espectro é normalmente utilizado no tratamento de infecções em pequenos animais ${ }^{39}$. Após repetição da sedação e anestesia da fase inicial, uma incisão horizontal na crista foi realizada da região distal do canino à região mesial do primeiro molar e implantes foram colocados de acordo com as recomendações do fabricante. Foram colocados 3 implantes com 4,3mm de diâmetro X 10 mm de comprimento (Replace Select Tapered, Nobel Biocare AB, Gotemburgo, Suécia), de superfície rugosa (TiUnite, Nobel Biocare AB, Gotemburgo, Suécia), em cada hemiarcada, totalizando 48 implantes neste estudo. Um implante foi selecionado para protocolo de carga imediata $(\mathrm{Cl})$, e os outros dois restantes na hemimandíbula receberam cicatrizadores até a colocação das próteses, de acordo com o tempo de ativação (figura 1). Após sete dias, o segundo implante recebeu a prótese para o protocolo de carga precoce $(\mathrm{CP})$. Catorze dias após a colocação dos implantes, o terceiro implante recebeu a prótese para o protocolo de carga precoce tardia (CPT). Os implantes submetidos aos diferentes protocolos de ativação foram distribuídos randomicamente com base em "cara ou coroa". Em todos os implantes a plataforma foi posicionada ao nível da crista óssea com torque de aproximadamente 40 N.cm.

O método de análise de freqüência de ressonância foi utilizado para aferir a estabilidade primária. A mensuração foi realizada com o aparelho Osstell (Integration Diagnostics, Gotemburgo, Suécia) com um transdutor 
disponível comercialmente. A orientação perpendicular do transdutor sobre o longo eixo do osso foi sempre mantida. O transdutor, que é fixado ao implante no osso, contém um produtor de onda e um analisador. A fonte de onda vibra com freqüência que aumenta gradualmente. O analisador grava a freqüência da fonte, causando a ressonância na interface do implante/transdutor. O valor de frequência gravado em $\mathrm{Hz}$ é convertido em um valor chamado quociente de estabilidade implantar (ISQ), que varia entre 0 a 100, sendo 100 o valor de maior estabilidade. Este método permite a mensuração com precisão de \pm 1 ISQ. Todas as mensurações deste estudo foram realizadas de acordo com as normas do fabricante, com 3 leituras para cada implante em cada etapa, sendo o resultado a média destas leituras, e com o transdutor padronizado numa posição vestíbulo-lingual com o cabo para vestibular em todas as mensurações do presente estudo ${ }^{27,37}$, de acordo com a figura 2.

Moldagens foram realizadas após colocação dos implantes para confecção de coroas metálicas definitivas (Optosil Xantopren, HeraeusKulzer $\mathrm{GmbH}$, Hanau, Alemanha). Estas coroas foram fabricadas sobre os modelos em liga de níquel-cromo (Verabond II, Aalba Dent. Inc., Cordelia, CA, USA) com um entalhe para retenção nas faces proximais, a fim de facilitar a esplintagem, de acordo com a seqüência de ativação, com resina quimicamente ativada (Duralay, Reliance Dental, MFG Co, Worth, IL, USA). As margens das coroas foram posicionadas ao nível gengival e a distância entre o ponto de contato e o osso da crista foi fixada em $3 \mathrm{~mm}$. No mesmo dia da colocação do implante, restaurações temporárias foram fabricadas 
diretamente sobre os dois implantes anteriores (bilateralmente), constituindo um protocolo de carga imediata (figura 3). Nos demais implantes foram colocados cicatrizadores e os retalhos foram reposicionados e suturados com fio não absorvível.

Foram realizados ajustes intra-orais para eliminar qualquer contato oclusal, verificado com papel de articulação (Accu Film II, Parkel, Farmingdale, NY, EUA).

Sete dias após a colocação dos implantes, nova mensuração da estabilidade implantar foi realizada, de forma semelhante à descrita anteriormente, e coroas de níquel-cromo foram colocadas nos implantes anteriores e médios. As retenções nas faces proximais foram unidas com resina de ativação química Duralay.

Quatorze dias após a colocação dos implantes, nova mensuração da estabilidade implantar foi realizada, e os implantes posteriores receberam as próteses definitivas (figura 4), unidas ao implante médio com resina acrílica Duralay.

Durante as 12 semanas, profilaxia com ultra-som foi realizada semanalmente, sob sedação com injeção intramuscular de pré-anestésico ( $2 \%$ cloridrato de xilazina, $20 \mathrm{mg} / \mathrm{kg}$ ), até a data da ultima mensuração da estabilidade e sacrifício.

\section{RESULTADOS}

Os dados de quociente de estabilidade implantar (ISQ) são relatados como valores médios e desvios padrão. Neste estudo, os dados foram 
submetidos à análise estatística (SPSS 15.0, SPSS Inc, Chicago - II, USA). A normalidade do grupo foi testada com o teste de Shapiro-Wilk. Depois, os dados foram submetidos à análise de variância não-paramétrica de Friedman. Houve diferença considerada estatisticamente significante quando $p<0,05$.

Os resultados obtidos estão resumidos na Tabela 1.

\section{Estabilidade Inicial}

Para cada grupo, 16 implantes foram realizados e os valores médios de estabilidade inicial, verificados nos diferentes tempos de ativação foram: 77,88 \pm 4,61 (carga imediata), 79,73 \pm 3,55 (7 dias) e 79,64 \pm 3,00 (14 dias).

Os dados foram submetidos à ANOVA, sem diferença estatisticamente significante entre os grupos $(p=0,30)$

\section{Estabilidade Final}

A estabilidade média final verificada nos diferentes tempos de ativação foi $80,46 \pm$ 4,23 (carga imediata), 81,88 \pm 3,55 (7 dias) e 81,88 \pm 3,42 (14 dias). Os dados foram submetidos à ANOVA, sem diferenças estatisticamente significantes entre os grupos $(p=0,47)$.

\section{Variação de estabilidade com o tempo}

Para avaliar a estabilidade primária em função do tempo, foi utilizada ANOVA para amostras repetidas e foi encontrada diferença estatisticamente 
significante $(p=0,003)$ indicando, para cada grupo, aumento significativo da estabilidade ao término do estudo.

Analisando a interação entre tempo e método, não houve diferença estatisticamente significante $(p=0,97)$, demonstrando que as variações foram similares para os três grupos estudados.

\section{DISCUSSÃO}

O transdutor Osstell foi concebido de forma a ressoar ao nível sônico, sendo a amplitude da vibração bem pequena, não aplicando estresse significativo ao implante que possa prejudicá-lo ${ }^{33,37}$. Um estudo histomorfométrico sugere que resultados de freqüências de ressonância são adequados para avaliar o nível de contato osso-implante ${ }^{32}$.

Entretanto, alguns cuidados são fundamentais para o uso correto do aparelho. Estudos demonstram que a posição da aleta durante a mensuração altera significativamente os resultados obtidos, ou seja, diferentes posições do transdutor em um mesmo implante geram diferentes resultados $^{37-39}$. Neste estudo usou-se, então, posição padronizada da aleta do transdutor na obtenção de todas as leituras.

A altura da plataforma do implante e, conseqüentemente, do transdutor em relação à crista óssea tem sido discutida na literatura como outro possível causador de alterações dos resultados das mensurações ${ }^{33-35}$. Embora não exista um consenso sobre o assunto, por cautela e padronização do tratamento, a plataforma foi mantida ao nível da crista óssea para todos os implantes. 
A análise da estabilidade dos implantes realizada imediatamente após a colocação dos mesmos, não mostrou diferenças estatisticamente significantes $(p=0,30)$, evidenciando que todos os implantes demonstraram condições iniciais equivalentes. É importante ressaltar que houve pequena variação nos resultados, evidenciada pelos pequenos desvios padrão encontrados. Entretanto, considerando informações de estudos anteriores ${ }^{25}$, o ISQ geral obtido no estudo $(79,80 \pm 3,80)$ indicou excelente estabilidade para todos os implantes colocados.

A análise da estabilidade final dos implantes mensurada após doze semanas, não demonstrou diferenças estatisticamente significantes $(p=0,47)$, evidenciando que a estabilidade foi equivalente para todos os implantes, também com pequenos desvios padrão. Deste modo após 12 semanas, existe melhor estabilidade implantar, evidenciando melhores condições ósseas quando comparadas com as do dia de colocação. Devido à evolução detectada, esta condição piora nas primeiras duas semanas, provavelmente devido à substituição do osso lamelar por osso neoformado, como discutido anteriormente, confirmando os achados de outros autores $^{25,28}$ e a ocorrência de processo ósseo cicatricial descrito por Cochran e colaboradores ${ }^{40}$. Entretanto, estas diferenças desaparecem após o período de 12 semanas, demonstrando que, apesar das discrepâncias em relação ao dia de colocação dos implantes, isto não leva a diferenças na qualidade da estabilidade implantar, nem em médio prazo, nem, provavelmente, em longo prazo, quando visto sob o ponto de vista da estabilidade implantar. 
Analisando em cada tempo de carga, a evolução da estabilidade implantar, existe variação estatisticamente significante $(p=0,003)$ entre o período inicial e o final. De forma geral, foram detectados valores iniciais menores dos que os obtidos após 3 meses da colocação dos implantes.

É interessante ressaltar que a substituição de osso lamelar por osso neoformado devido a trauma mecânico e térmico, típicos da colocação de implantes, afeta diretamente a estabilidade primária dos implantes testados, como visto nos resultados demonstrados neste estudo, considerando a evolução da cicatrização óssea.

Dos dois tipos de osso encontrados ao redor do implante, o osso lamelar é organizado, altamente mineralizado, e com melhor resistência mecânica. Entretanto, ele cresce lentamente quando comparado ao osso neoformado ${ }^{22}$, que é desorganizado, menos mineralizado e mecanicamente mais fraco, e cresce a uma taxa seis vezes maior ${ }^{23}$.

Roberts e colaboradores ${ }^{24}$ relataram uma área de desvitalização óssea de $1 \mathrm{~mm}$ ou mais ao redor de implantes em conseqüência da cirurgia. Enquanto este osso é reabsorvido, uma rápida aposição de matriz óssea nesta região é necessária para substituir o volume afetado. Levando em consideração que o osso neoformado cresce muito mais rapidamente, o implante é revestido por este osso nas primeiras semanas após cirurgia. Os autores demonstraram neste estudo que, após quatro meses, o osso ao redor do implante estava apenas $60 \%$ mineralizado.

Considerando as informações anteriores, a colocação de implantes com carga imediata ou precoce não estaria recomendada. O presente 
estudo demonstrou que, apesar desta fase inicial de remodelação óssea afetar diretamente a estabilidade primária dos implantes, isto não é suficiente para comprometer a osseointegração e conseqüentemente, o tratamento. Considerando a estabilidade primária, diferentes tempos de carga não causam alterações em médio prazo. É importante ressaltar que este estudo foi executado em cães e com implantes de superfície tratada. Cautela é recomendada ao transpor estes resultados para outras situações. De acordo com alguns autores ${ }^{41,42}$, o ISQ deve ser usado cuidadosamente e novos estudos são necessários, especialmente com metodologia de avaliação histológica longitudinal ${ }^{43}$.

Numa análise histomorfométrica Jayme e cols. ${ }^{44}$ puderam verificar que a taxa de contato osso-implante foi de 77,9 \pm 1,71\% (variação de 58,96 a $84,21 \%$ ) para o protocolo de carga imediata; para o protocolo de carga precoce foi de $79,25 \pm 2,11 \%$ (variação de 68,81 a 86,33\%); e para o grupo de carga precoce tardia foi de 79,42 \pm 1,49\% (variação de 68,39 a 84,33\%). A densidade óssea quando foi usada carga imediata foi de $69,97 \pm 3,81 \%$ (variação de 42,63 a 81,05\%); com carga precoce foi de 69,23 \pm 5,68\% (variação de 49,47 a 85,88\%); e para carga precoce tardia foi de 69,19 \pm 2,90\% (variação de 69,19 a 85,31\%). Considerando a perda da crista óssea, os autores verifcaram que, com carga imediata os valores foram $1,57 \pm 0,22$ mm (variação de 0,00 a 2,21 mm); para carga precoce a perda da crista óssea foi de 1,23 \pm 0,19 mm (variação de 0,00 a 1,97 mm) e para o grupo de carga precoce tardia foi de 1,17 $\pm 0,32 \mathrm{~mm}$ (variação de 0,00 a 1,76 mm). Não foram observadas diferenças estatisticamente significantes para 
nenhum dos parâmetros avaliados $(p>0,05)$. Concluíram que os diferentes tempos de ativação parecem não afetar de maneira significativa a resposta óssea ao redor dos implantes dentários. Os dados de estabilidade dos implantes, medidos pela análise de freqüência de ressonância, são compatíveis e corroboram estes resultados.

Este estudo também provou a utilidade do método de análise de freqüência de ressonância para monitorar a evolução da estabilidade funcional dos implantes.

\section{CONCLUSÕES}

Considerando as limitações deste trabalho, pôde-se chegar às seguintes conclusões:

- A estabilidade do implante sofre diminuição inicial, e melhora no período de 12 semanas. O período em que a estabilidade deixa de baixar e começa a aumentar não pôde ser definido neste estudo;

- O dia de colocação do implante não determina o período de maior fragilidade da estabilidade implantar;

- Em médio prazo não existem diferenças estatisticamente significantes na estabilidade de implantes ativados imediatamente, uma ou duas semanas após a colocação. 


\section{Agradecimentos}

Os autores agradecem à Nobel Biocare pela doação dos implantes e componentes protéticos e à Fundação de Apoio à Pesquisa do Estado de São Paulo - FAPESP pelo apoio financeiro (processo \#2006/04747-0) 


\section{REFERÊNCIAS}

1. Branemark PI, Hansson BO, Adell R, Breine U, Lindstrom J, Hallen O, et al. Osseointegrated implants in the treatment of the edentulous jaw. Experience from a 10-year period. Scand J Plast Reconstr Surg Suppl. 1977;16:1-132.

2. Schnitman PA, Wohrle PS, Rubenstein JE, DaSilva JD, Wang NH. Tenyear results for Branemark implants immediately loaded with fixed prostheses at implant placement. Int $\mathrm{J}$ Oral Maxillofac Implants. $1997 ; 12: 495-503$

3. Salama H, Rose LF, Salama M, Betts NJ. Immediate loading of bilaterally splinted titanium root-form implants in fixed prosthodontics--a technique reexamined: two case reports. Int J Periodontics Restorative Dent. 1995;15:344-61.

4. Tarnow DP, Emtiaz S, Classi A. Immediate loading of threaded implants at stage 1 surgery in edentulous arches: ten consecutive case reports with 1- to 5-year data. Int J Oral Maxillofac Implants. 1997;12:319-24.

5. Scortecci G. Immediate function of cortically anchored disk-design implants without bone augmentation in moderately to severely resorbed completely edentulous maxillae. J Oral Implantol. 1999;25:70-9.

6. Horiuchi K, Uchida H, Yamamoto K, Sugimura M. Immediate loading of Branemark system implants following placement in edentulous patients: a clinical report. Int J Oral Maxillofac Implants. 2000;15:824-30. 
7. Grunder U. Immediate functional loading of immediate implants in edentulous arches: two-year results. Int J Periodontics Restorative Dent. $2001 ; 21: 545-51$.

8. Olsson M, Urde G, Andersen JB, Sennerby L. Early loading of maxillary fixed cross-arch dental prostheses supported by six or eight oxidized titanium implants: results after 1 year of loading, case series. Clin Implant Dent Relat Res. 2003;5:81-7.

9. Nordin T, Nilsson R, Frykholm A, Hallman M. A 3-arm study of early loading of rough-surfaced implants in the completely edentulous maxilla and in the edentulous posterior maxilla and mandible: results after 1 year of loading. Int J Oral Maxillofac Implants. 2004;19:880-6.

10. van Steenberghe D, Glauser R, Blomback U, Andersson M, Schutyser F, Pettersson A, et al. A computed tomographic scan-derived customized surgical template and fixed prosthesis for flapless surgery and immediate loading of implants in fully edentulous maxillae: a prospective multicenter study. Clin Implant Dent Relat Res. 2005;7:S111-20.

11. Bergkvist G, Sahlholm S, Karlsson U, Nilner K, Lindh C. Immediately loaded implants supporting fixed prostheses in the edentulous maxilla: a preliminary clinical and radiologic report. Int J Oral Maxillofac Implants. 2005;20(3):399-405.

12. Balshi SF, Wolfinger GJ, Balshi TJ. A prospective study of immediate functional loading, following the Teeth in a Day protocol: a case series of 55 consecutive edentulous maxillas. Clin Implant Dent Relat Res. $2005 ; 7: 24-31$ 
13. Ostman PO, Hellman M, Sennerby L. Direct implant loading in the edentulous maxilla using a bone density-adapted surgical protocol and primary implant stability criteria for inclusion. Clin Implant Dent Relat Res. $2005 ; 7: 560-9$

14. Malo P, Friberg B, Polizzi G, Gualini F, Vighagen T, Rangert B. Immediate and early function of Branemark System implants placed in the esthetic zone: a 1-year prospective clinical multicenter study. Clin Implant Dent Relat Res. 2003;5:37-46.

15. Malo P, Rangert B, Dvarsater L. Immediate function of Branemark implants in the esthetic zone: a retrospective clinical study with 6 months to 4 years of follow-up. Clin Implant Dent Relat Res. 2000;2:138-46.

16. Cannizzaro G, Leone M, Esposito M. Immediate functional loading of implants placed with flapless surgery in the edentulous maxilla: 1-year follow-up of a single cohort study. Int J Oral Maxillofac Implants. $2007 ; 22: 87-95$

17. Bedrossian E, Rangert B, Stumpel L, Indresano T. Immediate function with the zygomatic implant: a graftless solution for the patient with mild to advanced atrophy of the maxilla. Int $\mathrm{J}$ Oral Maxillofac Implants. 2006;21:937-42.

18. Chow J, Hui E, Lee PK, Li W. Zygomatic implants--protocol for immediate occlusal loading: a preliminary report. J Oral Maxillofac Surg. 2006;64:804-11. 
19. Ganeles J, Wismeijer D. Early and Immediately Restored and Loaded Dental Implants for Single-Tooth and Partial-Arch Applications . Int J Oral Maxillofac Implants 2004;19(suppl):92-102.

20.Strid K. Radiographic results. Tissue-integrated Prostheses: Osseointegration in clinical dentistry. Chicago: Quintessence; 1985. p. 187-91.

21. Buchs AU, Levine L, Moy P. Preliminary report of immediately loaded Altiva Natural Tooth Replacement dental implants. Clin Implant Dent Relat Res. 2001;3:97-106.

22. Chiapasco M, Gatti C, Rossi E, Haefliger W, Markwalder TH. Implantretained mandibular overdentures with immediate loading. A retrospective multicenter study on 226 consecutive cases. Clin Oral Implants Res. 1997;8:48-57.

23. Roberts W, Turkey P, Brezniak N, Fielder P. Implants: bone physiology and metabolism. CDA Journal. 1987;31:3-9.

24. Roberts WE, Smith RK, Zilberman Y, Mozsary PG, Smith RS. Osseous adaptation to continuous loading of rigid endosseous implants. Am J Orthod. 1984;86:95-111.

25. Ersanli S, Karabuda C, Beck F, Leblebicioglu B. Resonance frequency analysis of one-stage dental implant stability during thr osseointegration period. J Periodontol. 2005;76:1006-1071.

26. Veltri M, Balleri $P$, Ferrari M. Influence of transducer orientation on Osstell stability measurements of osseointegrated implants. Clin Implant Dent Relat Res. 2007;9:60-4. 
27. Pattijn V, Jaecques SV, De Smet E, Muraru L, Van Lierde C, Van der Perre G, et al. Resonance frequency analysis of implants in the guinea pig model: influence of boundary conditions and orientation of the transducer. Med Eng Phys. 2007;29:182-90.

28. Barewal RM, Oates TW, Meredith N, Cochran DL. Resonance frequency measurement of implant stability in vivo on implants with a sandblasted and acid-etched surface. Int J Oral Maxillofac Implants. 2003;18:641-51.

29. Friberg B, Sennerby L, Meredith N, Lekholm U. A comparison between cutting torque and resonance frequency measurements of maxillary implants. A 20-month clinical study. Int J Oral Maxillofac Surg. 1999;28:297-303.

30. Glauser R, Sennerby L, Meredith N, Ree A, Lundgren A, Gottlow J, et al. Resonance frequency analysis of implants subjected to immediate or early functional occlusal loading. Successful vs. failing implants. Clin Oral Implants Res. 2004;15:428-34.

31 Heo SJ, Sennerby L, Odersjo M, Granstrom G, Tjellstrom A, Meredith N. Stability measurements of craniofacial implants by means of resonance frequency analysis. A clinical pilot study. J Laryngol Otol. 1998;112:53742.

32. Rasmusson L, Meredith N, Cho IH, Sennerby L. The influence of simultaneous versus delayed placement on the stability of titanium implants in onlay bone grafts. A histologic and biomechanic study in the rabbit. Int J Oral Maxillofac Surg. 1999;28:224-31. 
33. Meredith N, Alleyne D, Cawley P. Quantitative determination of the stability of the implant-tissue interface using resonance frequency analysis. Clin Oral Implants Res. 1996;7:261-7.

34. Meredith N, Book K, Friberg B, Jemt T, Sennerby L. Resonance frequency measurements of implant stability in vivo. A cross-sectional and longitudinal study of resonance frequency measurements on implants in the edentulous and partially dentate maxilla. Clin Oral Implants Res. 1997;8:226-33.

35. Meredith N, Shagaldi F, Alleyne D, Sennerby L, Cawley P. The application of resonance frequency measurements to study the stability of titanium implants during healing in the rabbit tibia. Clin Oral Implants Res. 1997;8:234-43.

36. Friberg B, Jemt T, Lekholm U. Early failures in 4,641 consecutively placed Branemark dental implants: a study from stage 1 surgery to the connection of completed prostheses. Int $\mathrm{J}$ Oral Maxillofac Implants. $1991 ; 6: 142-6$.

37. Pattijn V, Van Lierde C, Van der Perre G, Naert I, Vander Sloten J. The resonance frequencies and mode shapes of dental implants: Rigid body behaviour versus bending behaviour. A numerical approach. J Biomech. 2006;39:939-47.

38. AB Id. Clinical Manual Osstell. Savedalen, Sweden. (http://www.osstell.com/filearchive/2/2540/ID_25006-0_Clin_Manual.pdf) 39. Novaes Junior AB, Vidigal Junior GM, Novaes AB, Grisi MF, Pollonni S, Rosa A. Immediate implants placed into infected sites: a 
histomorphometric study in dogs. Int $\mathrm{J}$ Oral Maxillofac Implants. $1998 ; 13: 422-427$

40. Cochran DL, Schenk R, Lussi A, Higginbottom FL, Buser D. Bone response to unloaded titanium implant with a sandblasted and acidetched surface: A histometric study in the canine mandible. J Biomed Mater Res. 1998;40:1-11.

41. Rasmusson L, Kahnberg KE, Tan A. Effects of implant design and surface on bone regeneration and implant stability: an experimental study in the dog mandible. Clin Implant Dent Relat Res. 2001;3:2-8.

42. Bernard JP, Szmukler-Moncler S, Pessotto S, Vasquez L, Belser UC. The anchorage of Branemark and ITI implants of different lengths. I. An in vivo study in the canine mandible. Clin Oral Implants Res. 2003;14:593-600.

43. Bischof M, Nedir R, Szmucler-Moncler S, Bernard JP, Samson J. Implant stability measurement of delayed and immediately loaded implants during healing. A clinical resonance-frequency analysis study with sandblastedand-etched ITI implants. Clin Oral Implants Res. 2004; 15:529-539.

44. Jayme SJ, Muglia VA, Oliveira RR, Novaes AB Jr, Ribeiro RF. The effects of different loading time on the bone response around dental implants. a histomorphometric study in dogs. Int $\mathrm{J}$ Oral Maxillofac Implants. (Accepted for publication). 2009. 
Figuras

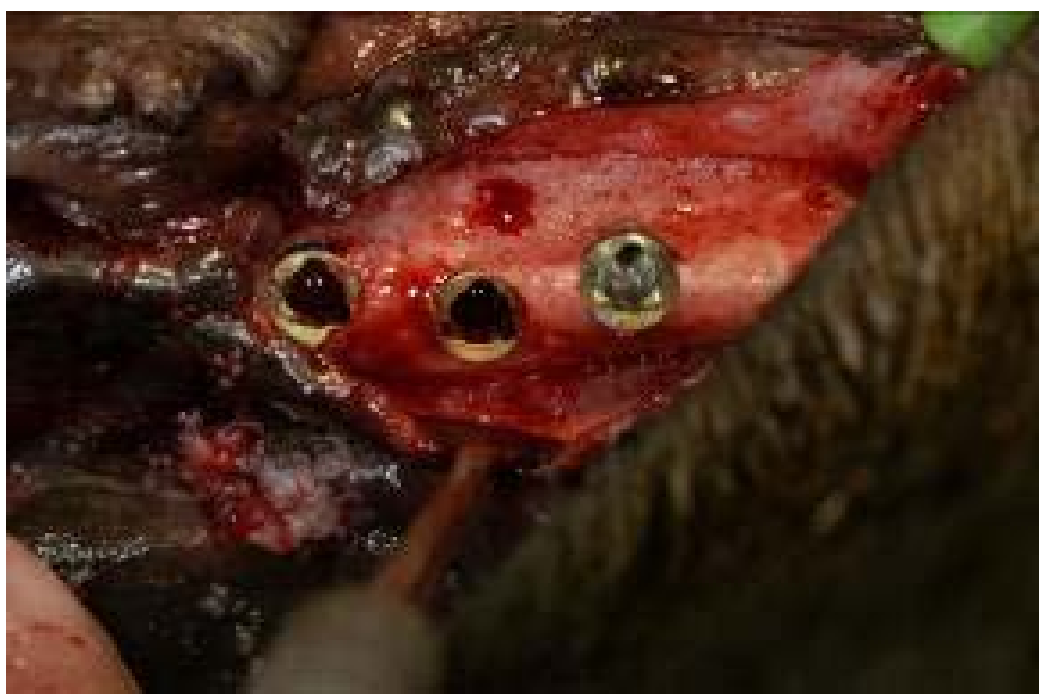

Figura 1- Colocação dos implantes.

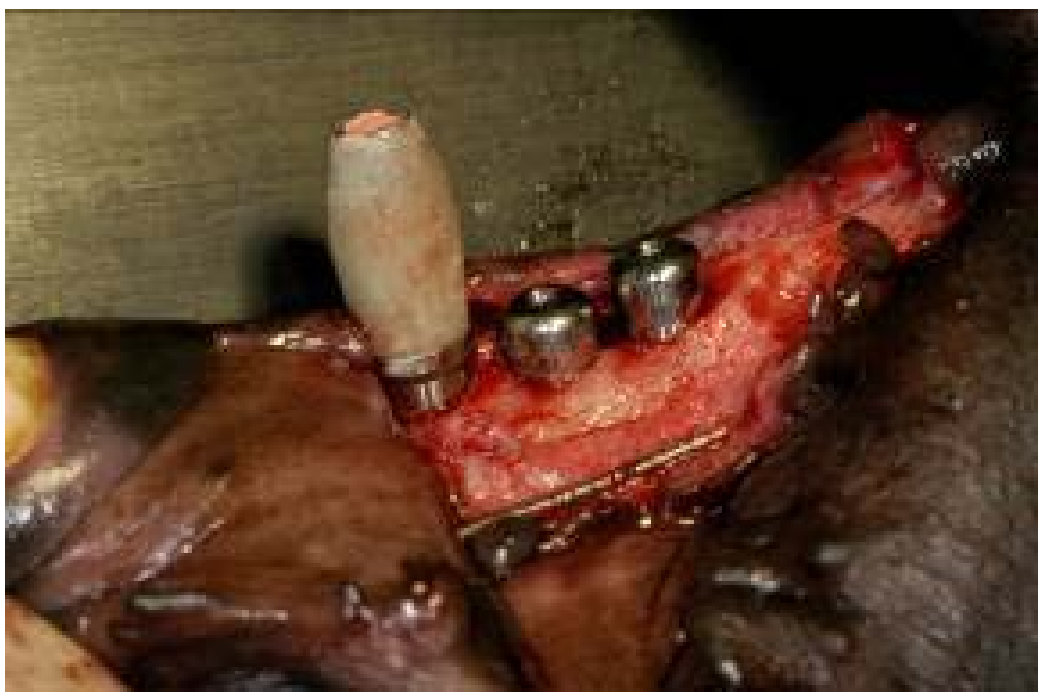

Figura 2- Restauração temporária. 


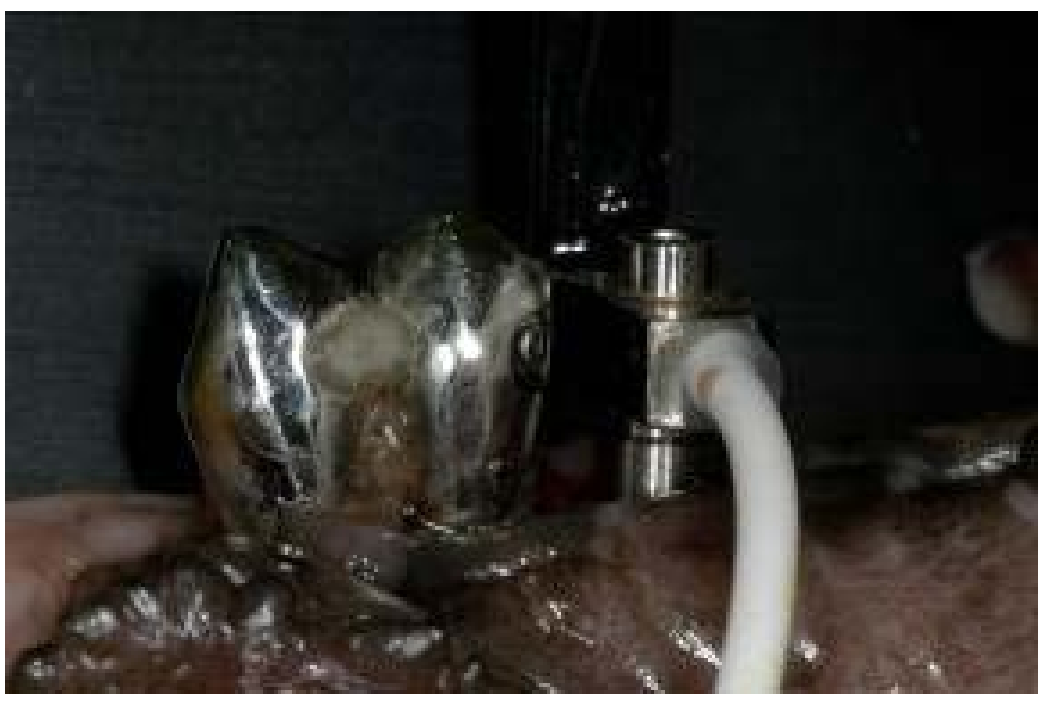

Figura 3- Mensuração da estabilidade primária no implante posterior.

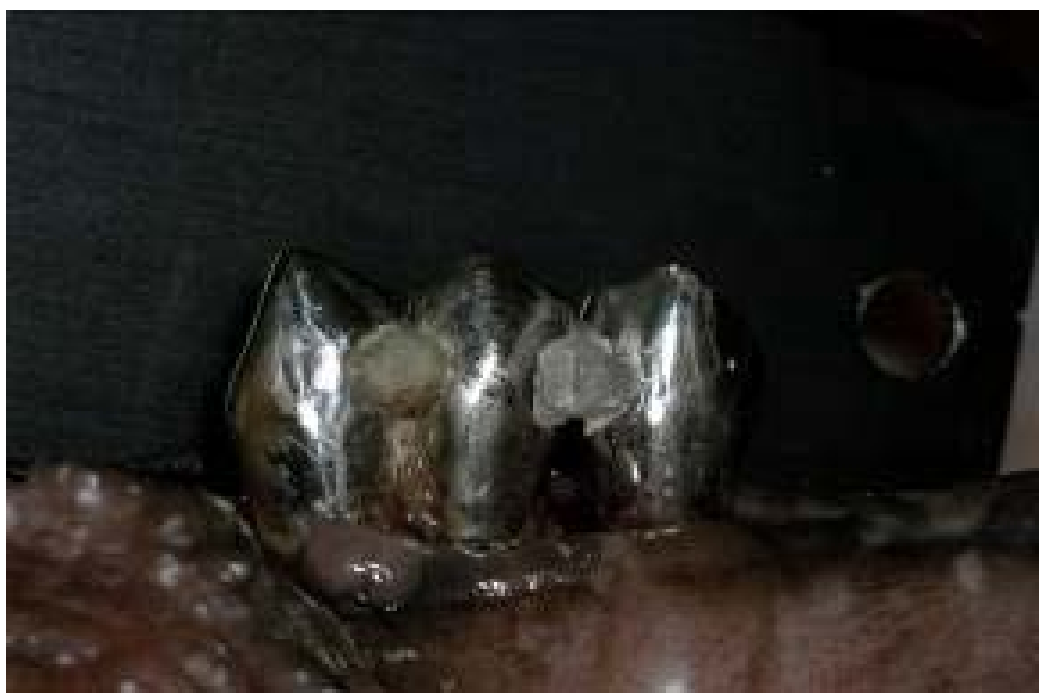

Figura 4- Coroas metálicas nos implantes, unidas com resina acrílica. 
Tabela 1- Estabilidade dos implantes em função do protocolo de carregamento

\begin{tabular}{|c|c|c|c|c|c|c|c|c|}
\hline & $\begin{array}{l}\text { Tamanho } \\
\text { da } \\
\text { amostra } \\
\text { (n) }\end{array}$ & $\begin{array}{c}\text { ISQi } \\
\text { (estabilidade } \\
\text { primária) }\end{array}$ & $\begin{array}{c}\text { Significância } \\
\text { estatística } \\
\text { entre grupos }\end{array}$ & $\begin{array}{c}\text { ISQf } \\
\text { (12 semanas) }\end{array}$ & $\begin{array}{l}\text { Significância } \\
\text { estatística } \\
\text { entre grupos }\end{array}$ & $\begin{array}{c}\Delta \mathrm{ISQ} \\
\text { (ISQf-ISQi) }\end{array}$ & $\begin{array}{c}\text { Diferença Estatística } \\
\qquad \mathrm{ISQ} \\
\text { (para tempo de } \\
\text { carrregamento) }\end{array}$ & $\begin{array}{c}\text { Significância } \\
\text { estatística } \\
\text { entre grupos }\end{array}$ \\
\hline $\begin{array}{l}\text { Imediato } \\
\text { (CI) }\end{array}$ & 16 & $77,88 \pm 4,61$ & & $80,46 \pm 4,23$ & & $1,88 \pm 5,28$ & & \\
\hline $\begin{array}{l}7 \text { dias } \\
(\mathrm{CP})\end{array}$ & 16 & $79,73 \pm 3,55$ & $0,30^{\mathrm{ns}}$ & $81,88 \pm 3,55$ & $0,47^{\mathrm{ns}}$ & $2,15 \pm 4,15$ & $0,003^{*}$ & $0,97^{\mathrm{ns}}$ \\
\hline $\begin{array}{l}14 \text { dias } \\
\text { (CPT) }\end{array}$ & 16 & $79,64 \pm 3,00$ & & $81,88 \pm 3,42$ & & $2,19 \pm 4,58$ & & \\
\hline Todos implantes & 48 & $79,08 \pm 3,80$ & & $81,40 \pm 3,73$ & & $2,14 \pm 4,59$ & & \\
\hline
\end{tabular}

ns $=>$ não significante; $*$ significante para $\alpha=0,05$ 


\section{ARTIGO 02}

Efeitos de diferentes tempos de ativação sobre a resposta óssea ao redor de implantes dentários. Estudo histomorfométrico em cães. 


\section{RESUMO}

Objetivo: O objetivo deste estudo foi avaliar o efeito que diferentes tempos de ativação exercem sobre a resposta óssea ao redor de implantes através de análise histomorfométrica. Materiais e Métodos: Foram colocados três implantes Replace Select em cada lado da mandíbula em 8 cães, no total de 48 implantes no estudo. Foi selecionado um par de implantes para o protocolo de carga imediata $(\mathrm{Cl})$. Após sete dias, o segundo par de implantes recebeu as próteses para o protocolo de carga precoce (CP). Catorze dias após a colocação dos implantes, o terceiro par de implantes recebeu as próteses para o protocolo de carga precoce tardia (CPT). Após um período total de doze semanas de uso das próteses, os animais foram sacrificados e os espécimes foram preparados para análise histomorfométrica. Foram avaliadas as diferenças entre os tempos de ativação para os seguintes parâmetros: contato osso-implante (COI), densidade óssea (DO) e perda da crista óssea (PCO) usando ANOVA. Resultados: A porcentagem de $\mathrm{COI}$ para $\mathrm{Cl}$ foi $77,9 \pm 1,71 \%$, para $\mathrm{CP}$ foi $79,25 \pm 2,11 \%$ e para CPT foi $79,42 \pm 1,49 \%$. A porcentagem de DO para $\mathrm{Cl}$ foi $69,97 \pm 3,81 \%$, para CP foi $69,23 \pm 5,68 \%$ e para CPT foi $69,19 \pm 2,90 \%$. A PCO para Cl foi $1,57 \pm 0,22 \mathrm{~mm}$, para CP foi $1,23 \pm 0,19 \mathrm{~mm}$ e para CPT foi 1,17 $\pm 0,32 \mathrm{~mm}$. Não foi observada diferença estatística para nenhum dos parâmetros avaliados $(p>0,05)$. Conclusão: Diferentes tempos de ativação parecem não afetar de maneira significativa a resposta óssea ao redor dos implantes dentários.

Palavras-chave: Implantes dentários, carga precoce, carga imediata, densidade óssea, contato osso-implante, osseointegração, estudos com animais.

\section{INTRODUÇÃO}

A cicatrização do osso mandibular com implantes dentários baseia-se no princípio da osseointegração ${ }^{1,2}$. Este princípio originalmente exigia um período de cicatrização de vários meses e tinha como objetivo estabelecer um contato direto osso-implante que, de acordo com a definição, deve ser comprovado por meio de análise histológica.

Os atuais índices de sucesso de reabilitação oral com implantes dentários na mandíbula ultrapassam $95 \%^{3}$. O protocolo original para implantes de Brånemark necessitava de um tempo de cicatrização de 3 a 6 
meses com o implante submerso e livre de estresse para obter a osseointegração ${ }^{4,5}$. O tempo de cicatrização prolongado sem carga era considerado necessário para evitar o encapsulamento dos implantes por tecido fibroso ao invés de osseointegração ${ }^{5}$; entretanto, evidências clínicas e experimentais posteriores revelaram que a osseointegração ocorre mesmo quando os implantes são deixados expostos à cavidade bucal durante a cicatrização ${ }^{6}$. Tradicionalmente, durante esse período de cicatrização os pacientes eram reabilitados usando próteses removíveis, entretanto, percebeu-se que as próteses provisórias eram desconfortáveis, devido à falta de estabilidade e retenção, e que seria, portanto, benéfico se o período de cicatrização pudesse ser encurtado sem prejudicar o sucesso do implante. Com os altos índices de sucesso clínico obtidos com o protocolo original de implantes, clínicos e pesquisadores ganharam confiança para continuarem a desenvolver e refinar a técnica com novos desenhos de implantes e conceitos de tratamento. ${ }^{3,6,7}$

Houve, também, uma mudança de foco na terapia com implantes, de um tratamento originalmente destinado exclusivamente à reabilitação funcional para uma modalidade de tratamento com grande ênfase na estética. A restauração imediata de implantes com carga funcional proporciona maior conforto ao paciente, permite o rápido restabelecimento da função mastigatória e estética ${ }^{8}$. Além disso, elimina o inconveniente de uma segunda cirurgia para a colocação de cicatrizadores. Isso freqüentemente leva a uma cicatrização precoce dos tecidos moles e resulta 
na estabilização precoce da mucosa periimplantar para assegurar maior sobrevida ao implante. ${ }^{7}$

Diversos estudos experimentais mostraram que a carga imediata sobre implantes não leva necessariamente à cicatrização por tecido fibroso. Em vez disso, com o tempo desenvolve-se contato osso-implante, que é comparável ao que ocorre com implantes que recebem carga de maneira convencional $^{7,9-11}$. Implantes retirados de seres humanos com o osso adjacente confirmaram esses resultados experimentais, tanto na mandíbula quanto na maxila, com contato osso-implante de até $93 \% .^{8,12,13}$

O osso periimplantar ajusta sua arquitetura em relação à sua carga funcional. As tensões induzidas por essas cargas afetam o processo de remodelação óssea. Sugere-se que a magnitude da carga entre o implante e o osso determina o sucesso do implante ${ }^{14}$. Portanto, um fator essencial para o sucesso do implante parece ser a adequada remodelagem do osso ao redor do implante. Um milímetro do osso adjacente ao implante necrosa após a colocação do implante, e este osso necrótico fornece suporte estrutural importante durante a fase inicial de cicatrização e, posteriormente, o osso formado substitui o osso necrótico ${ }^{15}$.

As atividades funcionais geram tensões sobre o osso que, direta ou indiretamente, desempenham um papel na adaptação celular do tecido ósseo $^{16}$. A manutenção do implante osseointegrado envolve a atividade de remodelação contínua na periferia do implante ${ }^{17}$. Neste contexto, não se considera mais que a carga imediata leva à cicatrização com tecido conjuntivo ao redor dos implantes ${ }^{18}$. Pelo contrário, certa microtensão pode 
propiciar melhor mineralização do osso periimplantar ${ }^{19}$. Alguns estudos experimentais disponíveis na literatura fornecem dados sobre contato ossoimplante e densidade óssea com implantes sob carga imediata ${ }^{9,20-24}$. Entretanto, esses parâmetros podem fornecer informações importantes sobre o processo da remodelagem óssea ao redor de implantes com carga imediata.

Portanto, o objetivo deste estudo foi verificar, na mandíbula de cães, o contato osso-implante, a densidade óssea e a perda de crista óssea ao redor de implantes com diferentes tempos de ativação.

\section{MATERIAIS E MÉTODOS}

O Comitê de Ética em Pesquisa com Animais aprovou o protocolo experimental (Processo 05.1.1318.53.1). Foram usados oito cães adultos, machos, sem raça definida $( \pm 25 \mathrm{~kg})$. Os cães possuíam maxilas e mandíbulas intactas, bom estado de saúde e não apresentavam lesões orais virais ou fúngicas. Os animais não foram alimentados por 12 horas antes da cirurgia para evitar vômito. Eles foram sedados e anestesiados por via intravenosa com thiopental $(1 \mathrm{ml} / \mathrm{kg} ; 20 \mathrm{mg} / \mathrm{kg}$ thiopental diluído em $50 \mathrm{~mL}$ de soro fisiológico). Na seqüência, foi levantado um retalho total na região dos 4 pré-molares mandibulares e os dentes foram cortados na direção buco-lingual e extraídos com fórceps. Os retalhos foram reposicionados e suturados com fio de sutura 4-0 absorvível. Durante o período de cicatrização, os animais foram avaliados periodicamente e tratados mensalmente com ultra-som profilático. Foram feitas moldagens da 
mandíbula inferior direita e esquerda (Xantopren \& Optosil, Heraeus Kulzer $\mathrm{GmbH}$, Hanau, Alemanha) e gerados modelos que foram usados durante a fase protética. Até o final do experimento a dieta foi alterada para consistência macia.

Após um período de cicatrização de três meses, os animais receberam $20000 \mathrm{UI}$ de penicilina e estreptomicina $(1,0 \mathrm{~g} / 10 \mathrm{~kg})$ na noite anterior à cirurgia de colocação de implantes. Esta dose proporcionou cobertura antibiótica por 4 dias; assim, foi dada outra dose 4 dias depois para proporcionar cobertura total de 8 dias. Essa cobertura antibiótica de amplo espectro é normalmente usada para tratar infecções em pequenos animais $^{25}$. Depois disso, repetindo a mesma sedação e anestesia descritas anteriormente, foi feita uma incisão horizontal na crista óssea da região distal do canino até a região mesial do primeiro molar, e os implantes foram colocados de acordo com as instruções do fabricante. Foram colocados três implantes de 4,3 x $10 \mathrm{~mm}$ (Replace Select ${ }^{\circledR}$ Tapered, Nobel Biocare, Suécia), com superfícies ásperas (TiUnite ${ }^{\circledR}$, Nobel Biocare, Suécia) ao nível da crista óssea (figura 1), de cada lado da mandíbula de cada animal, no total de 48 implantes no estudo. Um implante foi selecionado para protocolo de carga imediata ( $\mathrm{Cl}$ ) (figura 2), e os outros dois restantes na hemimandíbula receberam cicatrizadores até a colocação das próteses, de acordo com o tempo de ativação. Após sete dias, o segundo implante recebeu a prótese para o protocolo de carga precoce (CP) (figura 3). Catorze dias após a colocação dos implantes, o terceiro implante recebeu a prótese para o protocolo de carga precoce tardia (CPT) (figura 4). Os implantes 
submetidos aos diferentes protocolos de ativação foram distribuídos randomicamente com base em "cara ou coroa".

Após a colocação dos implantes foi obtido um molde e os implantes selecionados para carga imediata receberam coroas provisórias em resina acrílica (Duralay, Reliance Dental, MFG Co., Woth, IL, EUA), feitas diretamente sobre o implante.

As coroas metálicas foram fabricadas sobre modelos com pilares padrão em liga de níquel-cromo (VeraBond II, Aalba Dent. Inc., Cordelia, CA, EUA), com nicho para retenção nas faces proximais para facilitar a esplintagem das coroas, de acordo com a seqüência de ativação, usando resina quimicamente ativada (Duralay, Reliance Dental, MFG Co., Worth, IL, EUA). As margens das coroas foram colocadas ao nível gengival. Quando os implantes selecionados para carga precoce receberam as coroas definitivas, uma semana depois, as restaurações provisórias dos implantes de carga imediata foram removidas e substituídas pelos coroas definitivas metálicas. Durante o tempo em que as próteses permaneceram posicionadas, os cães foram sedados com uma injeção intramuscular de pré-anestésico ( $2 \%$ cloridrato de xylazina, $20 \mathrm{mg} / \mathrm{kg}$ ) e foi feita profilaxia com ultra-som semanalmente até o sacrifício.

Foram realizados ajustes intra-orais para eliminar qualquer contato oclusal, verificado com papel de articulação (Accu Film II, Parkell, Farmingdale, NY, EUA).

Após um período total de doze semanas com prótese, os animais foram sedados e depois sacrificados com uma overdose de thiopental. As 
coroas e os pilares foram removidos para facilitar o processamento histológico. As hemimandíbulas foram removidas, dissecadas e fixadas em formol 4\% pH 7,0 por 10 dias, e depois transferidas para uma solução de etanol $70 \%$ até serem processadas. Os espécimes foram desidratados em concentrações crescentes de álcool até 100\%, infiltrados e embutidos em resina (LR White, London Resin, Berkshire, Reino Unido), e cortados usando a técnica de "corte e polimento"26.

\section{Análise por Microscopia Ótica - Análise Histomorfométrica}

Um corte histológico longitudinal (mésio-distal) com 20-30 $\mu \mathrm{m}$, de cada implante, corado com Stevenel's Blue e Alizarin red S, foi capturado por uma câmera de vídeo (Leica Microsystems, Nussloch, Alemanha) conectada a um estereomicroscópio (Leica Microsystems, Nussloch, Alemanha) com aumento de 1,5X. As imagens foram analisadas por um programa de imagem (Image J, National Institutes of Health, Bethesda, MD, EUA). Foram feitas as seguintes mensurações (figura 5):

\section{Contato Osso-Implante:}

O contato osso-implante (COI) foi definido como o comprimento da borda da superfície óssea em contato direto com o implante/periferia total do implante [x100 (\%)] desde a rosca mais coronária até a rosca mais apical. 


\section{Densidade Óssea}

A densidade óssea (DO) ao redor dos implantes foi determinada como a área óssea/área tecidual [x100 (\%)] presente dentro de um retângulo de 1 mm x 5 mm, que corresponde a 512 x 2560 pixels. O retângulo foi posicionado na rosca mais coronária.

\section{Perda da Crista Óssea}

A magnitude de perda da crista óssea (PCO) foi determinada por mensurações lineares (expressas em $\mathrm{mm}$ ) desde o topo do implante até o primeiro contato osso-implante. Nos casos em que a crista óssea era coronária em relação ao topo do implante, a medida usada foi de $0 \mathrm{~mm}$.

As medições foram feitas por um único examinador às cegas em relação à identificação dos grupos. As figuras 6-8 representam os cortes histológicos de cada grupo.

\section{Análise Estatística}

Antes da análise estatística, foram agrupadas diversas medidas por animal e tratamento usando suas médias aritméticas. Foram calculados os valores médios e o desvio padrão. Os dados foram agrupados usando os cães como unidades para análise. As diferenças médias foram verificadas através do teste ANOVA não-paramétrica com nível de significância de 5\%. Todos os cálculos foram feitos por um programa estatístico específico (SPSS versão 15, SPSS inc., Chicago, IL, EUA). 


\section{RESULTADOS}

\section{Resultados clínicos}

Não foi observado nenhum evento durante a cicatrização após a extração. Na cirurgia de colocação dos implantes, 12 semanas depois, clinicamente os locais das extrações estavam aparentemente cicatrizados. Após a colocação dos implantes, a cicatrização também foi tranqüila, sem complicações durante todo o período experimental. Durante o período de cicatrização, todos os implantes ficaram estáveis até o final da investigação.

\section{Observações histológicas}

Nos três grupos, os implantes foram cercados por tecido ósseo composto de osso lamelar, osso alveolar e osso recém-formado. O tecido ósseo caracterizou-se por formações paralelas ou concêntricas. Os canais centrais tinham diâmetros diferentes, cobertos por um endósteo ativo e, em alguns pontos, estavam em contato íntimo com a superfície do implante. Além disso, durante a análise de densidade óssea, maiores densidades foram observadas em porções mais próximas à superfície dos implantes.

\section{Resultados histomorfométricos}

Os resultados histomorfométricos das porcentagens de COI direto ao redor dos implantes, apresentados na Tabela 1 , revelaram que a porcentagem média de COI direto no grupo Cl foi 77,9 \pm 1,71\% (variação de $58,96 \%$ a $84,21 \%$ ), no grupo CP foi $79,25 \pm 2,11 \%$ (variação de $68,81 \%$ a 86,33\%) e no grupo CPT foi 79,42 \pm 1,49\% (variação de 68,39\% a 84,33\%). 
Entre os grupos as diferenças não foram estatisticamente significantes $(p>0,05)$. As figuras 9 a 11 mostram a distribuição de freqüência de implantes em relação às porcentagens de $\mathrm{COI}$ para $\mathrm{Cl}, \mathrm{CP}$ e $\mathrm{CPT}$, respectivamente. Nos grupos $\mathrm{Cl}$ e $\mathrm{CP}$ observou-se maior freqüência de implantes (9) com valores de COI variando entre $70 \%$ e $80 \%$, e no grupo CPT (7). No grupo $\mathrm{Cl}$ somente um implante apresentou valor de COI variando entre 50\% e 60\%. Outros 3 implantes do grupo $\mathrm{Cl}, 5$ do $\mathrm{CP}$ e 6 do CPT apresentaram valores de COI variando entre $80 \%$ e $90 \%$. Não foram observadas porcentagens inferiores a 50\% em nenhum dos grupos.

A análise de densidade óssea, apresentada na Tabela 2, revelou que a porcentagem de osso dentro do retângulo para o grupo $\mathrm{Cl}$ foi de $69,97 \pm$ 3,81\% (variação de 42,63\% a 81,05\%), para o grupo CP foi de $69,23 \pm$ 5,68\% (variação de $49,47 \%$ a $85,88 \%$ ) e para o grupo CPT foi de $69,19 \pm$ 2,90\% (variação de 44,15\% a 85,31\%). As diferenças entre os grupos não foram estatisticamente significantes $(p>0,05)$.

As mensurações histomorfométricas para perda de crista óssea (PCO), apresentadas na Tabela 3, foram para o grupo $\mathrm{Cl}$ de 1,57 $\pm 0,22 \mathrm{~mm}$ (variação de 0,00 a 2,21 mm), para o grupo CP de 1,23 \pm 0,19 mm (variação de 0,00 a 1,97 $\mathrm{mm}$ ) e para o grupo CPT de 1,17 \pm 0,32 $\mathrm{mm}$ (variação de 0,00 a 1,76 mm). As diferenças entre os grupos não foram estatisticamente significantes $(p>0,05)$. A figura 12 mostra a distribuição de freqüência de implantes em relação à $\mathrm{PCO}$ para $\mathrm{Cl}, \mathrm{CP}$ e $\mathrm{CPT}$, respectivamente. Os grupos Cl e CP apresentaram 3 implantes e o grupo CPT 5 implantes sem perda óssea (0 mm). Os grupos $\mathrm{Cl}$, CP e CPT apresentaram distribuição de 
freqüência de PCO variando entre 1 a 2 mm para 9, 12 e 10 implantes, respectivamente. Somente 1 implante no grupo $\mathrm{Cl}$ apresentou PCO de $3 \mathrm{~mm}$ ou mais. Observou-se PCO entre 2 a $3 \mathrm{~mm}$ para 3 implantes no grupo $\mathrm{Cl}$ e para 1 implante nos grupos CP e CPT.

\section{DISCUSSÃO}

A alta previsibilidade da carga tardia em implantes dentários na mandíbula levou à reavaliação do protocolo cirúrgico e protético ${ }^{29}$. Atualmente é possível esperar índices de sucesso comparáveis com implantes de carga imediata e tem sido demonstrado que a carga imediata em implantes dentários não causou efeitos adversos sobre a interface osso/implante, produzindo, ao contrário, maior porcentagem de contato osso-implante que em implantes submersos ${ }^{7,9-11}$. Fatores como a estabilidade primária e esplintagem de implantes dentários ${ }^{30}$, adequada densidade óssea e ausência de sobrecarga foram descritos como influenciadores do processo de osseointegração e do prognóstico de implantes de carga imediata ${ }^{22,31}$.

O protocolo clássico de dois estágios está relacionado a um tempo de tratamento mais longo e a eliminação de um período de cicatrização prolongado oferece vantagens em termos de custo de tratamento e conveniência aos pacientes. Foi relatado, também, que a nova restauração é considerada uniformemente superior à situação de tratamento anterior em uma semana, especialmente quando comparada com a prótese total removível convencional $^{32,33}$. 
Diversos aspectos histológicos de implantes sob carga imediata foram ressaltados em diferentes estudos experimentais, mas, infelizmente, os animais usados nesses estudos apresentavam taxas metabólicas que eram no mínimo o dobro em relação às de seres humanos ${ }^{7-10,20,34}$. Além disso, em estudos com animais, mais parâmetros podem ser mantidos constantes do que seria possível em um estudo clínico, de forma que é preciso usar uma abordagem muito cautelosa para transferir os resultados histológicos para uma situação humana ${ }^{21}$. Entretanto, esses dados podem fornecer informações importantes para se entender o processo de resposta óssea precoce ao redor dos implantes.

A manutenção e o sucesso em longo prazo de implantes osseointegrados envolve a atividade de remodelagem contínua na periferia do implante para evitar fratura por fadiga óssea ${ }^{9}$ e para substituir osso que pode ter sofrido microfraturas em decorrência de cargas cíclicas ${ }^{35,36}$. A carga mecânica desempenha papel importante no desenvolvimento, na manutenção e na adaptação do esqueleto ${ }^{37}$. A lei de Wolf demonstra a relação entre eventos mecânicos, como remodelagem óssea, formação óssea e reabsorção óssea ${ }^{38-40}$. A adaptação óssea depende da magnitude, duração, freqüência, história, tipo e distribuição da tensão ${ }^{41}$.

Em um estudo com animais conduzido por Berglundh e cols. ${ }^{42}$, foi observado que implantes expostos a carga funcional apresentavam maior grau de contato osso-implante, e que a carga funcional pode aumentar a osseointegração. Os dados da presente investigação em relação ao contato osso-implante foram comparáveis com os valores encontrados na literatura 
atual e variaram de 72 a $85 \%^{20,21,43}$. A alta previsibilidade de implantes de carga imediata com restaurações provisórias fixas também foi mostrada em relatórios anteriores ${ }^{44,45}$. Este fato parece indicar que as próteses fixas podem ajudar a limitar as forças oclusais, que são aplicadas sobre a interface osso-implante, a uma faixa fisiológica ${ }^{18,32,46,47}$. Sabe-se bem que a mobilidade inicial do implante não impede inevitavelmente a osseointegração ${ }^{48}$. Entretanto, tem sido sugerido que micromovimentos de aproximadamente $28 \mu \mathrm{m}$ ou menos não causam nenhum efeito adverso sobre a osseointegração, enquanto que micromovimentos de $150 \mu \mathrm{m}$ ou mais levam à cicatrização por tecido fibroso ${ }^{18,49,50}$. A microtensão pode ser um estímulo favorável durante o período de cicatrização de implantes. Resultados obtidos em pesquisa de osteoporose revelaram que tensões resultam no aumento da densidade óssea ${ }^{19}$. Resultados semelhantes foram observados em implantes dentários ${ }^{51}$. Entretanto, neste estudo, a densidade óssea não foi aumentada por $\mathrm{Cl}$, CP ou CPT $(p>0,05)$. Isso poderia ser explicado pela excelente qualidade do osso obtido após a extração dentária ao manter o período de cicatrização óssea de 12 semanas.

Além disso, neste estudo, a reabsorção óssea foi avaliada por análise da perda de crista óssea, uma mensuração feita do topo do implante até o primeiro COI. Para padronizar a colocação dos implantes e obter uma referência para a mensuração da $\mathrm{PCO}$, todos os implantes foram colocados ao nível da crista óssea. Conforme observado neste estudo, não foram observadas diferenças significativas de PCO entre todos os grupos $(p>0,05)$, embora o grupo $\mathrm{Cl}$ tenha apresentado PCO numericamente maior. Além 
disso, a falha inicial da interface implante-tecido geralmente ocorre na região da crita de implantes osseointegrados com sucesso. Possíveis fatores etiológicos para a perda precoce de osso (desde a colocação dos implantes até 1 ano após a carga) incluem o trauma cirúrgico, a formação da distância biológica, módulo de crista do implante e outros fatores. Estes fatores todos, associdados à carga podem ter contribuído para a OCl observada em todos os grupos estudados. Entretanto, o trauma cirúrgico tem sido apontado como um dos mais comumente suspeitos fatores etiológicos da perda da crista óssea ${ }^{52}$. Foram relatadas falhas de adesão óssea quando implantes colocados em macacos eram submetidos a sobrecarga ${ }^{53}$. A possibilidade de defeitos do tipo triangular ou cratera em um modelo de coelhos foi observada em decorrência de forças oclusais excessivas ${ }^{54}$. Entretanto, essa observação foi contestada por outros investigadores quando não foi observada nenhuma reabsorção óssea periimplantar após a aplicação de força oclusal excessiva de $300 N^{55}$. Além disso, em outros estudos com animais, foi relatado que implantes com carga contínua eram rodeados por tecidos compactos e mineralizados com densidades 100-150\% maiores que o osso esponjoso original ${ }^{56}$. É importante enfatizar que está bem estabelecido que o colar polido destes tipos de implantes nunca retém a crista óssea e que a altura deste colar sempre corresponde à perda óssea mínima esperada ${ }^{57}$.

Um dos principais pontos contrários à carga imediata tem sido a presença de uma camada de osso necrótico adjacente à superfície do implante, principalmente relacionada ao trauma cirúrgico ${ }^{5}$. Foi postulado que 
essa camada necrótica deva ser substituída por osso novo antes da carga ${ }^{58}$. Entretanto, a remodelagem óssea não ocorre ao mesmo tempo ao redor do implante todo, senão seria de se esperar mobilidade durante o processo de remodelagem óssea. Aparentemente, a remodelagem é variável, com um equilíbrio entre as atividades osteoclástica e osteoblástica, de modo que um implante estável é sempre mantido durante a osseointegração ${ }^{9,59}$. Em decorrência da preparação inadequada do local do implante, pode ser produzida maior quantidade de osso necrótico na periferia de um implante, o que pode levar à perda do implante ${ }^{60}$. Entretanto, parece que na maioria dos casos a redução do contato osso-implante pode ser compensada de maneira eficaz pela esplintagem rígida, como a usada neste estudo.

Estudos clínicos suportaram o fato de que os resultados clínicos de carga imediata são comparáveis e até superiores aos de carga convencional $^{61-63}$. Isso foi confirmado pelos resultados deste estudo, que relatou, com base em análise histomorfométrica, que o tempo de carga não compromete a resposta óssea, representada por COI, DO e PCO. Não foram observadas diferenças significativas entre os 3 grupos, sugerindo que o resultado deve ser o mesmo.

\section{CONCLUSÃO}

Dentro das limitações deste estudo pôde ser concluído que, em mandíbulas de cães, diferentes tempos de carga parece não afetar significativamente a resposta óssea ao redor dos implantes. 


\section{AGRADECIMENTOS}

Este estudo foi parcialmente financiado pela Nobel Biocare e FAPESP (Processo \#2006/04747-0). 


\section{REFERÊNCIAS}

1. Brånemark PI, Adell R, Breine U, Hansson BO, Lindstrom J, Ohlsson A.Intra-osseous anchorage of dental prostheses. I. Experimental studies. Scand J Plast Reconstr Surg. 1969;3:81-100.

2. Schroeder A, Van Der Zypen E, Stich H, Sutter F. The reaction of bone, connective tissue and epithelium to endosteal implants with sprayed titanium surfaces. J Maxillofac Surg. 1981;9:15-25.

3. Testori T, Wiseman L, Woolfe S, Porter SS. A prospective multicenter clinical study of the Osseotite implant: four-year interim report. Int J Oral Maxillofac Implants. 2001;16:193-200.

4. Adell R, Lekholm U, Rockler B, Brånemark P-I. A 15-year study of osseointegrated implants in the treatment of edentulous jaw. Int $\mathrm{J}$ Oral Surg. 1981;10:387-416.

5. Albrektsson $\mathrm{T}$, Brånemark $\mathrm{Pl}$, Hansson HA, Lindström J. Osseointegrated titanium implants. Requirements for ensuring a longlasting, direct bone-to-implant anchorage in man. Acta Orthop Scand. 1981;52:155-170.

6. Becker $\mathrm{W}$, Becker $\mathrm{BE}$, Israelson $\mathrm{H}$, Lucchini JP, Handelsman $\mathrm{M}$, Ammons W, Rosenberg E, Rose L, Tucker LM, Lekholm U. One-step surgical placement of Brånemark implants: a prospective multicenter clinical study. Int J Oral Maxillofac Implants 1997:12: 454-462.

7. Romanos G, Toh CG, Siar CH, Swaminathan D, Ong AH, Donath K, Yaacob $\mathrm{H}$, Nentwig $\mathrm{GH}$. Peri-implant bone reactions to immediately 
loaded implants. An experimental study in monkeys. J Periodontol. 2001;72:506-511.

8. Ledermann PD, Schenk RK, Buser D. Long-lasting osseointegration of immediately loaded, bar-connected TPS screws after 12 years of function: a histologic case report of a 95-year-old patient. Int $\mathrm{J}$ Periodontics Restorative Dent. 1998;18:552-563.

9. Nkenke E, Lehner B, Weinzierl K, Thams U, Neugebauer J, Steveling H, Radespiel-Tröger M, Neukam FW. Bone contact, growth, and density around immediately loaded implants in the mandible of mini pigs. Clin Oral Implants Res. 2003;14:312-321.

10. Siar $\mathrm{CH}$, Toh CG, Romanos G, Swaminathan D, Ong AH, Yaacob $H$, Nentwig GH. Peri-implant soft tissue integration of immediately loaded implants in the posterior macaque mandible: a histomorphometric study. J Periodontol. 2003;74:571-578.

11. Nkenke E, Fenner M, Vairaktaris EG, Neukam FW, Radespiel-Tröger M. Immediate versus delayed loading of dental implants in the maxillae of minipigs. Part II: histomorphometric analysis. Int $\mathrm{J}$ Oral Maxillofac Implants. 2005;20:540-546.

12. Piattelli A, Paolantonio M, Corigliano M, Scarano A. Immediate loading of titanium plasma-sprayed screw-shaped implants in man: a clinical and histological report of two cases. J Periodontol. 1997;68:591-597.

13. Rocci A, Martignoni M, Burgos PM, Gottlow J, Sennerby L. Histology of retrieved immediately and early loaded oxidized implants: light 
microscopic observations after 5 to 9 months of loading in the posterior mandible. Clin Implant Dent Relat Res. 2003;5 Suppl 1:88-98.

14. Hoshaw SJ, Brunski JB, Cochran D. Mechanical loading of Brånemark implants affects interfacial bone modeling and remodeling. Int $\mathrm{J}$ Oral Maxillofac Implants. 1994;9:343-360.

15. Johansson C, Albrektsson T. Integration of screw implants in the rabbit: a 1-year follow-up of removal torque of titanium implants. Int $\mathrm{J}$ Oral Maxillofac Implants. 1987;2:69-75.

16. Fritton SP, McLeod KJ, Rubin CT. Quantifying the strain history of bone: spatial uniformity and self-similarity of low-magnitude strains. J Biomech. 2000;33:317-325.

17. Suzuki K, Aoki K, Ohya K. Effects of surface roughness of titanium implants on bone remodeling activity of femur in rabbits. Bone. 1997;21:507-514.

18. Szmukler-Moncler S, Piattelli A, Favero GA, Dubruille JH. Considerations preliminary to the application of early and immediate loading protocols in dental implantology. Clin Oral Implants Res. 2000;11:12-25. Review.

19. Frost HM. The role of changes in mechanical usage set points in the pathogenesis of osteoporosis. J Bone Miner Res. 1992;7:253-261. Review.

20. Piattelli A, Corigliano M, Scarano A, Quaranta M. Bone reactions to early occlusal loading of two-stage titanium plasma-sprayed implants: a pilot study in monkeys. Int J Periodontics Restorative Dent. 1997;17:162-169. 
21. Piattelli A, Corigliano M, Scarano A, Costigliola G, Paolantonio M. Immediate loading of titanium plasma-sprayed implants: an histologic analysis in monkeys. J Periodontol. 1998;69:321-327.

22. Zubery $\mathrm{Y}$, Bichacho $\mathrm{N}$, Moses $\mathrm{O}$, Tal $\mathrm{H}$. Immediate loading of modular transitional implants: a histologic and histomorphometric study in dogs. Int J Periodontics Restorative Dent. 1999;19:343-353.

23. Ghanavati F, Shayegh SS, Rahimi H, Sharifi D, Ghanavati F, Khalesseh $\mathrm{N}$, Eslami B. The effects of loading time on osseointegration and new bone formation around dental implants: a histologic and histomorphometric study in dogs. J Periodontol. 2006;77:1701-1707.

24. Moon SY, Kim SG, Lim SC, Ong JL. Histologic and histomorphometric evaluation of early and immediately loaded implants in the dog mandible. J Biomed Mater Res A. 2008;15:1122-1127.

25. Novaes Junior AB, Vidigal Junior GM, Novaes AB, Grisi MF, Polloni S, Rosa A. Immediate implants placed into infected sites: a histomorphometric study in dogs. Int $\mathrm{J}$ Oral Maxillofac Implants. 1998;13:422-427.

26. Degidi M, Piatelli A. Immediate functional and non-functional loading of dental implants: a 2- to 60-month follow up study of 646 titanium implants. J Periodontol. 2003;74:225-41.

27. Misch CE. Density of bone: effect on treatment planning, surgical approach, and healing. In: Misch CE. Contemporary Implant Dentistry. St. Louis: Mosby, 1993:469-485. 
28. Donath K, Breuner G. A method for the study of undercalcified bones and teeth with attached soft tissue. J Oral Pathol 1982;11:318-326.

29. Tarnow DP, Emtiaz S, Classi A. Immediate loading of threaded implants at stage 1 surgery in edentulous arches: ten consecutive case reports with 1- to 5-year data. Int J Oral Maxillofac Implants 1997:12:319-324.

30. Romanos GE. Surgical and prosthetic concepts for predictable immediate loading of oral implants. J Calif Dent Assoc. 2004;32:9911001.

31. Engquist B, Astrand $P$, Anze'n B, Dahlgren S, Engquist E, Feldmann H, Karlsson U, Nord PG, Sahlholm S, Svärdström P. Simplified methods of implant treatment in the edentulous lower jaw. A controlled prospective study. Part II: Early loading. Clin Implant Dent Relat Res 2004:6:90-100.

32. Chiapasco M, Gatti C, Rossi E, Haefliger W, Markwalder TH. Implantretained mandibular overdentures with immediate loading. A retrospective multicenter study on 226 consecutive cases. Clin Oral Implants Res. 1997;8:48-57.

33. Ganeles J, Rosenberg MM, Holt RL, Reichman LH. Immediate loading of implants with fixed restorations in the completely edentulous mandible: report of 27 patients from a private practice. Int $\mathrm{J}$ Oral Maxillofac Implants. 2001;16:418-426.

34. Hönig JF, Merten HA. Subperiosteal versus epiperiosteal forehead augmentation with hydroxylapatite for aesthetic facial contouring: experimental animal investigation and clinical application. Aesthetic Plast Surg. 1993;17:93-98. 
35. Norman TL, Wang Z. Microdamage of human cortical bone: incidence and morphology in long bones. Bone. 1997;20:375-379.

36. van Oosterwyck H, Duyck J, Vander Sloten J, Van der Perre G, De Cooman M, Lievens S, Puers R, Naert I. The influence of bone mechanical properties and implant fixation upon bone loading around oral implants. Clin Oral Implants Res. 1998;9:407-418.

37. Tanck E, Homminga J, van Lenthe $\mathrm{GH}$, Huiskes R. Increase in bone volume fraction precedes architectural adaptation in growing bone. Bone. 2001;28:650-654.

38. Hansson S. The implant neck: smooth or provided with retention elements. A biomechanical approach. Clin Oral Implants Res. 1999;10:394-405.

39. Hansson S. A conical implant-abutment interface at the level of the marginal bone improves the distribution of stresses in the supporting bone. An axisymmetric finite element analysis. Clin Oral Implants Res. 2003;14:286-293.

40. Hansson S, Werke M. The implant thread as a retention element in cortical bone: the effect of thread size and thread profile: a finite element study. J Biomech. 2003;36:1247-1258.

41. Turner $\mathrm{CH}$. Three rules for bone adaptation to mechanical stimuli. Bone. 1998;23:399-407. Review.

42. Berglundh T, Abrahamsson I, Lindhe J. Bone reactions to longstanding functional load at implants: an experimental study in dogs. J Clin Periodontol. 2005;32:925-932. 
43. Testori T, Szmukler-Moncler S, Francetti L, Del Fabbro M, Scarano A, Piattelli A, Weinstein RL. Immediate loading of Osseotite implants: a case report and histologic analysis after 4 months of occlusal loading. Int J Periodontics Restorative Dent. 2001;21:451-459.

44. Romanos GE, Nentwig GH. Immediate loading using cross-arch fixed restorations in heavy smokers: nine consecutive case reports for edentulous arches. Int J Oral Maxillofac Implants. 2008;23:513-519.

45. Ostman PO, Hellman M, Sennerby L, Wennerberg A. Temporary implantsupported prosthesis for immediate loading according to a chair-side concept: technical note and results from 37 consecutive cases. Clin Implant Dent Relat Res. 2008;10:71-77.

46. Brunski JB. Avoid pitfalls of overloading and micromotion of intraosseous implants. Dent Implantol Update. 1993;4:77-81.

47. Salama H, Rose LF, Salama M, Betts NJ. Immediate loading of bilaterally splinted titanium root-form implants in fixed prosthodontics--a technique reexamined: two case reports. Int J Periodontics Restorative Dent. 1995;15:344-361.

48. Ivanoff CJ, Sennerby L, Lekholm U. Influence of initial implant mobility on the integration of titanium implants. An experimental study in rabbits. Clin Oral Implants Res. 1996;7:120-127.

49. Pilliar RM, Lee JM, Maniatopoulos C. Observations on the effect of movement on bone ingrowth into porous-surfaced implants. Clin Orthop Relat Res. 1986;208:108-113. 
50. Brunski JB. Biomechanical factors affecting the bone-dental implant interface.Clin Mater. 1992;10:153-201. Review.

51. Matsumoto H, Ochi M, Abiko Y, Hirose Y, Kaku T, Sakaguchi K. Pulsed electromagnetic fields promote bone formation around dental implants inserted into the femur of rabbits. Clin Oral Implants Res. 2000; 11: 354360.

52. Oh T-J, Yoon J, Misch CE, Wang H-L. The causes of early implant bone loss. Myth or science? J Periodontol. 2002;73:322-333.

53. Isidor F. Histological evaluation of peri-implant bone at implants subjected to occlusal overload or plaque accumulation. Clin Oral Implants Res 1997;8:1-9.

54. Duyck J, Ronald H, Van Oosterwyck H, Naert I, Vander Solten J, Ellingsen JE. The influence of static and excessive dynamic loading on the marginal bone behaviour around implants: An animal experimental study. Clin Oral Implants Res 2001;12:207-218.

55. Hurzeler M, Quinones CR, Kohal R, Rohde M, Strub JR, Teuscher U, Caffesse RG. Changes in peri-implant tissues subjected to orthodontic forces and breakdown in monkeys. J Periodontol 1998;69:396-404.

56. Akin-Nergiz N, Nergiz I, Schulz A, Arpak N, Niedermeier W. Reactions of peri-implant tissues to continuous loading of osseointegrated implants. Am J Orthod Dentofacial Orthop 1998;114:292-298.

57. Hämmerle $\mathrm{CH}$, Brägger U, Bürgin W, Lang NP. The effect of subcrestal placement of the polished surface of ITI implants on marginal soft and hard tissues. Clin Oral Implants Res. 1996;7:111-9. 
58. Sagara M, Akagawa $Y$, Nikai $H$, Tsuru $H$. The effects of early occlusal loading on one stage titanium alloy implants in beagle dogs: A pilot study. J Prosthet Dent 1993;69:281-288.

59. Schnitman PA, Wöhrle PS, Rubenstein JE, DaSilva JD, Wang NH. Tenyear results for Brånemark implants immediately loaded with fixed prostheses at implant placement. Int $\mathrm{J}$ Oral Maxillofac Implants. 1997;12:495-503.

60. Tehemar SH. Factors affecting heat generation during implant site preparation: a review of biologic observations and future considerations. Int J Oral Maxillofac Implants. 1999;14:127-136. Review.

61. Donath K. Tissue reactions around loaded and unloaded titanium implants J. Hard Tissue Biol. 1993; 2: 37-47.

62. Esposito M, Grusovin MG, Willings M, Coulthard P, Worthington HV. The effectiveness of immediate, early, and conventional loading of dental implants: a Cochrane systematic review of randomized controlled clinical trials. Int J Oral Maxillofac Implants. 2007;22:893-904. Review.

63. De Smet E, Duyck J, Vander Sloten J, Jacobs R, Naert I. Timing of loading--immediate, early, or delayed--in the outcome of implants in the edentulous mandible: a prospective clinical trial. Int J Oral Maxillofac Implants. 2007;22:580-594. 
TABELAS:

Tabela 1: Porcentagens de contato direto osso-implante ao redor dos implantes com diferentes tempos de carga.

\begin{tabular}{cccc}
\hline $\begin{array}{c}\text { COI (\%) } \\
\text { cão }\end{array}$ & Cl & CPT \\
\hline 1 & 78,88 & 79,88 & 79,69 \\
2 & 77,11 & 76,57 & 78,23 \\
3 & 78,37 & 80,35 & 78,96 \\
4 & 78,12 & 75,75 & 79,12 \\
5 & 74,27 & 79,15 & 81,79 \\
6 & 79,04 & 81,60 & 77,43 \\
7 & 78,14 & 79,31 & 78,79 \\
8 & 79,95 & 81,40 & 81,39 \\
\hline Médias & 77,99 & 79,25 & 79,42 \\
Desvios-padrão & 1,71 & 2,11 & 1,49 \\
$P=0,817$ & $\mathrm{~ns}$ & $\mathrm{~ns}$ & $\mathrm{~ns}$ \\
\hline
\end{tabular}

Significância das diferenças com teste ANOVA não-paramétrico (ns: não significante) 
Tabela 2: Porcentagens de densidade óssea ao redor dos implantes com diferentes tempos de carga.

\begin{tabular}{cccc}
\hline DO (\%) & $\mathrm{Cl}$ & $\mathrm{CP}$ & $\mathrm{CPT}$ \\
cão & & & \\
\hline 1 & 65,79 & 68,34 & 65,21 \\
2 & 72,45 & 62,35 & 72,17 \\
3 & 68,70 & 75,56 & 68,69 \\
4 & 69,31 & 68,33 & 72,23 \\
5 & 65,47 & 61,99 & 68,48 \\
6 & 75,76 & 75,17 & 65,10 \\
7 & 68,02 & 66,39 & 69,84 \\
8 & 74,27 & 75,67 & 71,83 \\
\hline Médias & 69,97 & 69,23 & 69,19 \\
Desvios-padrão & 3,81 & 5,68 & 2,90 \\
$P=0,921$ & $\mathrm{~ns}$ & $\mathrm{~ns}$ & $\mathrm{~ns}$
\end{tabular}

Significância das diferenças com teste ANOVA não-paramétrico (ns: não significante) 
Table 3: Perda da crista óssea ao redor de implantes com diferentes tempos de carga.

\begin{tabular}{cccc}
\hline PCO $(\mathrm{mm})$ & $\mathrm{Cl}$ & $\mathrm{CP}$ & $\mathrm{CPT}$ \\
$\operatorname{dog}$ & 1,55 & 1,36 & 1,28 \\
\hline 1 & 1,68 & 1,37 & 0,66 \\
2 & 1,20 & 0,82 & 0,74 \\
3 & 1,33 & 1,12 & 1,13 \\
4 & 1,68 & 1,20 & 1,42 \\
5 & 1,55 & 1,40 & 1,60 \\
7 & 1,64 & 1,36 & 1,30 \\
8 & 1,89 & 1,21 & 1,26 \\
\hline Médias & 1,57 & 1,23 & 1,17 \\
Desvios-padrão & 0,22 & 0,19 & 0,32 \\
$P=0,753$ & $\mathrm{~ns}$ & $\mathrm{~ns}$ & $\mathrm{~ns}$ \\
\hline
\end{tabular}

Significância das diferenças com teste ANOVA não-paramétrico (ns: não significante) 
FIGURAS:

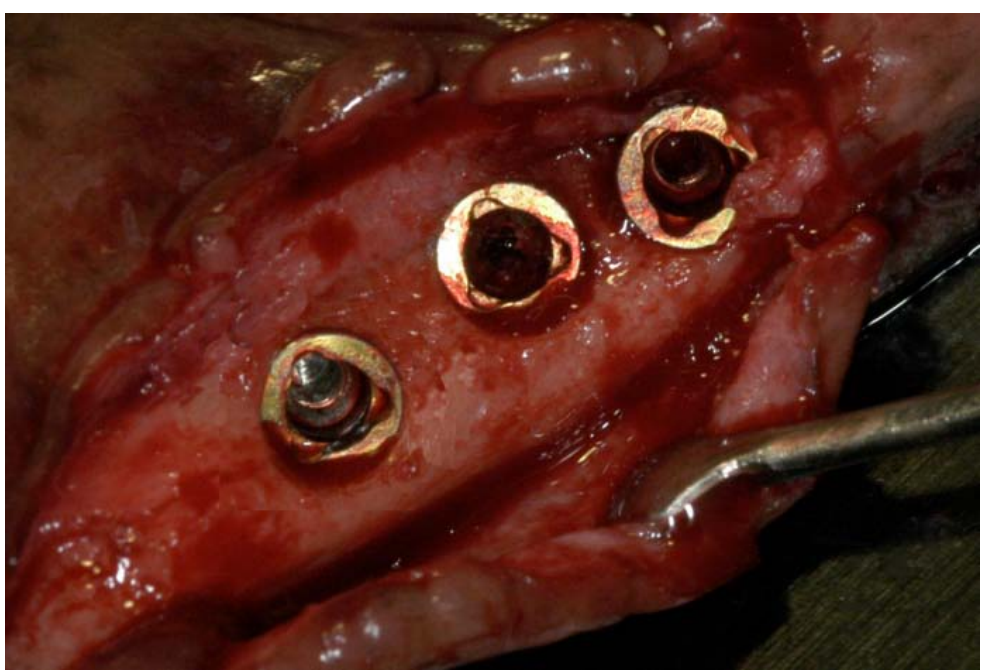

figura 1

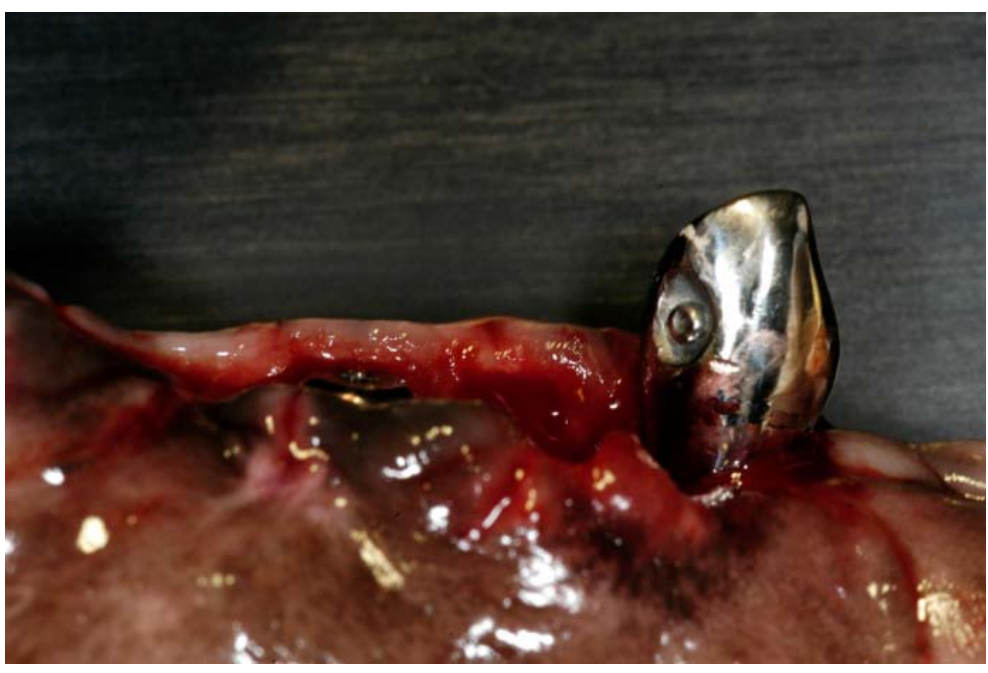

figura 2 


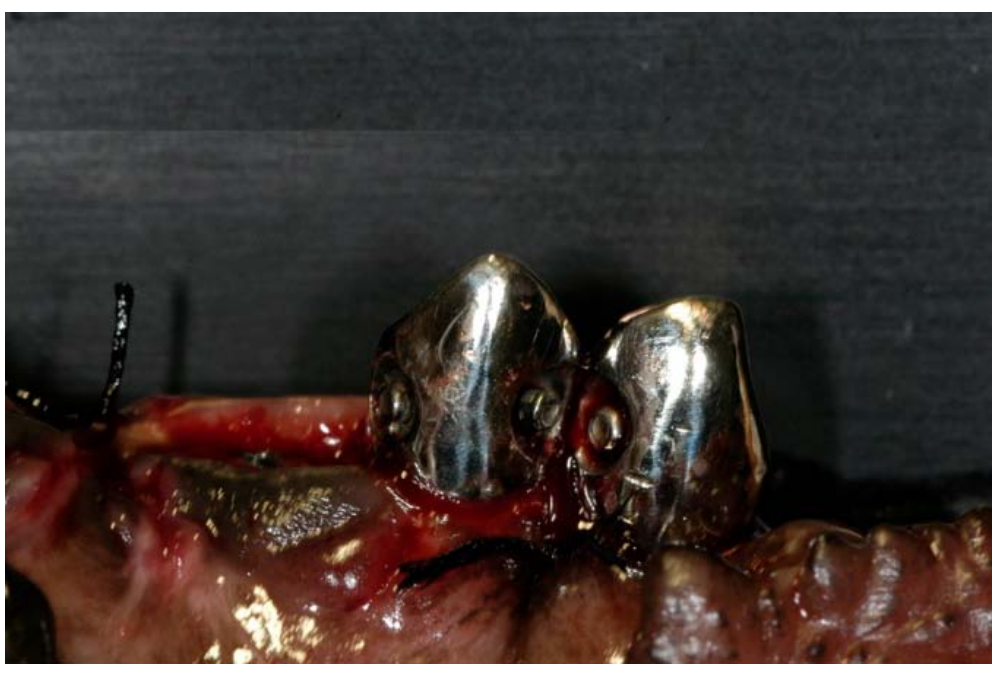

figura 3

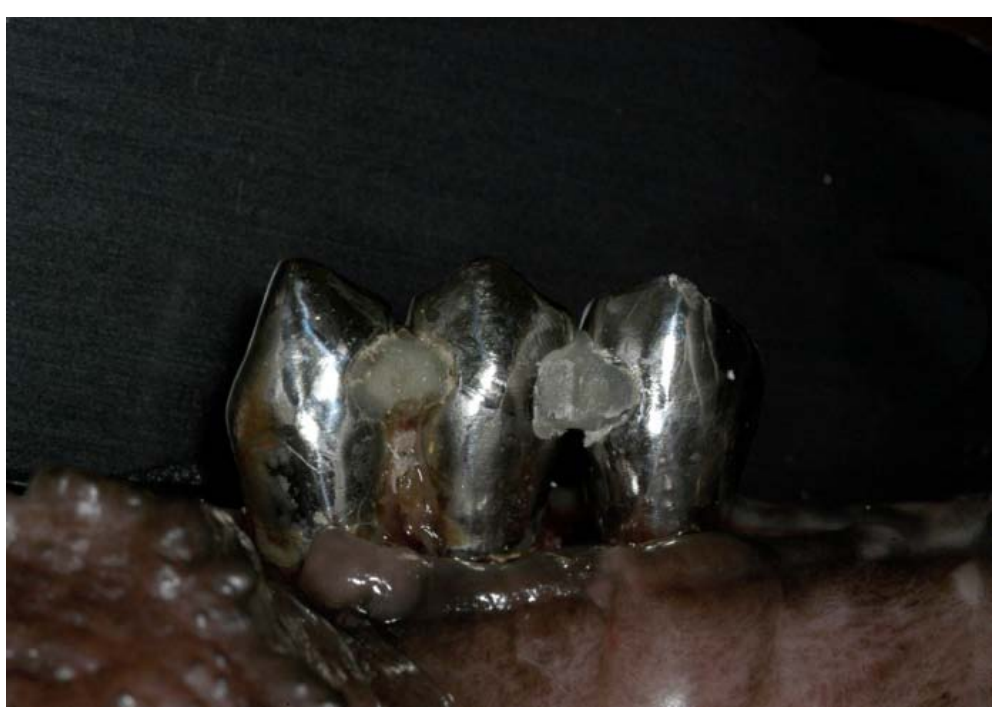

figura 4 


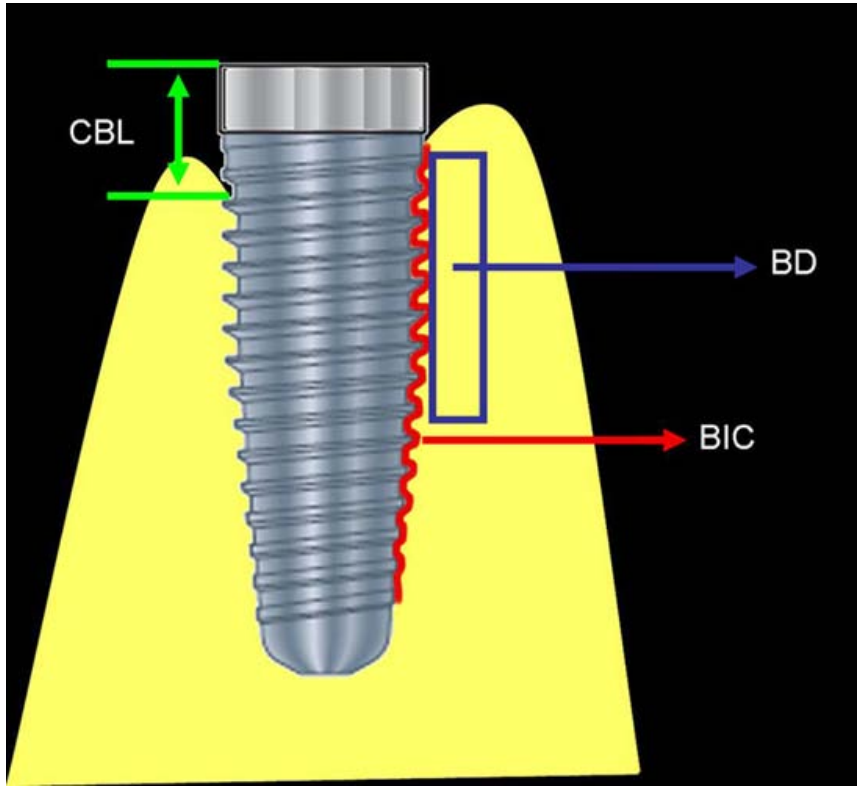

figura 5

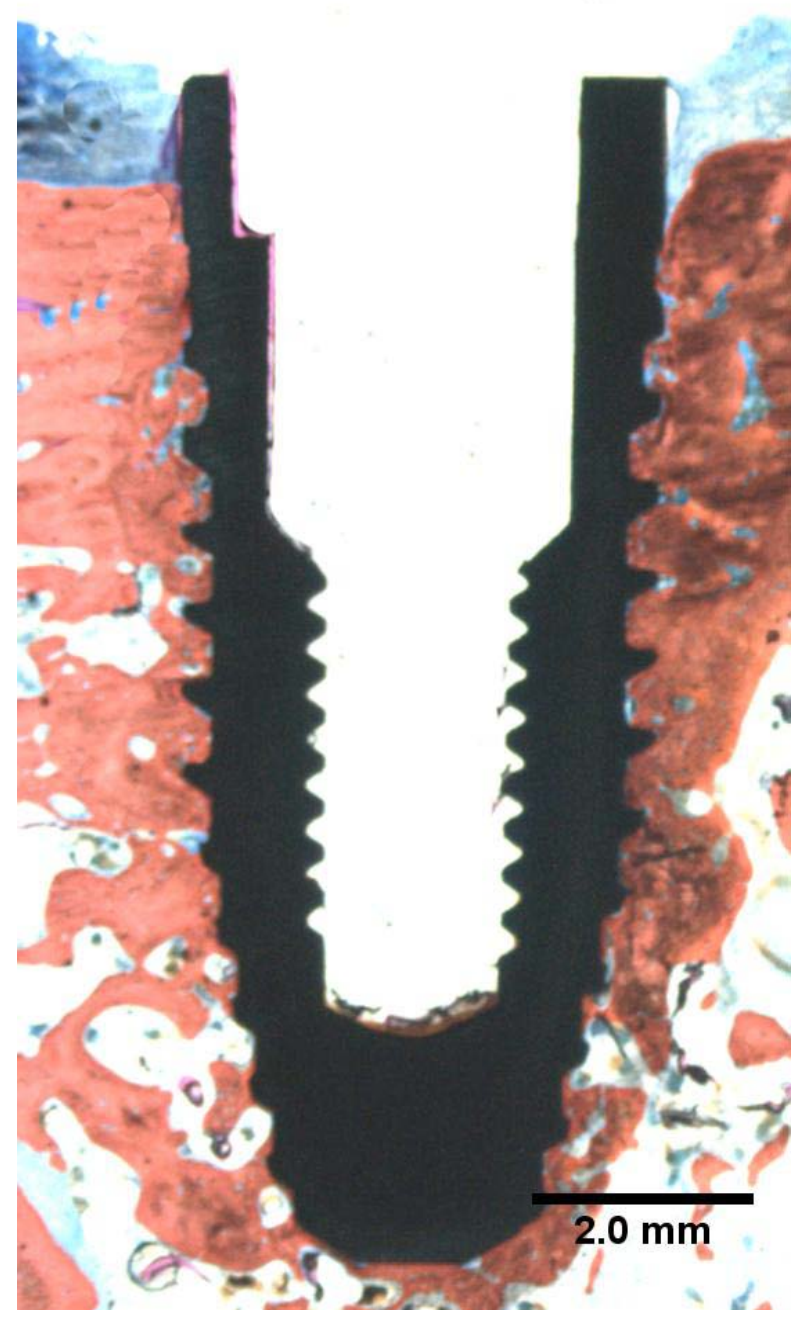

figura 6 


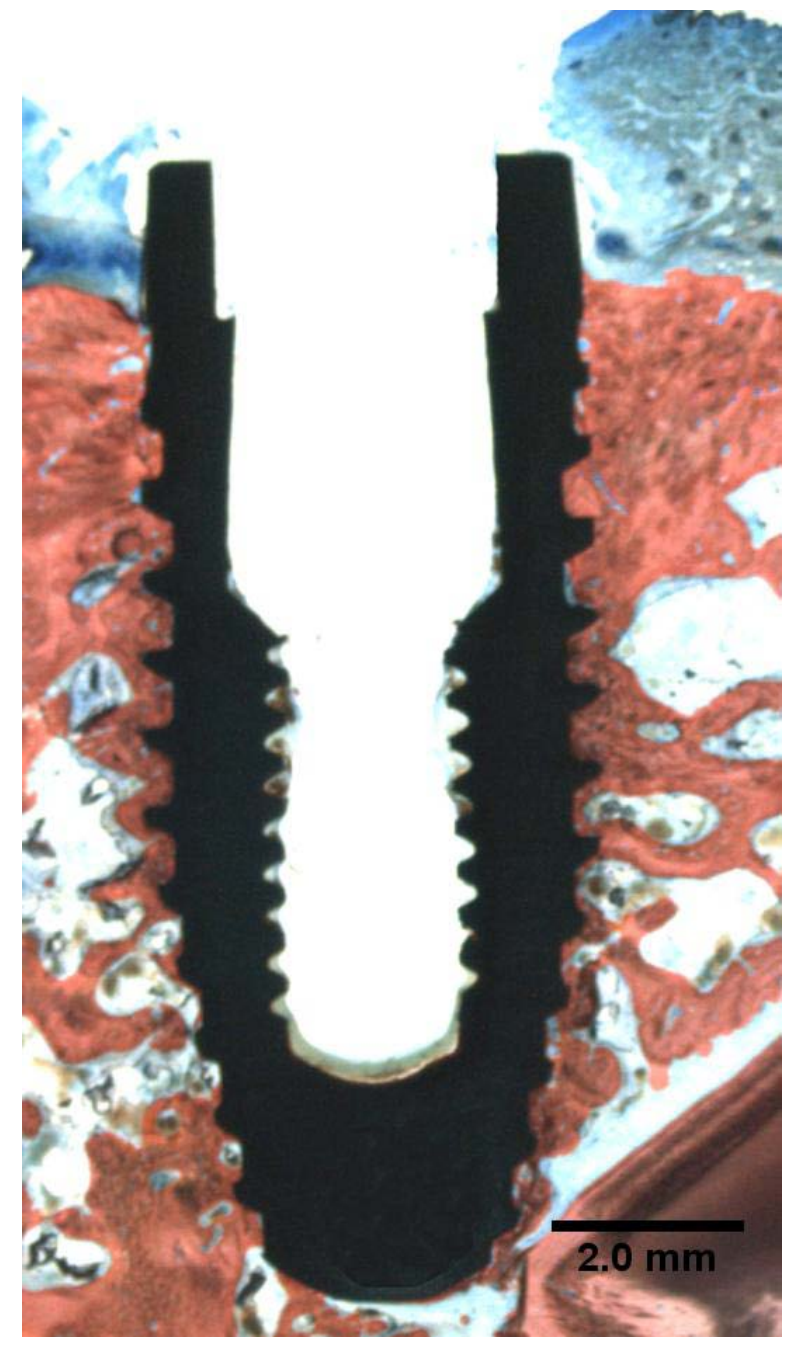

figura 7 


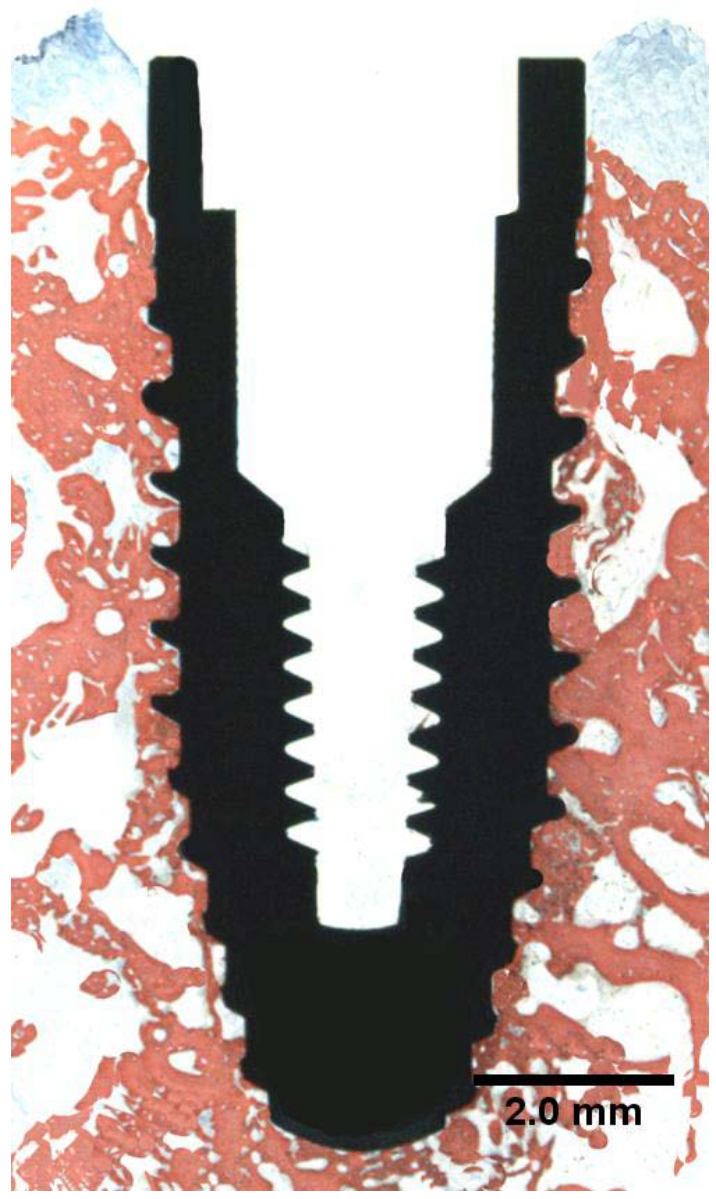

figura 8 


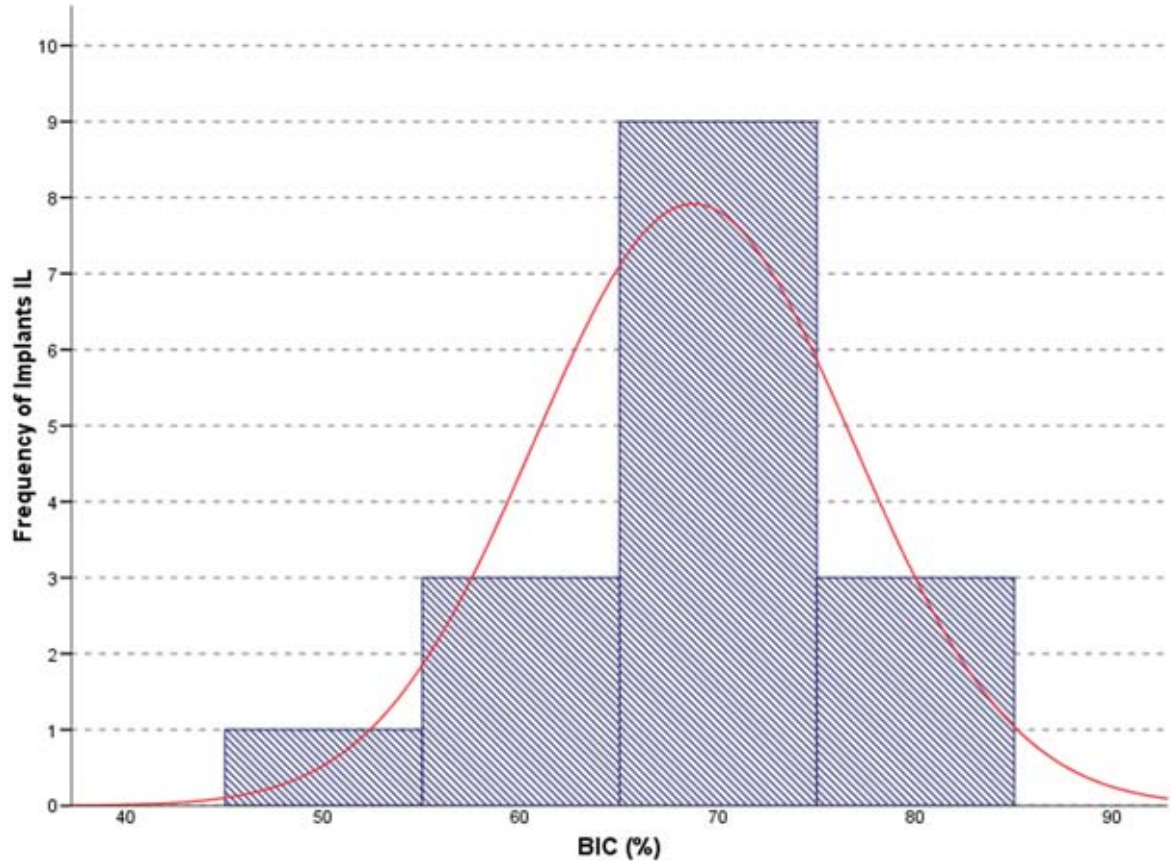

figura 9

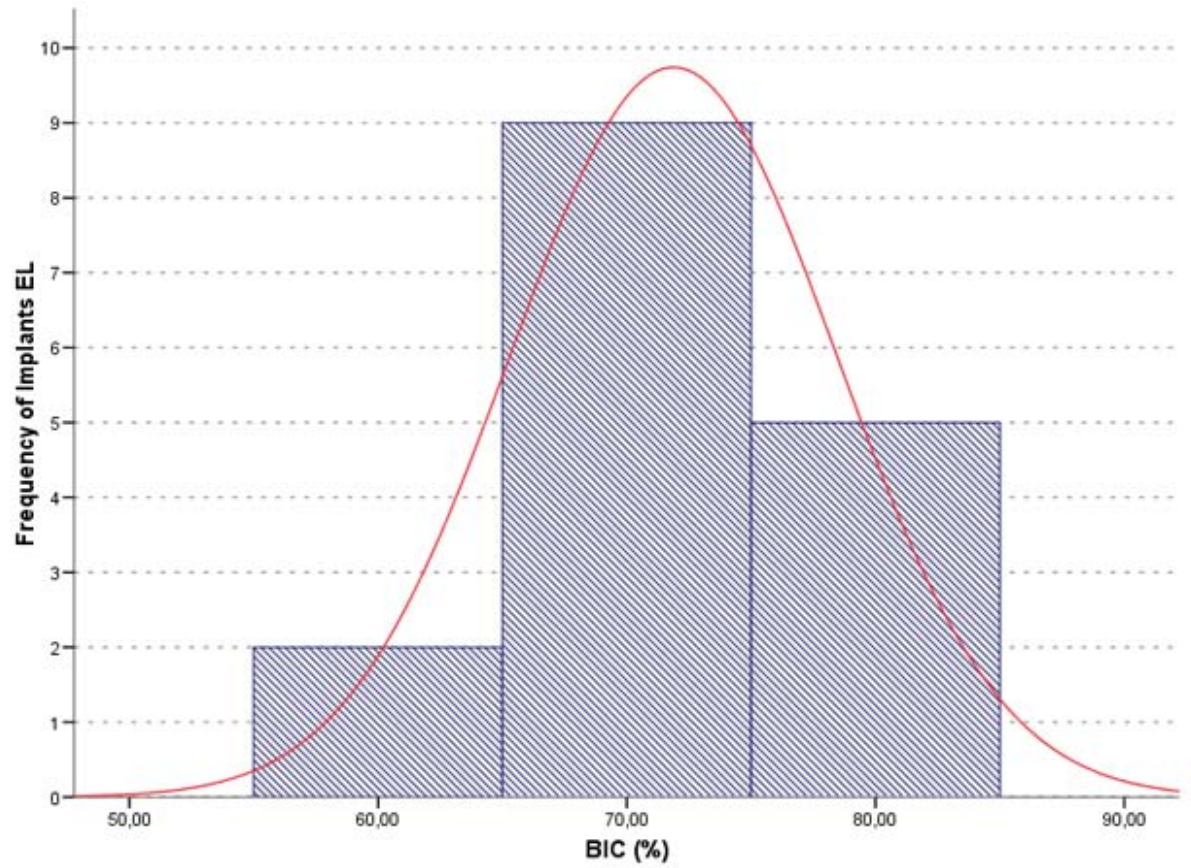

figura 10 


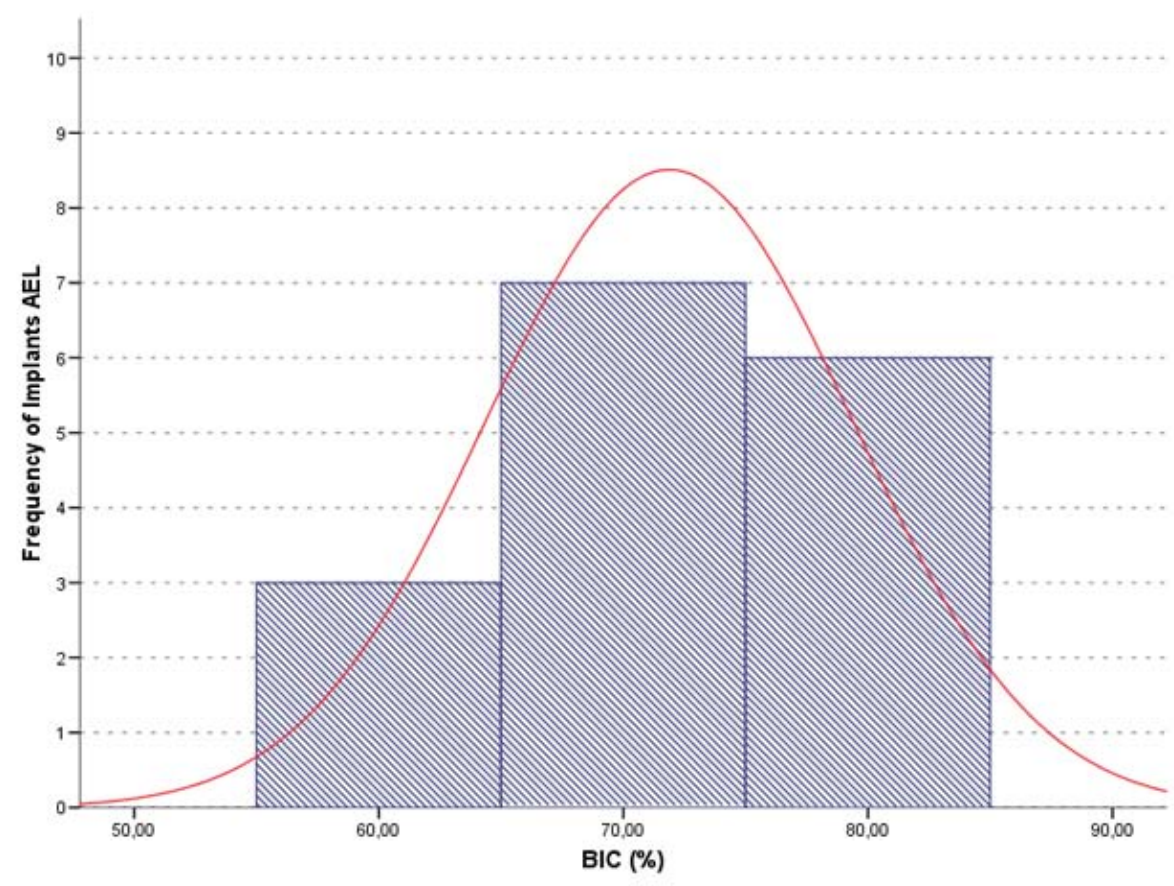

figura 11

\section{Crestal Bone Loss}

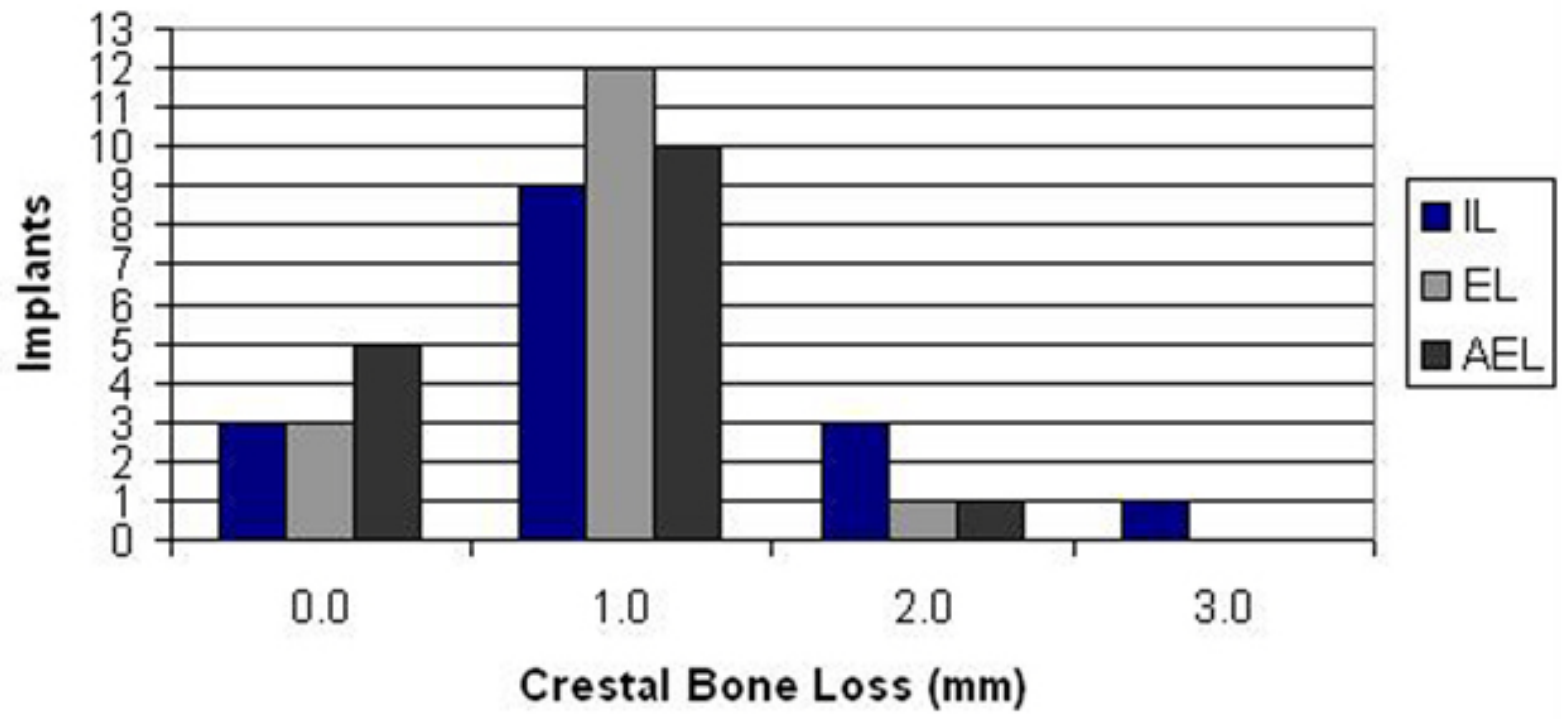

figura 12 


\section{LEGENDAS DAS FIGURAS:}

Figura 1: Implantes em posição

Figura 2: Coroa metálica colocada sobre o implante selecionado para carga imediata, os dois outros implantes receberam cicatrizadores.

Figura 3: Após sete dias da colocação dos implantes, o implante selecionado para carga precoce recebe a prótese. Observar o nicho para retenção nas superfícies proximais.

Figura 4: Após 14 dias da colocação dos implantes, o implante selecionado para carga precoce tardia recebeu a prótese. Observe as coroas unidas com resina.

Figura 5: Representação esquemática da análise histomorfométrica.

Figura 6: Corte histológico representativo do grupo de carga imediata. (azul de Stevenel e vermelho de alizarina S, aumento original 1,5X).

Figura 7: Corte histológico representativo do grupo de carga precoce. (azul de Stevenel e vermelho de alizarina $S$, aumento original $\mathrm{X} 1,5$ ).

Figura 8: Corte histológico representativo do grupo de carga precoce tardia. (azul de Stevenel e vermelho de alizarina S, aumento original $\mathrm{X} 1,5)$.

Figura 9: O histograma mostra uma distribuição normal com a maioria dos valores para o grupo de carga imediata ao redor da média.

Figura 10: O histograma mostra uma distribuição normal com a maioria dos valores para o grupo de carga precoce ao redor da média. 
Figura 11: O histograma mostra uma distribuição normal com a maioria dos valores para o grupo de carga precoce avançada ao redor da média.

Figura 12: Distribuição de freqüência do número de implantes em relação à perda de crista óssea. 
Considerando as limitações deste trabalho, feito em cães, e a metodologia descrita, conclui-se que:

- A estabilidade do implante sofre diminuição inicial para então melhorar. O período em que a estabilidade deixa de diminuir e começa a aumentar não pôde ser definido por este trabalho;

- O dia de colocação do implante não compreende o período em que o implante está mais fragilizado, quando analisada a estabilidade do implante;

- Em médio prazo não existem diferenças estatisticamente significantes quanto à estabilidade dos implantes, se ativados imediatamente, uma ou duas semanas após a colocação;

- O tempo de carga parece não afetar significativamente a resposta óssea ao redor dos implantes. 
REFERÊNCIAS BIBLIOGRÁFCAS 
AB Id. Clinical Manual Osstell. Savedalen, Sweden. (http://www.osstell.com/filearchive/2/2540/ID_25006-0_Clin_Manual.pdf)

Adell R, Lekholm U, Rockler B, Brånemark P-I. A 15-year study of osseointegrated implants in the treatment of edentulous jaw. Int J Oral Surg. 1981;10:387-416.

Akin-Nergiz N, Nergiz I, Schulz A, Arpak N, Niedermeier W. Reactions of peri-implant tissues to continuous loading of osseointegrated implants. Am J Orthod Dentofacial Orthop 1998;114:292-298.

Albrektsson T, Brånemark PI, Hansson HA, Lindström J. Osseointegrated titanium implants. Requirements for ensuring a long-lasting, direct bone-toimplant anchorage in man. Acta Orthop Scand. 1981;52:155-170.

Babbush CA, Kent JN, et al. Titanium plasma-sprayed (TPS) screw implants for the reconstruction of the edentulous mandible. J Oral Maxillofac Surg, v.44, n.4, Apr, p.274-282. 1986.

Balshi SF, Wolfinger GJ, Balshi TJ. A prospective study of immediate functional loading, following the Teeth in a Day protocol: a case series of 55 consecutive edentulous maxillas. Clin Implant Dent Relat Res. 2005;7:24-31. 
Barewal RM, Oates TW, Meredith N, Cochran DL. Resonance frequency measurement of implant stability in vivo on implants with a sandblasted and acid-etched surface. Int J Oral Maxillofac Implants. 2003;18:641-51.

Becker W, Becker BE, Israelson H, Lucchini JP, Handelsman M, Ammons W, Rosenberg E, Rose L, Tucker LM, Lekholm U. One-step surgical placement of Brånemark implants: a prospective multicenter clinical study. Int J Oral Maxillofac Implants 1997:12: 454-462.

Bedrossian E, Rangert B, Stumpel L, Indresano T. Immediate function with the zygomatic implant: a graftless solution for the patient with mild to advanced atrophy of the maxilla. Int J Oral Maxillofac Implants. 2006;21:93742.

Bergkvist G, Sahlholm S, Karlsson U, Nilner K, Lindh C. Immediately loaded implants supporting fixed prostheses in the edentulous maxilla: a preliminary clinical and radiologic report. Int J Oral Maxillofac Implants. 2005;20(3):399405.

Berglundh T, Abrahamsson I, Lindhe J. Bone reactions to longstanding functional load at implants: an experimental study in dogs. J Clin Periodontol. $2005 ; 32: 925-932$.

Bernard JP, Szmukler-Moncler S, Pessotto S, Vasquez L, Belser UC. The anchorage of Branemark and ITI implants of different lengths. I. An in vivo study in the canine mandible. Clin Oral Implants Res. 2003;14:593-600. 
Bischof M, Nedir R, Szmucler-Moncler S, Bernard JP, Samson J. Implant stability measurement of delayed and immediately loaded implants during healing. A clinical resonance-frequency analysis study with sandblasted-andetched ITI implants. Clin Oral Implants Res. 2004; 15:529-539.

Brånemark PI, Adell R, Breine U, Hansson BO, Lindstrom J, Ohlsson A.Intraosseous anchorage of dental prostheses. I. Experimental studies. Scand J Plast Reconstr Surg. 1969;3:81-100.

Branemark PI, Hansson BO, Adell R, Breine U, Lindstrom J, Hallen O, et al. Osseointegrated implants in the treatment of the edentulous jaw. Experience from a 10-year period. Scand J Plast Reconstr Surg Suppl. 1977;16:1-132.

Brunski JB. Avoid pitfalls of overloading and micromotion of intraosseous implants. Dent Implantol Update. 1993;4:77-81.

Brunski JB. Biomechanical factors affecting the bone-dental implant interface.Clin Mater. 1992;10:153-201. Review.

Buchs AU, Levine L, Moy P. Preliminary report of immediately loaded Altiva Natural Tooth Replacement dental implants. Clin Implant Dent Relat Res. 2001;3:97-106

Buser D, Weber HP, et al. Tissue integration of one-stage ITI implants: 3year results of a longitudinal study with Hollow-Cylinder and Hollow-Screw implants. Int J Oral Maxillofac Implants, v.6, n.4, Winter, p.405-412. 1991. 
Cannizzaro G, Leone M, Esposito M. Immediate functional loading of implants placed with flapless surgery in the edentulous maxilla: 1-year followup of a single cohort study. Int J Oral Maxillofac Implants. 2007;22:87-95.

Chiapasco M, Abati S, et al. Implant-retained mandibular overdentures with Branemark System MKII implants: a prospective comparative study between delayed and immediate loading. Int J Oral Maxillofac Implants, v.16, n.4, JulAug, p.537-546. 2001.

Chiapasco M, Gatti C, Rossi E, Haefliger W, Markwalder TH. Implantretained mandibular overdentures with immediate loading. A retrospective multicenter study on 226 consecutive cases. Clin Oral Implants Res. $1997 ; 8: 48-57$.

Chow J, Hui E, Lee PK, Li W. Zygomatic implants--protocol for immediate occlusal loading: a preliminary report. J Oral Maxillofac Surg. 2006;64:80411.

Cochran DL, Schenk R, Lussi A, Higginbottom FL, Buser D. Bone response to unloaded titanium implant with a sandblasted and acid-etched surface: A histometric study in the canine mandible. J Biomed Mater Res. 1998;40:1-11.

De Smet E, Duyck J, Vander Sloten J, Jacobs R, Naert I. Timing of loading-immediate, early, or delayed--in the outcome of implants in the edentulous mandible: a prospective clinical trial. Int $\mathrm{J}$ Oral Maxillofac Implants. $2007 ; 22: 580-594$. 
Degidi M, Piatelli A. Immediate functional and non-functional loading of dental implants: a 2- to 60 -month follow up study of 646 titanium implants. J Periodontol. 2003;74:225-41.

Donath K, Breuner G. A method for the study of undercalcified bones and teeth with attached soft tissue. The Sage-Schliff (sawing and grinding) technique. J Oral Pathol 1982;11:318-326.

Donath $\mathrm{K}$. Tissue reactions around loaded and unloaded titanium implants $\mathrm{J}$. Hard Tissue Biol. 1993; 2: 37-47.

Duyck J, Ronald H, Van Oosterwyck H, Naert I, Vander Solten J, Ellingsen JE. The influence of static and excessive dynamic loading on the marginal bone behaviour around implants: An animal experimental study. Clin Oral Implants Res 2001;12:207-218.

Engquist B, Astrand P, Anze'n B, Dahlgren S, Engquist E, Feldmann H, Karlsson U, Nord PG, Sahlholm S, Svärdström P. Simplified methods of implant treatment in the edentulous lower jaw. A controlled prospective study. Part II: Early loading. Clin Implant Dent Relat Res 2004:6:90-100.

Ersanli S, Karabuda C, Beck F, Leblebicioglu B. Resonance frequency analysis of one-stage dental implant stability during thr osseointegration period. J Periodontol. 2005;76:1006-1071.

Esposito M, Grusovin MG, Willings M, Coulthard P, Worthington HV. The effectiveness of immediate, early, and conventional loading of dental 
implants: a Cochrane systematic review of randomized controlled clinical trials. Int J Oral Maxillofac Implants. 2007;22:893-904. Review.

Friberg B, Jemt T, Lekholm U. Early failures in 4,641 consecutively placed Branemark dental implants: a study from stage 1 surgery to the connection of completed prostheses. Int J Oral Maxillofac Implants. 1991;6:142-6.

Friberg B, Sennerby L, Meredith N, Lekholm U. A comparison between cutting torque and resonance frequency measurements of maxillary implants. A 20-month clinical study. Int J Oral Maxillofac Surg. 1999;28:297-303.

Fritton SP, McLeod KJ, Rubin CT. Quantifying the strain history of bone: spatial uniformity and self-similarity of low-magnitude strains. J Biomech. 2000;33:317-325.

Frost HM. The role of changes in mechanical usage set points in the pathogenesis of osteoporosis. J Bone Miner Res. 1992;7:253-261. Review.

Ganeles J, Rosenberg MM, Holt RL, Reichman LH. Immediate loading of implants with fixed restorations in the completely edentulous mandible: report of 27 patients from a private practice. Int $\mathrm{J}$ Oral Maxillofac Implants. 2001;16:418-426.

Ganeles J, Wismeijer D. Early and Immediately Restored and Loaded Dental Implants for Single-Tooth and Partial-Arch Applications 
Gatti C, Haefliger W, et al. Implant-retained mandibular overdentures with immediate loading: a prospective study of ITI implants. Int J Oral Maxillofac Implants, v.15, n.3, May-Jun, p.383-388. 2000.

Ghanavati F, Shayegh SS, Rahimi H, Sharifi D, Ghanavati F, Khalesseh N, Eslami B. The effects of loading time on osseointegration and new bone formation around dental implants: a histologic and histomorphometric study in dogs. J Periodontol. 2006;77:1701-1707.

Glauser R, Sennerby L, Meredith N, Ree A, Lundgren A, Gottlow J, et al. Resonance frequency analysis of implants subjected to immediate or early functional occlusal loading. Successful vs. failing implants. Clin Oral Implants Res. 2004;15:428-34.

Gotfredsen K, Hjorting-Hansen E. Histologic and histomorphometric evaluation of submerged and non submerged titanium implants. In: Laney WR, Tolman DE. Tissue Integration in Oral, Orthopedic, and Maxillofacial Reconstruction. 1990, p.31-40.

Grunder U. Immediate functional loading of immediate implants in edentulous arches: two-year results. Int J Periodontics Restorative Dent. 2001;21:54551.

Hämmerle $\mathrm{CH}$, Brägger $U$, Bürgin $\mathrm{W}$, Lang NP. The effect of subcrestal placement of the polished surface of ITI implants on marginal soft and hard tissues. Clin Oral Implants Res. 1996;7:111-9. 
Hansson S, Werke M. The implant thread as a retention element in cortical bone: the effect of thread size and thread profile: a finite element study. $\mathrm{J}$ Biomech. 2003;36:1247-1258.

Hansson S. A conical implant-abutment interface at the level of the marginal bone improves the distribution of stresses in the supporting bone. An axisymmetric finite element analysis. Clin Oral Implants Res. 2003;14:286293.

Hansson S. The implant neck: smooth or provided with retention elements. A biomechanical approach. Clin Oral Implants Res. 1999;10:394-405.

Henry P, Rosenberg I. Single-stage surgery for rehabilitation of the edentulous mandible: preliminary results. Pract Periodontics Aesthet Dent, v.6, n.9, Nov-Dec, p.15-22; quiz 24. 1994.

Heo SJ, Sennerby L, Odersjo M, Granstrom G, Tjellstrom A, Meredith N. Stability measurements of craniofacial implants by means of resonance frequency analysis. A clinical pilot study. J Laryngol Otol. 1998;112:537-42.

Hönig JF, Merten HA. Subperiosteal versus epiperiosteal forehead augmentation with hydroxylapatite for aesthetic facial contouring: experimental animal investigation and clinical application. Aesthetic Plast Surg. 1993;17:93-98.

Horiuchi K, Uchida H, Yamamoto K, Sugimura M. Immediate loading of Branemark system implants following placement in edentulous patients: a clinical report. Int J Oral Maxillofac Implants. 2000;15:824-30. 
Hoshaw SJ, Brunski JB, Cochran D. Mechanical loading of Brånemark implants affects interfacial bone modeling and remodeling. Int $\mathrm{J}$ Oral Maxillofac Implants. 1994;9:343-360.

Hurzeler M, Quinones CR, Kohal R, Rohde M, Strub JR, Teuscher U, Caffesse RG. Changes in peri-implant tissues subjected to orthodontic forces and breakdown in monkeys. J Periodontol 1998;69:396-404.

Isidor F. Histological evaluation of peri-implant bone at implants subjected to occlusal overload or plaque accumulation. Clin Oral Implants Res 1997;8:19.

Ivanoff CJ, Sennerby L, Lekholm U. Influence of initial implant mobility on the integration of titanium implants. An experimental study in rabbits. Clin Oral Implants Res. 1996;7:120-127.

Jaffin RA, Kumar A, et al. Immediate loading of implants in partially and fully edentulous jaws: a series of 27 case reports. J Periodontol, v.71, n.5, May, p.833-838. 2000.

Jayme SJ, Muglia VA, Oliveira RR, Novaes AB Jr, Ribeiro RF. The effects of different loading time on the bone response around dental implants. a histomorphometric study in dogs. Int J Oral Maxillofac Implants. (Accepted for publication). 2009.

Johansson C, Albrektsson T. Integration of screw implants in the rabbit: a 1year follow-up of removal torque of titanium implants. Int $\mathrm{J}$ Oral Maxillofac Implants. 1987;2:69-75. 
Ledermann PD, Schenk RK, Buser D. Long-lasting osseointegration of immediately loaded, bar-connected TPS screws after 12 years of function: a histologic case report of a 95-year-old patient. Int J Periodontics Restorative Dent. 1998;18:552-563.

Malo P, Friberg B, Polizzi G, Gualini F, Vighagen T, Rangert B. Immediate and early function of Branemark System implants placed in the esthetic zone: a 1-year prospective clinical multicenter study. Clin Implant Dent Relat Res. 2003;5:37-46.

Malo P, Rangert B, Dvarsater L. Immediate function of Branemark implants in the esthetic zone: a retrospective clinical study with 6 months to 4 years of follow-up. Clin Implant Dent Relat Res. 2000;2:138-46.

Malo P, Rangert B, et al. All-on-4 immediate-function concept with Branemark System implants for completely edentulous maxillae: a 1-year retrospective clinical study. Clin Implant Dent Relat Res, v.7 Suppl 1, p.S8894. 2005.

Matsumoto H, Ochi M, Abiko Y, Hirose Y, Kaku T, Sakaguchi K. Pulsed electromagnetic fields promote bone formation around dental implants inserted into the femur of rabbits. Clin Oral Implants Res. 2000; 11: 354-360.

Meredith N, Alleyne D, Cawley P. Quantitative determination of the stability of the implant-tissue interface using resonance frequency analysis. Clin Oral Implants Res. 1996;7:261-7. 
Meredith N, Book K, Friberg B, Jemt T, Sennerby L. Resonance frequency measurements of implant stability in vivo. A cross-sectional and longitudinal study of resonance frequency measurements on implants in the edentulous and partially dentate maxilla. Clin Oral Implants Res. 1997;8:226-33.

Meredith N, Shagaldi F, Alleyne D, Sennerby L, Cawley P. The application of resonance frequency measurements to study the stability of titanium implants during healing in the rabbit tibia. Clin Oral Implants Res. 1997;8:234-43.

Misch CE, Wang HL, et al. Rationale for the application of immediate load in implant dentistry: Part I. Implant Dent, v.13, n.3, Sep, p.207-217. 2004.

Misch CE. Density of bone: effect on treatment planning, surgical approach, and healing. In: Misch CE. Contemporary Implant Dentistry. St. Louis: Mosby, 1993:469-485.

Moon SY, Kim SG, Lim SC, Ong JL. Histologic and histomorphometric evaluation of early and immediately loaded implants in the dog mandible. $\mathrm{J}$ Biomed Mater Res A. 2008;15:1122-1127.

Nkenke E, Fenner M, Vairaktaris EG, Neukam FW, Radespiel-Tröger M. Immediate versus delayed loading of dental implants in the maxillae of minipigs. Part II: histomorphometric analysis. Int J Oral Maxillofac Implants. 2005;20:540-546.

Nkenke E, Lehner B, Weinzierl K, Thams U, Neugebauer J, Steveling H, Radespiel-Tröger M, Neukam FW. Bone contact, growth, and density around 
immediately loaded implants in the mandible of mini pigs. Clin Oral Implants Res. 2003;14:312-321.

Nordin T, Nilsson R, Frykholm A, Hallman M. A 3-arm study of early loading of rough-surfaced implants in the completely edentulous maxilla and in the edentulous posterior maxilla and mandible: results after 1 year of loading. Int J Oral Maxillofac Implants. 2004;19:880-6.

Norman TL, Wang Z. Microdamage of human cortical bone: incidence and morphology in long bones. Bone. 1997;20:375-379.

Novaes Junior AB, Vidigal Junior GM, Novaes AB, Grisi MF, Polloni S, Rosa A. Immediate implants placed into infected sites: a histomorphometric study in dogs. Int J Oral Maxillofac Implants. 1998;13:422-427.

Oh T-J, Yoon J, Misch CE, Wang H-L. The causes of early implant bone loss. Myth or science? J Periodontol. 2002;73:322-333.

Olsson M, Urde G, Andersen JB, Sennerby L. Early loading of maxillary fixed cross-arch dental prostheses supported by six or eight oxidized titanium implants: results after 1 year of loading, case series. Clin Implant Dent Relat Res. 2003;5:81-7.

Ostman PO, Hellman M, Sennerby L, Wennerberg A. Temporary implantsupported prosthesis for immediate loading according to a chair-side concept: technical note and results from 37 consecutive cases. Clin Implant Dent Relat Res. 2008;10:71-77. 
Ostman PO, Hellman M, Sennerby L. Direct implant loading in the edentulous maxilla using a bone density-adapted surgical protocol and primary implant stability criteria for inclusion. Clin Implant Dent Relat Res. 2005;7:S60-9.

Pattijn V, Jaecques SV, De Smet E, Muraru L, Van Lierde C, Van der Perre G, et al. Resonance frequency analysis of implants in the guinea pig model: influence of boundary conditions and orientation of the transducer. Med Eng Phys. 2007;29:182-90.

Pattijn V, Van Lierde C, Van der Perre G, Naert I, Vander Sloten J. The resonance frequencies and mode shapes of dental implants: Rigid body behaviour versus bending behaviour. A numerical approach. J Biomech. 2006;39:939-47.

Piattelli A, Corigliano M, Scarano A, Costigliola G, Paolantonio M. Immediate loading of titanium plasma-sprayed implants: an histologic analysis in monkeys. J Periodontol. 1998;69:321-327.

Piattelli A, Corigliano M, Scarano A, Quaranta M. Bone reactions to early occlusal loading of two-stage titanium plasma-sprayed implants: a pilot study in monkeys. Int J Periodontics Restorative Dent. 1997;17:162-169.

Piattelli A, Paolantonio M, Corigliano M, Scarano A. Immediate loading of titanium plasma-sprayed screw-shaped implants in man: a clinical and histological report of two cases. J Periodontol. 1997;68:591-597. 
Pilliar RM, Lee JM, Maniatopoulos C. Observations on the effect of movement on bone ingrowth into porous-surfaced implants. Clin Orthop Relat Res. 1986;208:108-113.

Portney L, Watkins M. Foundations of clinical research: applications to practice. London: Prentice Hall. 2000

Randow K, Ericsson I, et al. Immediate functional loading of Branemark dental implants. An 18-month clinical follow-up study. Clin Oral Implants Res, v.10, n.1, Feb, p.8-15. 1999.

Rasmusson L, Kahnberg KE, Tan A. Effects of implant design and surface on bone regeneration and implant stability: an experimental study in the dog mandible. Clin Implant Dent Relat Res. 2001;3:2-8.

Rasmusson L, Meredith N, Cho IH, Sennerby L. The influence of simultaneous versus delayed placement on the stability of titanium implants in onlay bone grafts. A histologic and biomechanic study in the rabbit. Int $\mathrm{J}$ Oral Maxillofac Surg. 1999;28:224-31.

Roberts W, Turkey P, Brezniak N, Fielder P. Implants: bone physiology and metabolism. CDA Journal. 1987;31:3-9.

Roberts WE, Smith RK, Zilberman Y, Mozsary PG, Smith RS. Osseous adaptation to continuous loading of rigid endosseous implants. Am J Orthod. 1984;86:95-111. 
Rocci A, Martignoni M, Burgos PM, Gottlow J, Sennerby L. Histology of retrieved immediately and early loaded oxidized implants: light microscopic observations after 5 to 9 months of loading in the posterior mandible. Clin Implant Dent Relat Res. 2003;5 Suppl 1:88-98.

Romanos G, Toh CG, Siar CH, Swaminathan D, Ong AH, Donath K, Yaacob $\mathrm{H}$, Nentwig GH. Peri-implant bone reactions to immediately loaded implants. An experimental study in monkeys. J Periodontol. 2001;72:506-511.

Romanos GE, Nentwig GH. Immediate loading using cross-arch fixed restorations in heavy smokers: nine consecutive case reports for edentulous arches. Int J Oral Maxillofac Implants. 2008;23:513-519.

Romanos GE. Surgical and prosthetic concepts for predictable immediate loading of oral implants. J Calif Dent Assoc. 2004;32:991-1001.

Sagara M, Akagawa Y, Nikai H, Tsuru H. The effects of early occlusal loading on one stage titanium alloy implants in beagle dogs: A pilot study. $\mathrm{J}$ Prosthet Dent 1993;69:281-288.

Salama H, Rose LF, Salama M, Betts NJ. Immediate loading of bilaterally splinted titanium root-form implants in fixed prosthodontics--a technique reexamined: two case reports. Int J Periodontics Restorative Dent. $1995 ; 15: 344-61$.

Schnitman PA, Wohrle PS, et al. Immediate fixed interim prostheses supported by two-stage threaded implants: methodology and results. J Oral Implantol, v.16, n.2, p.96-105. 1990. 
Schnitman PA, Wohrle PS, Rubenstein JE, DaSilva JD, Wang NH. Ten-year results for Branemark implants immediately loaded with fixed prostheses at implant placement. Int J Oral Maxillofac Implants. 1997;12:495-503.

Schroeder A, Van Der Zypen E, Stich H, Sutter F. The reaction of bone, connective tissue and epithelium to endosteal implants with sprayed titanium surfaces. J Maxillofac Surg. 1981;9:15-25.

Scortecci G. Immediate function of cortically anchored disk-design implants without bone augmentation in moderately to severely resorbed completely edentulous maxillae. J Oral Implantol. 1999;25:70-9.

Siar $\mathrm{CH}$, Toh CG, Romanos G, Swaminathan D, Ong AH, Yaacob $H$, Nentwig GH. Peri-implant soft tissue integration of immediately loaded implants in the posterior macaque mandible: a histomorphometric study. $\mathrm{J}$ Periodontol. 2003;74:571-578.

Strid K. Radiographic results. In: (Ed.). Tissue-integrated Prostheses: Osseointegration in clinical dentistry. Chicago: Quintessence, 1985. Radiographic results, p.187-191

Strid K. Radiographic results. Tissue-integrated Prostheses: Osseointegration in clinical dentistry. Chicago: Quintessence; 1985. p. 18791.

Suzuki K, Aoki K, Ohya K. Effects of surface roughness of titanium implants on bone remodeling activity of femur in rabbits. Bone. 1997;21:507-514. 
Szmukler-Moncler S, Piattelli A, Favero GA, Dubruille JH. Considerations preliminary to the application of early and immediate loading protocols in dental implantology. Clin Oral Implants Res. 2000;11:12-25. Review.

Tanck E, Homminga J, van Lenthe GH, Huiskes R. Increase in bone volume fraction precedes architectural adaptation in growing bone. Bone. 2001;28:650-654.

Tarnow DP, Emtiaz S, Classi A. Immediate loading of threaded implants at stage 1 surgery in edentulous arches: ten consecutive case reports with 1- to 5-year data. Int J Oral Maxillofac Implants 1997:12:319-324.

Tehemar SH. Factors affecting heat generation during implant site preparation: a review of biologic observations and future considerations. Int $\mathrm{J}$ Oral Maxillofac Implants. 1999;14:127-136. Review.

Testori T, Szmukler-Moncler S, Francetti L, Del Fabbro M, Scarano A, Piattelli A, Weinstein RL. Immediate loading of Osseotite implants: a case report and histologic analysis after 4 months of occlusal loading. Int $\mathrm{J}$ Periodontics Restorative Dent. 2001;21:451-459.

Testori T, Wiseman L, Woolfe S, Porter SS. A prospective multicenter clinical study of the Osseotite implant: four-year interim report. Int J Oral Maxillofac Implants. 2001;16:193-200.

Turner $\mathrm{CH}$. Three rules for bone adaptation to mechanical stimuli. Bone. 1998;23:399-407. Review. 
Van Den Bogaerde L., Pedretti G, et al. Early function of splinted implants in maxillas and posterior mandibles using branemark system machine surface implants: an 18 month prospective clinical multicenter study. Clin Implant Dent Relat Res, v.5, p.21-28. 2002.

van Oosterwyck H, Duyck J, Vander Sloten J, Van der Perre G, De Cooman M, Lievens S, Puers R, Naert I. The influence of bone mechanical properties and implant fixation upon bone loading around oral implants. Clin Oral Implants Res. 1998;9:407-418.

van Steenberghe D, Glauser R, Blomback U, Andersson M, Schutyser F, Pettersson A, et al. A computed tomographic scan-derived customized surgical template and fixed prosthesis for flapless surgery and immediate loading of implants in fully edentulous maxillae: a prospective multicenter study. Clin Implant Dent Relat Res. 2005;7:S111-20.

Veltri M, Balleri P, Ferrari M. Influence of transducer orientation on Osstell stability measurements of osseointegrated implants. Clin Implant Dent Relat Res. 2007;9:60-4.

Wohrle PS. Single-tooth replacement in the aesthetic zone with immediate provisionalization: fourteen consecutive case reports. Pract Periodontics Aesthet Dent, v.10, n.9, Nov-Dec, p.1107-1114; quiz 1116. 1998.

Wolfinger GJ, Balshi TJ, et al. Immediate functional loading of Branemark system implants in edentulous mandibles: clinical report of the results of 
developmental and simplified protocols. Int J Oral Maxillofac Implants, v.18, n.2, Mar-Apr, p.250-257. 2003.

Zubery $\mathrm{Y}$, Bichacho $\mathrm{N}$, Moses $\mathrm{O}$, Tal $\mathrm{H}$. Immediate loading of modular transitional implants: a histologic and histomorphometric study in dogs. Int J Periodontics Restorative Dent. 1999;19:343-353. 
Anexos

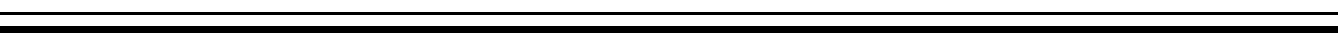




\section{Anexo 1}

Aprovação no Comitê de Ética em Pesquisa 


\section{E R T I F I C A D O}

Certificamos que o trabalho (Protocolo $n^{\circ}$ 05.1.1318.53.1), intitulado:

"Estudo em Animais sobre Carga Imediata em Mndíbulas Parcialmente Edêntulas Utilizando Implantes Replace Select Tapered com Superficie TiUnit ${ }^{\mathrm{TM}}$ ", de autoria de Sérgio Jorge Jayme, por estar de acordo com os Princípios Éticos na Experimentação Animal adotado pela Comissão de Ética no Uso de Animais (CEUA) do Campus de Ribeirão Preto - USP, foi aprovado em reunião da CEUA de 04.05 .06

Ribeirão Preto, 5 de maio de 2006

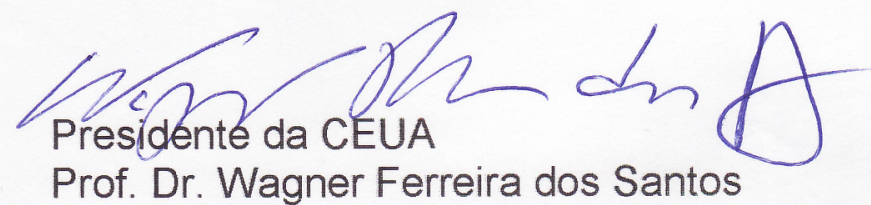

Prof. Dr. Wagner Ferreira dos Santos

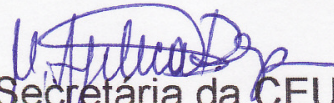

Secretaria da CEUA

Marila Angélica Depiro 


\section{Anexo 2 - ARTIGO 01(Versão em inglês)}

Evaluation of Functional Implant Stability with Immediate, Early or

Advanced Early Loading: A Resonance Frequency Analysis Study in Dogs. 


\begin{abstract}
Purpose: The purpose of this study was to evaluate the functional implant stability after immediate or early loading in dogs. Material and Methods: Three Replace Select implants were placed on each side of the mandible in 8 dogs totaling 48 implants in the study. One pair of implants was selected for immediate loading protocol (IL). After seven days the second pair of implants received the prostheses for the early loading protocol (EL). Fourteen days after the implant placement the third pair of implants received the prostheses for the advanced early loading (AEL). The resonance frequency analysis method was used to measure the implant stability quotient (ISQ) immediately, 7 days, 14 days and 12 weeks after implantation. Results: The average value of initial stability under the different loading times were $77.9 \pm$ 4.6 (IL), $79.7 \pm 3.6$ (EL) and $79.6 \pm 3.0$ (AEL). The data were subjected to ANOVA, and no significant difference was detected $(p=0.30)$. The values (mean \pm STD) for final stability (12 weeks) were $80.5 \pm 4.2$ (IL), $81.9 \pm 3.56$ $(E L)$ and $81.9 \pm 3.4(A E L)$, without statistical difference $(p=0.47)$. To evaluate functional implant stability over time, an ANOVA for repeated samples was performed indicating a significant increase $(p=0.003)$ in stability for each group. The lack of time versus method interaction $(p=0.97)$ indicates that the variations are similar in all groups. Conclusions: At 12 weeks, there are no significant differences in the stability of implants in function of different loading times.
\end{abstract}

Key words: dental implants, immediate loading, early loading, resonance frequency analysis, functional implant stability, animal studies

\title{
INTRODUCTION
}

Dental implants are considered a predictable treatment for the replacement of lost teeth. In modern dental implantology advanced treatment protocols (e.g. immediate or early loading) are frequently used to reduce treatment time. Nowadays patients would like their dental treatment have caused therapies to be faster, with little or no suffering to the patient. Researchers and professionals seek alternative ways of treatment with dental implants which do not require the waiting period of 3-6 months, are commended initially by Branemark ${ }^{1}$. 
This has led to the introduction of dental implant techniques using protocols of immediate or early loading, aiming at shortening or eliminating the time the patient stays without the prosthesis or uses a removable temporary prosthesis. This benefits comfort, chewing function, speech and stability, besides improving psychological factors during the process ${ }^{2,3}$.

Several studies have shown the success and predictability of immediate or early loading in rehabilitations with implants ${ }^{4-18}$. However, these studies do not assess whether these different treatment protocols cause differences in treatment quality in a short and long term.

There are several definitions in literature for the term immediate and early loading, according to Ganeles \& Wismeijer ${ }^{19}$, immediate loading or restoration has been defined as attachment of a restoration in or out of direct occlusal function within 48 hours of surgical placement. Early loading of dental implants has been defined as restoration of implants in or out of occlusion at least 48 hours after implant placement, but at a shorter time interval than conventional healing.

Despite the belief that any waiting in loading provides a more suitable basal zone of the bone for implant activation, the study on bone remodeling demonstrates the opposite. On the day of the implant placement, the bone around the implant is stronger, with the presence of the lamellar bone. From the implant placement, a bone remodeling process begins, with resorption of this lamellar bone, stronger and more resistant, being substituted by newly formed bone, weaker and disorganized. This newly formed bone will only be substituted by the lamellar bone eventually and the period for the substitution 
of the lamellar bone by the woven bone and its maturation into lamellar bone is critical and constitutes a period with higher non-infectious risk ${ }^{20-27}$. According to $\mathrm{Strid}^{20}$, the periimplantar bone on the day of implant placement has a more lamellar bone when compared with the same area three months later.

In this context, it is questioned whether immediate loading protocols imply differences in the short and long term compared with early loading protocols.

A way of performing the assessment would be with instruments that assess implant stability through resonance frequency analysis $(R F A)^{28-35}$. It has been suggested that the primary stability of an implant is important for success in osseointegration ${ }^{36}$. Clinically, results of resonance frequency analysis have been correlated with changes in implant stability during bone healing and failures in implant osseointegration ${ }^{33,34}$. The device is used to clinically assess dental implant stability, being sensitive to differences in periimplantar bone hardness ${ }^{34,37}$. The result is an index named "Implant Stability Quotient" (ISQ), which varies from 1 to $100{ }^{38}$. Based on this quotient, comparisons can be established between different treatment times. There is evidence that an ISQ index between 57 and 82 ensures successful implant placement ${ }^{25}$.

The present study was carried out to evaluate the hypothesis that there are no differences in implant stability which were subject to immediate loading, early or advanced early loading protocols after a 12-weeks healing period, using resonance frequency measurements on an animal model. 


\section{MATERIAL AND METHODS}

The study protocol was approved by the University Animal Research Committee (Process 05.1.1318.53.1). Eight young adult male mongrel dogs $( \pm 25 \mathrm{Kg})$ were used. They had intact maxillae and mandibles, were in good general health, and had no viral or fungal oral lesions.

The dogs were not fed 12 hours before the surgey in order to prevent vomiting. They received an intramuscular injection of preanesthetic (2\% xylazinhydrocloride, $20 \mathrm{mg} / \mathrm{kg}$ ) and then anesthetized intravenously with thiopental $(1 \mathrm{~mL} / \mathrm{kg} ; 20 \mathrm{mg} / \mathrm{kg}$ thiopental diluted in $50 \mathrm{~mL}$ saline). A full thickness flap was raised in the region of the 4 mandibular premolars and the teeth were sectioned in the buccolingual direction and extracted with forceps. The flaps were repositioned and sutured with absorbable 4-0 sutures. Until the end of experiment the diet was modified to a soft consistency.

A healing period of 3 months was allowed before second-stage surgery. During the healing period, the animals were evaluated periodically and received, under sedation with an intramuscular injection of preanesthetic (2\% xylazinhydrocloride, $20 \mathrm{mg} / \mathrm{kg}$ ), monthly ultrasound prophylaxis.

After the healing period, the animals received 20,000 IU penicillin and streptomycin $(1.0 \mathrm{~g} / 10 \mathrm{~kg})$ the night before surgery. This dose provided antibiotic coverage for 4 days. So, another dose was given 4 days later; thus, coverage was provided for a total of 8 days. This broad-spectrum antibiotic is commonly used to treat infections in small animals ${ }^{26}$. 
After repeating the same sedation and anesthesia as in phase 1 , a horizontal crestal incision was made from the distal region of the canine to the mesial region of the first molar, and implants were placed according to the manufacturer's instructions. Three $4.3 \times 10 \mathrm{~mm}$ implants (Replace Select Tapered, Nobel Biocare, Sweden), with rough surfaces, (TiUnite surfaces, Nobel Biocare, Sweden) were placed at the level of bone crest on each side of the mandible of each animal, for a total of 48 implants (Figure 1).

Impressions were taken from each hemimandible (Xantopren \& Optosil, Heraeus Kulzer GmbH, Hanau, Germany), and casts were poured to be used at the prosthetic phase.

The resonance frequency analysis (RFA) method was used to measure functional implant stability. The measurement was performed using an Osstell instrument (Integration Diagnostics AB, Gothenburg, Sweden) with a commercially available transducer. The perpendicular orientation of the transducer along the long axis of the bone was always maintained. The transducer, which is fixed to the implant in the bone, contains a wave source and an analyzer. The wave source vibrates with gradually increasing frequency. The analyzer records the frequency of the source, causing the resonance in the transducer-implant interface. The recorded frequency value in $\mathrm{Hz}$ is converted to an implant stability quotient (ISQ) value, which varies in a range from 0 to 100 , with 100 indicating maximum stability. The method allows measurement with a precision of \pm 1 ISQ. All measurements in this study were performed according to the manufacturer's norms, with 3 readings for each implant in each step, the result being the mean, and with 
the transducer standardized in a bucco-lingual position with the same cable orientation in all measurements in the present study ${ }^{27,37}$, according to Figure 2.

The definitive metallic crowns were fabricated over the casts with standard abutments in a nickel-chromium alloy (VeraBond II, Aalba Dent. Inc., Cordelia, CA, USA), with a gap for retention in the proximal faces in order to facilitate the splinting between the crows, according to the sequence of loading, with chemical resin (Duralay, reliance Dental, MFG Co., Worth, IL, USA). The crown margins were placed at the gingival level and the distance between the contact point and the crestal bone was $3 \mathrm{~mm}$. The first implant was selected for immediate loading protocol (IL), and the two remaining received healing abutments until the delivery of the prostheses according to loading protocol. After the surgery to place the implants, the one selected for immediate load received a temporary acrylic restoration (Duralay, Reliance Dental, MFG Co., Worth IL, USA) made directly over the implant. In the remaining implants healing abutments were connected and the flaps were repositioned and sutured with nonresorbable sutures (figure 3).

Intraoral adjustments were performed to eliminate any direct occlusal contact, verified with double-sided occlusal marking film (Accu Film II, Parkell, Farmingdale, NY, USA).

After seven days, the temporary restoration of $\mathrm{IL}$ implants were removed and a new stability measurement was performed in compliance with the same procedures described before. Following the first and the second (middle) implants received the metallic prostheses, with the last representing 
the early loading protocol $(E L)$. These crowns had retention holes in the proximals and were bonded with Duralay acrylic resin (Reliance Dental, MFG Co., Raleigh - CA, USA).

Fourteen days after the implant placement, a new implant stability measurement was performed, and the posterior implant received the definitive prosthesis (Figure 4) for the advanced early loading protocol (AEL), which was bonded to the middle implant with Duralay acrylic resin.

During the time that the prostheses remained in place the dogs were sedated with intramuscular injection of preanesthetic $(2 \%$ xylazinhydrocloride, $20 \mathrm{mg} / \mathrm{kg}$ ) and ultrasound prophylaxis was done weekly. Twelve weeks after the prostheses the last stability measurement were made and the animals were sacrificed.

\section{RESULTS}

Implant stability quotient (ISQ) data are reported as mean values with standard deviations (SD). In this study, the data were subjected to statistical analysis (SPSS 15.0, SPSS Inc., Chicago - III, USA). Group normality was tested using the Shapiro-Wilk test. Afterwards, the data were subjected to nonparametric Friedman's analysis of variance (ANOVA). A difference was considered significant when $p<0.05$.

The obtained results are summarized in Table 1. 


\section{Initial stability}

For each group, 16 implants were performed and the mean values of initial stability verified in the different loading times were $77.88 \pm 4.61$ (IL), $79.73 \pm 3.55(E L)$ and $79.64 \pm 3.00(A E L)$. The data were subject to ANOVA, with no statistically significant difference between the groups $(p=0.30)$.

\section{Final stability}

The mean final stability values verified in the different implant loading times were $80.46 \pm 4.23(\mathrm{IL}), 81.88 \pm 3.55(\mathrm{EL})$ and $81.88 \pm 3.42(\mathrm{AEL})$. The data were subject to ANOVA, without any statistically significant difference between the groups $(p=0.47)$.

\section{Variation of implant stability over time}

To evaluate the functional implant stability in function of time, the ANOVA for repeated samples was used and a statistically significant difference was found $(p=0.003)$ indicating, for each group, a significant increase in final stability at the end of the study.

Analyzing the time versus method interaction, there was no statistically significant difference $(p=0.97)$, showing that the variations were similar for the three studied groups.

\section{DISCUSSION}

The Osstell transducer was conceived so as to resonate at sonic level, and the vibration amplitude was small, neither applying significant stress to 
the implant nor impairing $\mathrm{it}^{33,37}$. A histomorphometric study suggests that the resonance frequency results were suitable to evaluate the level of boneimplant contact ${ }^{32}$

However, some caution is fundamental to use the device correctly. Studies demonstrate that the transducer orientation during the device measurement significantly alters the results, that is, different transducer positions in the same implant generate differences in the results ${ }^{27,37,39}$. Thus, it is necessary to standardize the position for all readings.

The height of the implant platform and, consequently, of the transducer in relation with the osseous crest, has been discussed in the literature as a likely cause of alterations in measurement results ${ }^{33-35}$. Even though there is no consensus about the topic, for caution and standardization reasons, the platform was always placed at the level of the crestal bone.

The analysis of the implants' primary stability, performed right after implant placement, did not show statistically significant differences $(p=0.30)$, evidencing that all implants showed equivalent initial conditions. It is important to note that there was little variation in the results, demonstrated by the standard deviations found. Yet, taking into account data from previous studies $^{25}$, the general ISQi index obtained in this study $(79.80 \pm 3.80)$ indicates excellent stability for all implants placed.

Furthermore, the analysis of the implants' final stability measured after 12 weeks, did not show statistically significant differences $(p=0.47)$, evidencing that stability was equivalent for all implants, also with small standard deviations. This way, after 12 weeks, there is better implant 
stability, evidencing better osseous conditions when compared to those on the day of implant placement. Due to the detected evolution, this condition worsens in the first two weeks, probably because of the substitution of the lamellar bone for newly formed bone, as discussed previously, confirming the findings of other authors ${ }^{25,28}$ and the occurrence of the bone cicatricial process described by Cochran and colleagues ${ }^{40}$. However, these differences disappeared after a 12-week healing period, demonstrating that, despite discrepancies in relation to the day of implant placement, this does not lead to differences in the quality of implant stability, neither in the medium nor, probably, in the long term when seen from the implant stability standpoint.

Analyzing, each loading time, the evolution of the implant stability, there was a statistically significant variation $(p=0.003)$ between the initial and the final period. Overall, there were lower initial values than those obtained after three months of implant placement.

It is interesting to point out that the substitution of the lamellar bone for newly formed bone due to mechanical or thermal injury, typical of the implant placement, directly affects the primary stability of the tested implants, as seen in the results demonstrated by this study, considering the evolution of the bone tissue healing.

Of the two types of bone found around the implant, the lamellar bone is an organized bone, highly mineralized, and with higher mechanical resistance. However, it grows fairly slowly when compared to the newly formed bone ${ }^{22}$, which is disorganized, less mineralized and mechanically weaker, and grows at a six-times higher rate ${ }^{23}$. 
Roberts and colleagues ${ }^{24}$ reported a $1 \mathrm{~mm}$ or more area with osseous devitalization around the implant as a consequence of the surgery. While this bone is reabsorbed, a fast bone matrix apposition in this region is necessary to substitute the affected volume. Taking into account that the newly formed bone grows much faster, the implant is surrounded by this bone in the first weeks after surgery. The authors demonstrated that, in this study, after 4 months the bone around the implant is only $60 \%$ mineralized.

Considering the above mentioned information, the placement of immediate or early load in the implants would not be advisable. The present paper has demonstrated that, even though this initial phase of bone remodeling directly affects the primary stability of the implant, it is not enough to compromise the osseointegration and, consequently, the treatment. Considering the primary stability, different loading times do not cause alterations in the medium term. It is important to point out that this study was performed in dogs and with rough surface implants. Precaution is required when using the results in other situations. According to some authors ${ }^{41,42}$, the ISQ index should be used carefully and new studies are required, especially with a histologic and longitudinal design ${ }^{43}$.

With histomorphometric analysis Jayme and cols. ${ }^{44}$ verified that the rate of bone-to-implant contact was $77,9 \pm 1,71 \%$ (ranging from 58,96 to $84,21 \%)$ for immediate loading protocol; for early loading protocol was 79,25 $\pm 2,11 \%$ (ranging from 68,81 to $86,33 \%$ ); and for advanced early loading protocol was $79,42 \pm 1,49 \%$ (ranging from 68,39 to $84,33 \%$ ). The bone density for immediate load implants was $69,97 \pm 3,81 \%$ (ranging from 42,63 
to $81,05 \%$ ); for early loaded implants was $69,23 \pm 5,68 \%$ (ranging from 49,47 to $85,88 \%$ ); and, finally, for the advanced early loaded implants was $69,19 \pm$ $2,90 \%$ (ranging from 69,19 to $85,31 \%$ ). In relation to crestal bone loss, the authors verified that when immediate load protocol was used the value was $1,57 \pm 0,22 \mathrm{~mm}$ (ranging from 0,00 to $2,21 \mathrm{~mm}$ ); for early load protocol was $1,23 \pm 0,19 \mathrm{~mm}$ (ranging from 0,00 to $1,97 \mathrm{~mm}$ ) and for the advanced early load protocol was $1,17 \pm 0,32 \mathrm{~mm}$ (ranging from 0,00 to $1,76 \mathrm{~mm}$ ). There were no significant differences for any evaluated parameter $(p>0.05)$. Therefore, it was concluded that different early loading times seems not significantly affect the bone response around dental implants. The implant stability data achieved in this study, by resonance frequency analysis, were compatible and corroborate these results.

This study also proves the usefulness of RFA to monitor the evolution of functional implant stability.

\section{CONCLUSION}

Considering the limitations of this study, the following conclusions are made:

- Implant stability diminishes in the initial periods after the surgery, and increases in a 12-week period. The period in which the stability ceases to decrease and begins increasing could not be defined in this study;

- The day of the implant placement does not determine the period that implant stability is more fragilized; 
- In the medium term, there were no statistically significant differences in the stability of implants immediately activated or one or two weeks after the implant placement.

\section{ACKNOWLEDGEMENTS}

The authors thank Nobel Biocare for donating the implants and prosthetic components and the São Paulo State Research Support Foundation - FAPESP for the financial support (grant \#2006/04747-0). 


\section{REFERENCES}

1. Branemark PI, Hansson BO, Adell R, Breine $U$, Lindstrom J, Hallen O, et al. Osseointegrated implants in the treatment of the edentulous jaw. Experience from a 10-year period. Scand J Plast Reconstr Surg Suppl. 1977;16:1-132.

2. Schnitman PA, Wohrle PS, Rubenstein JE, DaSilva JD, Wang NH. Tenyear results for Branemark implants immediately loaded with fixed prostheses at implant placement. Int $\mathrm{J}$ Oral Maxillofac Implants. $1997 ; 12: 495-503$

3. Salama H, Rose LF, Salama M, Betts NJ. Immediate loading of bilaterally splinted titanium root-form implants in fixed prosthodontics--a technique reexamined: two case reports. Int J Periodontics Restorative Dent. 1995;15:344-61.

4. Tarnow DP, Emtiaz S, Classi A. Immediate loading of threaded implants at stage 1 surgery in edentulous arches: ten consecutive case reports with 1- to 5-year data. Int J Oral Maxillofac Implants. 1997;12:319-24.

5. Scortecci G. Immediate function of cortically anchored disk-design implants without bone augmentation in moderately to severely resorbed completely edentulous maxillae. J Oral Implantol. 1999;25:70-9.

6. Horiuchi K, Uchida H, Yamamoto K, Sugimura M. Immediate loading of Branemark system implants following placement in edentulous patients: a clinical report. Int J Oral Maxillofac Implants. 2000;15:824-30. 
7. Grunder U. Immediate functional loading of immediate implants in edentulous arches: two-year results. Int J Periodontics Restorative Dent. $2001 ; 21: 545-51$.

8. Olsson M, Urde G, Andersen JB, Sennerby L. Early loading of maxillary fixed cross-arch dental prostheses supported by six or eight oxidized titanium implants: results after 1 year of loading, case series. Clin Implant Dent Relat Res. 2003;5:81-7.

9. Nordin T, Nilsson R, Frykholm A, Hallman M. A 3-arm study of early loading of rough-surfaced implants in the completely edentulous maxilla and in the edentulous posterior maxilla and mandible: results after 1 year of loading. Int J Oral Maxillofac Implants. 2004;19:880-6.

10. van Steenberghe D, Glauser R, Blomback U, Andersson M, Schutyser F, Pettersson A, et al. A computed tomographic scan-derived customized surgical template and fixed prosthesis for flapless surgery and immediate loading of implants in fully edentulous maxillae: a prospective multicenter study. Clin Implant Dent Relat Res. 2005;7:S111-20.

11. Bergkvist G, Sahlholm S, Karlsson U, Nilner K, Lindh C. Immediately loaded implants supporting fixed prostheses in the edentulous maxilla: a preliminary clinical and radiologic report. Int J Oral Maxillofac Implants. 2005;20(3):399-405.

12. Balshi SF, Wolfinger GJ, Balshi TJ. A prospective study of immediate functional loading, following the Teeth in a Day protocol: a case series of 55 consecutive edentulous maxillas. Clin Implant Dent Relat Res. $2005 ; 7: 24-31$ 
13. Ostman PO, Hellman M, Sennerby L. Direct implant loading in the edentulous maxilla using a bone density-adapted surgical protocol and primary implant stability criteria for inclusion. Clin Implant Dent Relat Res. $2005 ; 7: 560-9$

14. Malo P, Friberg B, Polizzi G, Gualini F, Vighagen T, Rangert B. Immediate and early function of Branemark System implants placed in the esthetic zone: a 1-year prospective clinical multicenter study. Clin Implant Dent Relat Res. 2003;5:37-46.

15. Malo P, Rangert B, Dvarsater L. Immediate function of Branemark implants in the esthetic zone: a retrospective clinical study with 6 months to 4 years of follow-up. Clin Implant Dent Relat Res. 2000;2:138-46.

16. Cannizzaro G, Leone M, Esposito M. Immediate functional loading of implants placed with flapless surgery in the edentulous maxilla: 1-year follow-up of a single cohort study. Int J Oral Maxillofac Implants. 2007;22:87-95.

17. Bedrossian E, Rangert B, Stumpel L, Indresano T. Immediate function with the zygomatic implant: a graftless solution for the patient with mild to advanced atrophy of the maxilla. Int $\mathrm{J}$ Oral Maxillofac Implants. $2006 ; 21: 937-42$.

18. Chow J, Hui E, Lee PK, Li W. Zygomatic implants--protocol for immediate occlusal loading: a preliminary report. J Oral Maxillofac Surg. 2006;64:804-11. 
19. Ganeles J, Wismeijer D. Early and Immediately Restored and Loaded Dental Implants for Single-Tooth and Partial-Arch Applications . Int J Oral Maxillofac Implants 2004;19(suppl):92-102.

20.Strid K. Radiographic results. Tissue-integrated Prostheses: Osseointegration in clinical dentistry. Chicago: Quintessence; 1985. p. 187-91.

21. Buchs AU, Levine L, Moy P. Preliminary report of immediately loaded Altiva Natural Tooth Replacement dental implants. Clin Implant Dent Relat Res. 2001;3:97-106.

22. Chiapasco M, Gatti C, Rossi E, Haefliger W, Markwalder TH. Implantretained mandibular overdentures with immediate loading. A retrospective multicenter study on 226 consecutive cases. Clin Oral Implants Res. 1997;8:48-57.

23. Roberts W, Turkey P, Brezniak N, Fielder P. Implants: bone physiology and metabolism. CDA Journal. 1987;31:3-9.

24. Roberts WE, Smith RK, Zilberman Y, Mozsary PG, Smith RS. Osseous adaptation to continuous loading of rigid endosseous implants. Am J Orthod. 1984;86:95-111.

25. Ersanli S, Karabuda C, Beck F, Leblebicioglu B. Resonance frequency analysis of one-stage dental implant stability during thr osseointegration period. J Periodontol. 2005;76:1006-1071.

26. Veltri M, Balleri $P$, Ferrari M. Influence of transducer orientation on Osstell stability measurements of osseointegrated implants. Clin Implant Dent Relat Res. 2007;9:60-4. 
27. Pattijn V, Jaecques SV, De Smet E, Muraru L, Van Lierde C, Van der Perre G, et al. Resonance frequency analysis of implants in the guinea pig model: influence of boundary conditions and orientation of the transducer. Med Eng Phys. 2007;29:182-90.

28. Barewal RM, Oates TW, Meredith N, Cochran DL. Resonance frequency measurement of implant stability in vivo on implants with a sandblasted and acid-etched surface. Int J Oral Maxillofac Implants. 2003;18:641-51.

29. Friberg B, Sennerby L, Meredith N, Lekholm U. A comparison between cutting torque and resonance frequency measurements of maxillary implants. A 20-month clinical study. Int J Oral Maxillofac Surg. 1999;28:297-303.

30. Glauser R, Sennerby L, Meredith N, Ree A, Lundgren A, Gottlow J, et al. Resonance frequency analysis of implants subjected to immediate or early functional occlusal loading. Successful vs. failing implants. Clin Oral Implants Res. 2004;15:428-34.

31 Heo SJ, Sennerby L, Odersjo M, Granstrom G, Tjellstrom A, Meredith N. Stability measurements of craniofacial implants by means of resonance frequency analysis. A clinical pilot study. J Laryngol Otol. 1998;112:53742.

32. Rasmusson L, Meredith N, Cho IH, Sennerby L. The influence of simultaneous versus delayed placement on the stability of titanium implants in onlay bone grafts. A histologic and biomechanic study in the rabbit. Int J Oral Maxillofac Surg. 1999;28:224-31. 
33. Meredith N, Alleyne D, Cawley P. Quantitative determination of the stability of the implant-tissue interface using resonance frequency analysis. Clin Oral Implants Res. 1996;7:261-7.

34. Meredith N, Book K, Friberg B, Jemt T, Sennerby L. Resonance frequency measurements of implant stability in vivo. A cross-sectional and longitudinal study of resonance frequency measurements on implants in the edentulous and partially dentate maxilla. Clin Oral Implants Res. 1997;8:226-33.

35. Meredith N, Shagaldi F, Alleyne D, Sennerby L, Cawley P. The application of resonance frequency measurements to study the stability of titanium implants during healing in the rabbit tibia. Clin Oral Implants Res. 1997;8:234-43.

36. Friberg B, Jemt T, Lekholm U. Early failures in 4,641 consecutively placed Branemark dental implants: a study from stage 1 surgery to the connection of completed prostheses. Int $\mathrm{J}$ Oral Maxillofac Implants. $1991 ; 6: 142-6$

37. Pattijn V, Van Lierde C, Van der Perre G, Naert I, Vander Sloten J. The resonance frequencies and mode shapes of dental implants: Rigid body behaviour versus bending behaviour. A numerical approach. J Biomech. 2006;39:939-47.

38. AB Id. Clinical Manual Osstell. Savedalen, Sweden. (http://www.osstell.com/filearchive/2/2540/ID_25006-0_Clin_Manual.pdf) 39. Novaes Junior AB, Vidigal Junior GM, Novaes AB, Grisi MF, Pollonni S, Rosa A. Immediate implants placed into infected sites: a 
histomorphometric study in dogs. Int $\mathrm{J}$ Oral Maxillofac Implants. $1998 ; 13: 422-427$

40. Cochran DL, Schenk R, Lussi A, Higginbottom FL, Buser D. Bone response to unloaded titanium implant with a sandblasted and acidetched surface: A histometric study in the canine mandible. J Biomed Mater Res. 1998;40:1-11.

41. Rasmusson L, Kahnberg KE, Tan A. Effects of implant design and surface on bone regeneration and implant stability: an experimental study in the dog mandible. Clin Implant Dent Relat Res. 2001;3:2-8.

42. Bernard JP, Szmukler-Moncler S, Pessotto S, Vasquez L, Belser UC. The anchorage of Branemark and ITI implants of different lengths. I. An in vivo study in the canine mandible. Clin Oral Implants Res. 2003;14:593-600.

43. Bischof M, Nedir R, Szmucler-Moncler S, Bernard JP, Samson J. Implant stability measurement of delayed and immediately loaded implants during healing. A clinical resonance-frequency analysis study with sandblastedand-etched ITI implants. Clin Oral Implants Res. 2004; 15:529-539.

44. Jayme SJ, Muglia VA, Oliveira RR, Novaes AB Jr, Ribeiro RF. The effects of different loading time on the bone response around dental implants. a histomorphometric study in dogs. Int $\mathrm{J}$ Oral Maxillofac Implants. (Accepted for publication). 2009. 


\section{Figures}

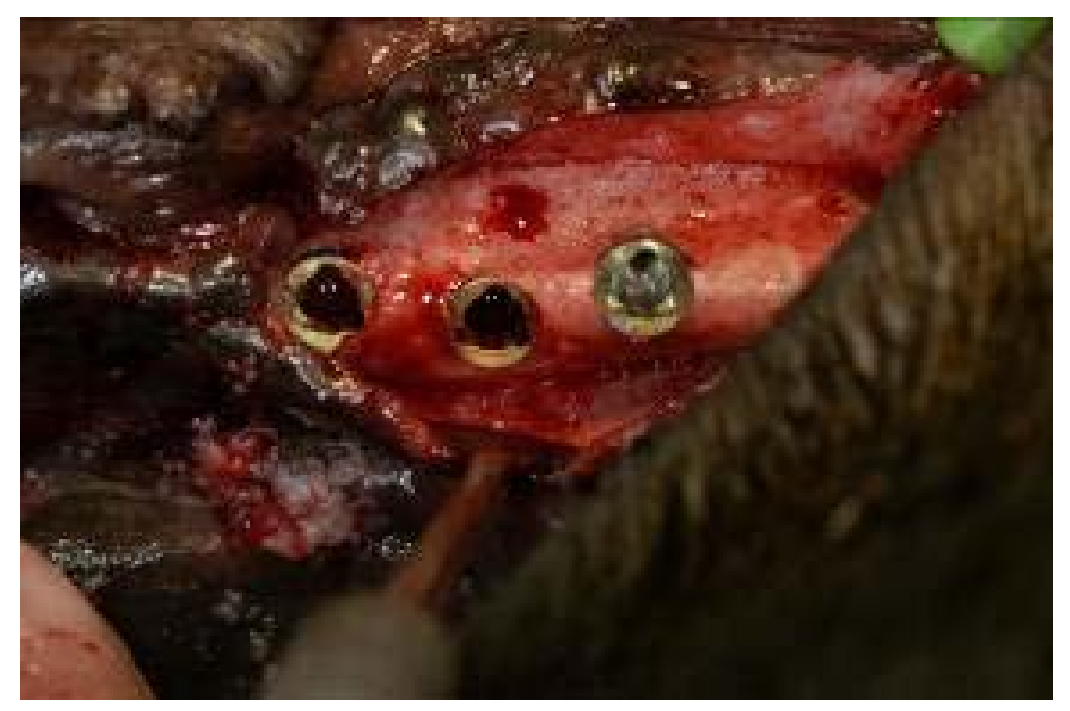

Figure 1

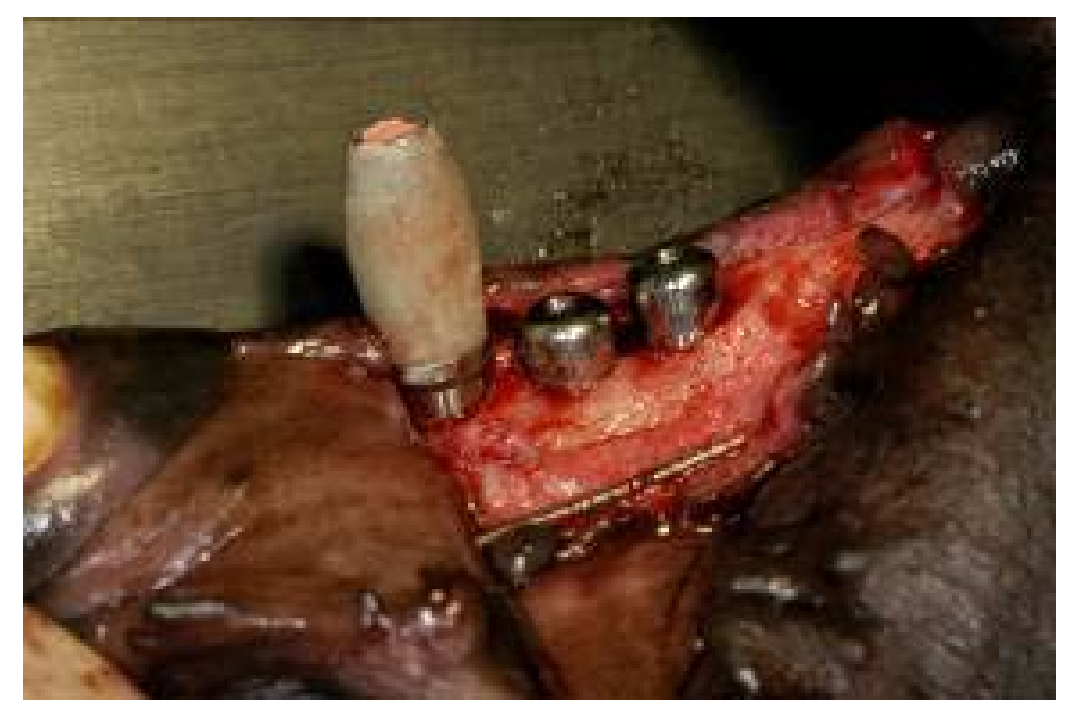

Figure 2 


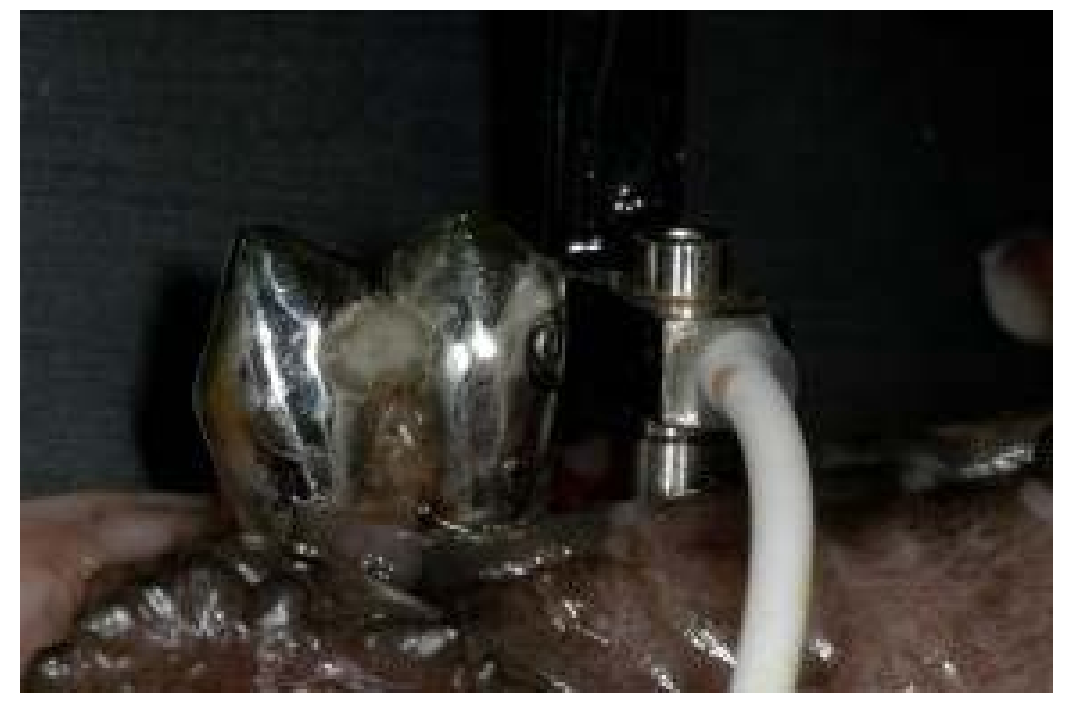

Figure 3

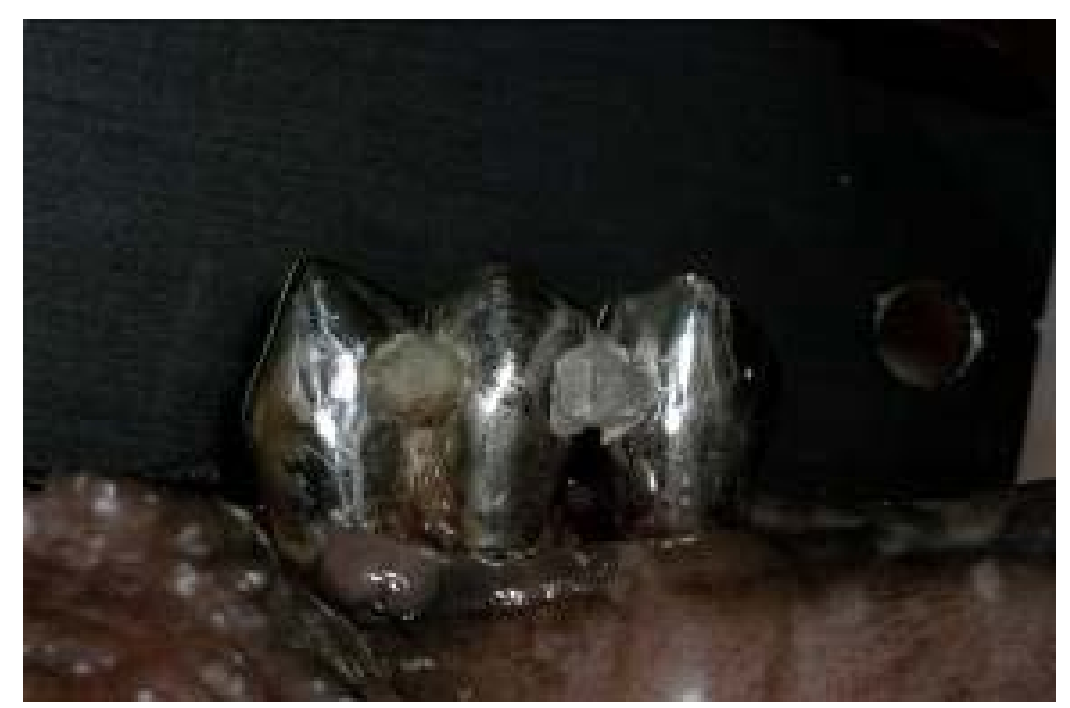

Figure 4 
Table 1- Stability of implants in function of loading protocol

\begin{tabular}{|c|c|c|c|c|c|c|c|c|}
\hline & $\begin{array}{l}\text { Sample } \\
\text { size (n) }\end{array}$ & $\begin{array}{c}\text { ISQi } \\
\text { (primary } \\
\text { stability) }\end{array}$ & $\begin{array}{c}\text { Statistical } \\
\text { significance } \\
\text { between } \\
\text { groups }\end{array}$ & $\begin{array}{c}\text { ISQf } \\
\text { (12 weeks) }\end{array}$ & $\begin{array}{c}\text { Statistical } \\
\text { significance } \\
\text { between } \\
\text { groups }\end{array}$ & $\begin{array}{c}\Delta \mathrm{ISQ} \\
\text { (ISQf-ISQi) }\end{array}$ & $\begin{array}{c}\text { Statistical } \\
\text { difference } \\
\qquad \mathrm{ISQ} \\
\text { (for each time } \\
\text { loading) }\end{array}$ & $\begin{array}{c}\text { Statistical } \\
\text { significance } \\
\text { between } \\
\text { groups }\end{array}$ \\
\hline $\begin{array}{c}\text { Immediate } \\
\text { (IL) }\end{array}$ & 16 & $77.88 \pm 4.61$ & & $80.46 \pm 4.23$ & & $1.88 \pm 5.28$ & & \\
\hline $\begin{array}{c}7 \text { days } \\
(E L)\end{array}$ & 16 & $79.73 \pm 3.55$ & $0.30^{\mathrm{ns}}$ & $81.88 \pm 3.55$ & $0.47^{\mathrm{ns}}$ & $2.15 \pm 4.15$ & $0.003^{*}$ & $0.97^{\mathrm{ns}}$ \\
\hline All implants & 48 & $79.08 \pm 3.80$ & & $81.40 \pm 3.73$ & & $2.14 \pm 4.59$ & & \\
\hline
\end{tabular}

ns => not significant; * significant at $\alpha=0.05$ 


\section{Figure legends:}

Figure 1- Implants placement.

Figure 2- Temporary acrylic restoration.

Figure 3- Measuring the implant stability at posterior implant.

Figure 4- Metallic crowns on implants, splinted with acrylic resin. 


\section{Anexo 3 - ARTIGO 02 (Versão em inglês)}

The effects of different loading time on the bone response around dental implants. A histomorphometric study in dogs. 
Abstract

Purpose: The aim of this study was to evaluate the effect that different loading time will have on the bone response around implants through a histomorphometric analysis. Materials and Methods: Three Replace Select implants were placed on each side of the mandible in 8 dogs totaling 48 implants in the study. One pair of implants was selected for immediate loading protocol (IL). After seven days the second pair of implants received the prostheses for the early loading protocol (EL). Fourteen days after the implant placement the third pair of implants received the prostheses for the advanced early loading (AEL). Following a period totaling twelve weeks of prosthetics, the animals were sacrificed and the specimens were prepared for histomorphometric analysis. The differences between loading time in the following parameters: bone-to-implant contact (BIC), bone density (BD) and crestal bone loss (CBL) were evaluated through ANOVA. Results: The percentage of $\mathrm{BIC}$ for IL was $77.9 \pm 1.71 \%$, for EL was $79.25 \pm 2.11 \%$ and for AEL was $79.42 \pm 1.49 \%$. The percentage of $B D$ for IL was $69.97 \pm 3.81 \%$, for EL was $69.23 \pm 5.68 \%$ and for AEL was $69.19 \pm 2.90 \%$. The CBL for IL was $1.57 \pm 0.22 \mathrm{~mm}$, for EL was $1.23 \pm 0.19 \mathrm{~mm}$ and for AEL was $1.17 \pm 0.32 \mathrm{~mm}$. There was no statistical difference for any of the parameters evaluated ( $p>0.05)$. Conclusion: Different early loading time does not seem to significantly affect the bone response around dental implants.

Key Words: dental implants, early loading, immediate loading, bone density, bone-to-implant contact, osseointegration, animal studies 


\section{INTRODUCTION}

The healing of dental implants into the jawbone is based on the principle of osseointegration $^{1,2}$; this principle originally called for healing period of several months and was aimed at the establishment of a direct bone-to-implant contact that, according to definition, must be proved by means of histologic analysis.

The current successful rates for oral rehabilitation with dental implants in the mandible have reached more than $95 \%{ }^{3}$. The original Brånemark implant protocol required a stress-free submerged healing time of 3 to 6 months to obtain osseointegration ${ }^{4,5}$. The prolonged undisturbed healing time was thought to be necessary to avoid fibrous tissue encapsulation around the implants instead of osseointegration ${ }^{5}$; however, later clinical and experimental evidence revealed that implants osseointegrate even when left exposed to the oral cavity during healing ${ }^{6}$. Traditionally, during this healing period patients were rehabilitated by means of removable prostheses, however, it was noticed that provisionals prostheses were uncomfortable due of the lack of stability and retention, it would therefore be beneficial if the healing period could be shortened without jeopardizing implant success. With the high clinical success rates obtained by the original implant protocol clinicians and researchers achieved confidence to further develop and refine the technique with new implant designs and treatment concepts. .,6,7 $^{3}$

There has also been a change of focus in implant therapy from being originally a strictly functional rehabilitation to be a treatment modality with a major emphasis on aesthetics. Immediate implant restoration with functional 
loading provides better patient comfort, allows quick masticatory function and esthetics. ${ }^{8}$ In addition, it also eliminates the inconvenient of a second surgery approach for placement of healing abutments. This often leads to early soft tissue healing and results in early stabilization of the peri-implant mucosa to ensure higher implant survival. ${ }^{7}$

Several experimental studies have shown that immediate loading of implants did not necessarily lead to fibrous tissue healing. Instead, a bone-toimplant contact develops over time, which is comparable with that of implants that are loaded conventionally ${ }^{7,9-11}$. Implants retrieved from humans with adjacent bone have confirmed these experimental results both in the mandible and maxilla with bone-to-implant contact of up to $93 \% \%^{8,12,13}$.

The peri-implant bone adjusts its architecture in relation to its functional load bearing. The strains induced by these loads affect the bone remodelling process. It is suggested that the magnitude of the load between implant and bone determines the implant success ${ }^{14}$. Therefore, one key for implant success seems to be whether or not bone surrounding of the implant adequately remodels. One millimeter of the bone adjacent to the implant undergoes necrosis after implant placement, this necrotic bone provides important structural support during the initial healing phase, later the formed bone replaces the necrotic one ${ }^{15}$.

Functional activities generate strains on the bone that either directly or indirectly plays a role in the cellular adaptation of bone tissue ${ }^{16}$. The maintenance of the osseointegrated implant involves continued remodelling activity at the periphery of the implant ${ }^{17}$. In this context it is no longer 
considered that immediate loading leads to connective tissue healing of implants ${ }^{18}$. In contrast, a certain amount of microstrain may lead to improved mineralization of the peri-implant bone ${ }^{19}$. Some experimental studies available in the literature provides data on bone-to-implant contact and bone density with immediately loaded implants ${ }^{9,20-24}$. However, these parameters can provide important information on the course of bone remodeling around immediately loaded implants.

Therefore, the aim of this study is to verify, in the dog mandible, the bone-to-implant contact, bone density and crestal bone loss around implants with different loading time.

\section{MATERIAL AND METHODS}

The University Animal Research Committee approved the experimental protocol (Process 05.1.1318.53.1). Eight young adult male mongrel dogs $( \pm 25 \mathrm{~kg})$ were used. The dogs had intact maxillae and mandibles, were in good general health and had no viral or fungal oral lesions. The animals were not fed 12 hours before the surgery to prevent vomiting. They were sedated and then anesthetized intravenously with thiopental (1 $\mathrm{ml} / \mathrm{kg} ; 20 \mathrm{mg} / \mathrm{kg}$ thiopental diluted in $50 \mathrm{ml}$ saline). In sequence, a full thickness flap was raised in the region of the 4 mandibular premolars and the teeth were sectioned in the buccolingual direction and extracted with forceps. The flaps were repositioned and sutured with absorbable 4-0 sutures. During the healing period, the animals were evaluated periodically and received monthly ultrasound prophylaxis. Impressions were taken from 
the right and left lower mandible (Xantopren \& Optosil, Heraeus Kulzer $\mathrm{GmbH}$, Hanau, Germany), and casts were generated and used during the prosthetic phase. Until the end of experiment the diet was modified to a soft consistency.

After a healing period of three months, the animals received 20,000 IU penicillin and streptomycin $(1.0 \mathrm{~g} / 10 \mathrm{~kg})$ the night before surgery. This dose provided antibiotic coverage for 4 days; thus another dose was given 4 days later to provide coverage for a total of 8 days. This broad spectrum antibiotic is commonly used to treat infections in small animals ${ }^{25}$. After, repeating the same sedation and anesthesia as described before, a horizontal crestal incision was made from the distal region of the canine to the mesial region of the first molar and implants were placed according to the manufacturer's instructions. Three $4.3 \times 10 \mathrm{~mm}$ implants (Replace Select ${ }^{\circledR}$ Tapered, Nobel Biocare, Sweden), with rough surfaces (TiUnite ${ }^{\circledR}$, Nobel Biocare, Sweden) were placed at the level of bone crest (figure 1), on each side of the mandible of each animal totaling 48 implants in the study. One implant was selected for immediate loading protocol (IL) (figure 2), the two remaining implants in the hemi-mandible received healing abutments until the delivery of the prostheses according to the loading time. After seven days the second implant received the prostheses for the early loading protocol (EL) (figure 3). Fourteen days after the implant placement the third implant received the prostheses for the advanced early loading (AEL) (figure 4). The implants which received the different loading protocols ${ }^{26,27}$ were randomly assigned through a coin toss. 
After implant placement an impression was made and the implants selected for the immediate loading protocol received a temporary acrylic restoration (Duralay, Reliance Dental, MFG Co., Worth, IL, USA) made directly over the implant. The metallic crowns were fabricated over the casts with standard abutments in a nickel-chromium alloy (VeraBond II, Aalba Dent. Inc., Cordelia, CA, USA), with a gap for retention in the proximal faces in order to facilitate the splinting between the crowns, according the sequence of loading, with chemical activated resin (Duralay, Reliance Dental, MFG Co., Worth, IL, USA). The crown margins were placed at the gingival level. When the implants selected for the early loading received the definitive metallic crowns one week later, the provisional acrylic restorations of the immediate loading implants were removed and replaced by the definitive metallic crowns. During the time that the prostheses remained in place, the dogs were sedated with an intramuscular injection of preanesthetic $(2 \%$ xylazinhydrocloride, $20 \mathrm{mg} / \mathrm{kg}$ ) and ultrasound prophylaxis was done weekly until sacrifice.

Intraoral adjustments were performed to eliminate any direct occlusal contact, verified with double-sided occlusal marking film (Accu Film II, Parkell, Farmingdale, NY, USA).

Following a period totaling twelve weeks of prosthetics, the animals were sedated and then sacrificed with an overdose of thiopental. The crowns and abutments were removed in order to facilitate the histological process. The hemi-mandibles were also removed, dissected and fixed in $4 \%$ formalin $\mathrm{pH} 7.0$ for 10 days, and then transferred to a solution of $70 \%$ ethanol until 
processing. The specimens were dehydrated in increasing concentrations of alcohol up to $100 \%$, infiltrated and embedded in resin (LR White, London Resin, Berkshire, U.K), and sectioned using the "sawing and grinding" technique ${ }^{28}$.

\section{Optic Microscopic analysis - Histomorphometric analysis}

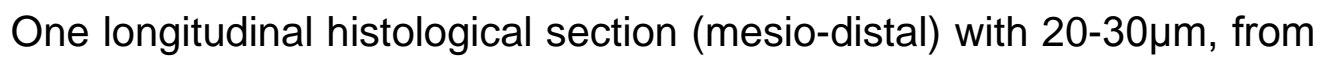
each implant, stained with Stevenel's blue and Alizarin red S was captured through a video camera (Leica Microsystems, Nussloch, Germany) joined to a stereomicroscope (Leica Microsystems, Nussloch, Germany) with a magnification of $1.5 \mathrm{x}$. The images were analyzed through an imaging program (Image J, National Institutes of Health, Bethesda, MD, USA). The following measurements were made (figure 5):

\section{Bone- to- Implant Contact:}

The bone-to-implant contact (BIC) was defined as the length of the bone surface border in direct contact with the implant/complete implant periphery $[\times 100(\%)]$ starting from the most coronal thread down to the most apical thread.

\section{Bone Density}

The bone density (BD) around implants was determined as bone area/tissue area $[\times 100(\%)]$, present within the rectangle that measured $1 \mathrm{~mm}$ 
x $5 \mathrm{~mm}$, corresponding to $512 \times 2560$ pixels. The rectangle was positioned on the most coronal thread.

\section{Crestal Bone Loss}

Through linear measurements (expressed in $\mathrm{mm}$ ), from the top of the implant to the first bone-implant contact, the amount of crestal bone loss $(\mathrm{CBL})$ was determined. When the crestal bone was coronal to the top of the implant, 0mm was used as measurement.

A blinded single examiner made the measurements. The figures 6-8 represent the histological sections from each group.

\section{Statistical Analysis}

Prior to statistical analysis, multiple measurements per animal and treatment were aggregated using their arithmetic mean. Mean values and standard deviation were calculated. The data were grouped using the dogs as units for analysis. The mean differences were verified through the ANOVA non-parametric test with a significance level of $5 \%$. All calculations were performed using a specific statistical program (SPSS version 15, SPSS inc., Chicago, IL, USA).

\section{RESULTS}

\section{Clinical findings}

Post extraction healing was uneventful in all animals. At implant surgery 12 weeks later, the extraction sites appeared healed, clinically. After 
implant placement, healing was also uneventful, without complications throughout the experimental period. During the healing period, all the implants were stable until the end of the investigation.

\section{Histological observations}

In the three groups, implants were surrounded by bone tissue that was comprised of lamellar, woven bone and newly formed bone. The bone tissue was characterized by parallel or concentric formations. Central canals were of different diameters, covered by an active endosteum, and at some points were in close contact with the implant surface. Additionally, during the bone density analysis higher densities were observed closer to the implants surface.

\section{Histomorphometric results}

The histomorphometric results of percentages of direct BIC around the implants, shown in Table 1 revealed that the average percentage of direct $\mathrm{BIC}$, in the IL group was $77.9 \pm 1.71 \%$ (ranging from $58.96 \%$ to $84.21 \%$ ), in the EL group was $79.25 \pm 2.11 \%$ (ranging from $68.81 \%$ to $86.33 \%$ ) and in the AEL group was $79.42 \pm 1.49 \%$ (ranging from $68.39 \%$ to $84.33 \%$ ). The differences were not statistically significant between groups ( $p>0.05)$. Figures 9 to 11 show implant frequency distribution in relation to the BIC percentages for IL, EL and AEL, respectively. The IL and EL group showed a higher frequency of implants (9) and AEL (7) with values varying between $70 \%$ and $80 \% \mathrm{BIC}$. In the IL group only one implant showed value varying between 
$50 \%$ and $60 \%$ BIC. Another 3 implants for IL group, 5 for EL and 6 for AEL showed values varying between $80 \%$ and $90 \%$ BIC. Percentages of less than $50 \%$ were not found in all groups.

Bone density analysis, shown in Table 2 , revealed that the percentage of bone inside de rectangle for the IL group was $69.97 \pm 3.81 \%$ (ranging from $42.63 \%$ to $81.05 \%$ ), for the EL group was $69.23 \pm 5.68 \%$ (ranging from $49.47 \%$ to $85.88 \%$ ) and for the AEL group was $69.19 \pm 2.90 \%$ (ranging from $44.15 \%$ to $85.31 \%$ ). The differences were not statistically significant between the groups $(p>0.05)$.

The histomorphometric measurements for the crestal bone loss shown in Table 3 revealed that the CBL for the IL group was $1.57 \pm 0.22 \mathrm{~mm}$ (ranging from 0.00 to $2.21 \mathrm{~mm}$ ), for the EL group was $1.23 \pm 0.19 \mathrm{~mm}$ (ranging from 0.00 to $1.97 \mathrm{~mm}$ ) and for the AEL group was $1.17 \pm 0.32 \mathrm{~mm}$ (ranging from 0.00 to $1.76 \mathrm{~mm}$ ). The differences were not statistically significant between the groups $(p>0.05)$. Figure 12 presents the implant frequency distribution in relation to the CBL for the IL, EL and AEL, respectively. The IL and EL groups showed 3 and AEL 5 implants without bone loss (0mm). The IL, EL and AEL groups showed CBL frequency distribution varying between 1 to $2 \mathrm{~mm}$ for 9,12 and 10 implants, respectively. Only one implant in the IL group showed CBL of $3 \mathrm{~mm}$ or more. The CBL between 2 to $3 \mathrm{~mm}$ were found in 3 implants for IL group and 1 implant for EL and AEL groups. 


\section{DISCUSSION}

The high predictability of delayed loading of dental implants in the mandible has led to a re-evaluation of the surgical and prosthetic protocol ${ }^{29}$. Nowadays, comparable success rates can be expected from immediately loaded implants and it has been shown that immediate loading of dental implants has not caused untoward effects on the bone/implant interface, producing, on the contrary, a higher percentage of bone-to-implant contact than in submerged implants. ${ }^{7,9-11}$ Factors such as the primary stability and splinting of dental implants ${ }^{30}$, adequate bone density and absence of overloading have been reported to influence the osseointegration process and prognosis of immediate loading implants ${ }^{22,31}$.

The classic two-stage protocol is associated with longer treatment time and the elimination of a long healing period offers advantages in terms of cost of treatment and convenience to patients. It has also been reported that the new restoration is uniformly judged superior to the pre-treatment situation within one week, especially when contrasted to conventional removable complete denture ${ }^{32,33}$.

In different experimental trials, several histological aspects of immediately loaded implants have been highlighted, unfortunately, the animals used in these studies shown metabolic rates that were at least more than twice of that of humans ${ }^{7-10,20,34}$, also in animal studies more parameters can be kept constant than ever possible in a clinical trial, so a very cautious approach to the transfer the histological results to a human situation has to 
be made ${ }^{21}$. However, these data can provide important information to understand the course of the early bone response around implants.

Long term maintenance and success of osseointegrated implants involves the continued remodeling activity at the periphery of the implant to avoid bone fatigue fracture ${ }^{9}$ and to replace bone that may have sustained microfractures as a result of cyclic loading ${ }^{35,36}$. Mechanical load plays an important role in the development, maintenance and adaptation of the skeleton ${ }^{37}$. Wolf's law demonstrates the connection between mechanical events such as bone remodeling, bone formation and bone resorption ${ }^{38-40}$. Bone adaptation is dependent upon strain magnitude, duration, frequency, history, type and distribution ${ }^{41}$.

In an animal study performed by Berglundh et al. ${ }^{42}$ it was reported that implants exposed to a functional load exhibit a higher degree of bone-toimplant contact, and the functional load may enhance osseointegration. The data of the present investigation regarding to bone-to-implant-contact were comparable with the values that can be found in the current literature ranging from 72 to $85 \%^{20,21,43}$. The high predictability of immediately loaded implants supplied with fixed provisional restorations has also been shown in previous reports ${ }^{44,45}$. This fact seems to indicate that fixed prostheses may help to confine the occlusal forces, which are applied to the bone-to-implant interface, to a physiological range ${ }^{18,32,46,47}$. It is well known that initial implant mobility does not inevitably prevent osseointegration ${ }^{48}$. However, it has been suggested that a micromovement about $28 \mu \mathrm{m}$ or less has no adverse effect on osseointegration, while a micromovement of $150 \mu \mathrm{m}$ or more lead to a 
fibrous tissue healing ${ }^{18,49,50}$. Microstrain may be a favorable stimulus during the healing period of implants. Results obtained with osteoporosis research revealed that strains results in an increased bone density ${ }^{19}$. Similar results were found in dental implants ${ }^{51}$. However, in the present study the bone density has not been increased by IL, EL or AEL ( $>>0.05)$, this could be explained due an excellent bone quality obtained after tooth extraction by allowing a 12-week bone-healing period.

Furthermore in this study, bone resorption was evaluated through crestal bone loss analysis, a measurement made from the top of the implant to the first BIC. To standardize implant placements and to have a reference for the measurement of $\mathrm{CBL}$, all implants were placed at the level of bone crest. As observed in this study, no significant difference in CBL was observed between all groups ( $p>0.05$ ), although, numerically higher $C B L$ was noted in the IL group. Additionally, initial breakdown of the implant-tissue interface generally begins at the crestal region in successfully osseointegrated dental implants. Possible etiological factors of early implant bone loss (from implant placement to 1-year postloading) include surgical trauma, formation of biologic width, implant crestal module, and other factors. This factors associated with loading may have contributed to the CBL achieved in all groups evaluated. However, surgical trauma has been regarded as one of the most commonly suspected etiologies for early crestal bone loss. ${ }^{52}$ Failures in bone adhesion were reported when implants placed in monkeys were overloaded ${ }^{53}$. The possibility of triangular or crater-type defects in a rabbit model was observed as a result of excessive occlusal 
force ${ }^{54}$. However, this observation was contradicted by other investigators when no peri-implant bone resorption in monkeys was observed after applying an excessive occlusal force of $300 \mathrm{~N}^{55}$. Additionally, in other animal studies, continuously loaded implants were reported to be surrounded by compact and mineralized tissues with densities of $100-150 \%$ higher than the original spongy bone ${ }^{56}$. Its important to emphasize that it is well established that the polished collar of theses type of implants never retain crestal bone and as such the height of the collar will always equal the minimum bone loss expected $^{57}$.

One of the major points against immediate loading has been the presence of a necrotic layer of bone adjacent to the implant surface mainly related to a surgical trauma ${ }^{5}$. It has been postulated that this necrotic layer should be replaced by new bone before loading ${ }^{58}$. However, bone remodeling does not occur at the same time around the entire implant, otherwise, mobility would have to be expected during the bone remodeling process. It appears that remodeling is variable, with osteoclastic and osteoblastic activity balanced, so that a stable implant is always maintained during osseointegration ${ }^{9,59}$. Because of inadequate implant site preparation, an increased amount of necrotic bone in the periphery of an implant can be produced, which may lead to the loss of the implant ${ }^{60}$. However, it seems that in the majority of the cases the reduction of the vital bone-to-implant contact can be compensated effectively by the rigid splinting fixation as it has been used in the present study. 
Clinical studies supported the fact that the clinical outcomes of immediate loading are comparable and even superior to conventional loading $^{61-63}$. The results of this study confirm these studies by reporting that loading time does not histomorphometric compromise the bone response, represented by $\mathrm{BIC}, \mathrm{BD}$ and $\mathrm{CBL}$. There were no significant differences among the 3 groups suggesting they may be the same.

\section{CONCLUSIONS}

Within the limits of this study it could be concluded that in dog mandibles, different early loading time does not seem to significantly affect the bone response around implants.

\section{ACKNOWLEDGEMENTS}

This study was partially supported by XXXXXXXXX and XXXXXXXXXXX (Grant \#2006/04747-0). 


\section{REFERENCES}

1. Brånemark PI, Adell R, Breine U, Hansson BO, Lindstrom J, Ohlsson A.Intra-osseous anchorage of dental prostheses. I. Experimental studies. Scand J Plast Reconstr Surg. 1969;3:81-100.

2. Schroeder A, Van Der Zypen E, Stich H, Sutter F. The reaction of bone, connective tissue and epithelium to endosteal implants with sprayed titanium surfaces. J Maxillofac Surg. 1981;9:15-25.

3. Testori T, Wiseman L, Woolfe S, Porter SS. A prospective multicenter clinical study of the Osseotite implant: four-year interim report. Int J Oral Maxillofac Implants. 2001;16:193-200.

4. Adell R, Lekholm U, Rockler B, Brånemark P-I. A 15-year study of osseointegrated implants in the treatment of edentulous jaw. Int $\mathrm{J}$ Oral Surg. 1981;10:387-416.

5. Albrektsson T, Brånemark PI, Hansson HA, Lindström J. Osseointegrated titanium implants. Requirements for ensuring a long-lasting, direct boneto-implant anchorage in man. Acta Orthop Scand. 1981;52:155-170.

6. Becker W, Becker BE, Israelson H, Lucchini JP, Handelsman M, Ammons W, Rosenberg E, Rose L, Tucker LM, Lekholm U. One-step surgical placement of Brånemark implants: a prospective multicenter clinical study. Int J Oral Maxillofac Implants 1997:12: 454-462.

7. Romanos G, Toh CG, Siar CH, Swaminathan D, Ong AH, Donath K, Yaacob $\mathrm{H}$, Nentwig $\mathrm{GH}$. Peri-implant bone reactions to immediately loaded implants. An experimental study in monkeys. J Periodontol. $2001 ; 72: 506-511$. 
8. Ledermann PD, Schenk RK, Buser D. Long-lasting osseointegration of immediately loaded, bar-connected TPS screws after 12 years of function: a histologic case report of a 95-year-old patient. Int $\mathrm{J}$ Periodontics Restorative Dent. 1998;18:552-563.

9. Nkenke E, Lehner B, Weinzierl K, Thams U, Neugebauer J, Steveling H, Radespiel-Tröger M, Neukam FW. Bone contact, growth, and density around immediately loaded implants in the mandible of mini pigs. Clin Oral Implants Res. 2003;14:312-321.

10. Siar $\mathrm{CH}$, Toh CG, Romanos $\mathrm{G}$, Swaminathan $\mathrm{D}$, Ong $\mathrm{AH}$, Yaacob $\mathrm{H}$, Nentwig GH. Peri-implant soft tissue integration of immediately loaded implants in the posterior macaque mandible: a histomorphometric study. J Periodontol. 2003;74:571-578.

11. Nkenke E, Fenner M, Vairaktaris EG, Neukam FW, Radespiel-Tröger M. Immediate versus delayed loading of dental implants in the maxillae of minipigs. Part II: histomorphometric analysis. Int J Oral Maxillofac Implants. 2005;20:540-546.

12. Piattelli A, Paolantonio M, Corigliano M, Scarano A. Immediate loading of titanium plasma-sprayed screw-shaped implants in man: a clinical and histological report of two cases. J Periodontol. 1997;68:591-597.

13. Rocci A, Martignoni M, Burgos PM, Gottlow J, Sennerby L. Histology of retrieved immediately and early loaded oxidized implants: light microscopic observations after 5 to 9 months of loading in the posterior mandible. Clin Implant Dent Relat Res. 2003;5 Suppl 1:88-98. 
14. Hoshaw SJ, Brunski JB, Cochran D. Mechanical loading of Brånemark implants affects interfacial bone modeling and remodeling. Int $\mathrm{J}$ Oral Maxillofac Implants. 1994;9:343-360.

15. Johansson $\mathrm{C}$, Albrektsson T. Integration of screw implants in the rabbit: a 1-year follow-up of removal torque of titanium implants. Int $\mathrm{J}$ Oral Maxillofac Implants. 1987;2:69-75.

16. Fritton SP, McLeod KJ, Rubin CT. Quantifying the strain history of bone: spatial uniformity and self-similarity of low-magnitude strains. J Biomech. 2000;33:317-325.

17. Suzuki K, Aoki K, Ohya K. Effects of surface roughness of titanium implants on bone remodeling activity of femur in rabbits. Bone. 1997;21:507-514.

18. Szmukler-Moncler S, Piattelli A, Favero GA, Dubruille JH. Considerations preliminary to the application of early and immediate loading protocols in dental implantology. Clin Oral Implants Res. 2000;11:12-25. Review.

19. Frost HM. The role of changes in mechanical usage set points in the pathogenesis of osteoporosis. J Bone Miner Res. 1992;7:253-261. Review.

20. Piattelli A, Corigliano M, Scarano A, Quaranta M. Bone reactions to early occlusal loading of two-stage titanium plasma-sprayed implants: a pilot study in monkeys. Int J Periodontics Restorative Dent. 1997;17:162-169.

21. Piattelli A, Corigliano M, Scarano A, Costigliola G, Paolantonio M. Immediate loading of titanium plasma-sprayed implants: an histologic analysis in monkeys. J Periodontol. 1998;69:321-327. 
22. Zubery $\mathrm{Y}$, Bichacho $\mathrm{N}$, Moses $\mathrm{O}$, Tal $\mathrm{H}$. Immediate loading of modular transitional implants: a histologic and histomorphometric study in dogs. Int J Periodontics Restorative Dent. 1999;19:343-353.

23. Ghanavati F, Shayegh SS, Rahimi H, Sharifi D, Ghanavati F, Khalesseh $\mathrm{N}$, Eslami B. The effects of loading time on osseointegration and new bone formation around dental implants: a histologic and histomorphometric study in dogs. J Periodontol. 2006;77:1701-1707.

24. Moon SY, Kim SG, Lim SC, Ong JL. Histologic and histomorphometric evaluation of early and immediately loaded implants in the dog mandible. J Biomed Mater Res A. 2008;15:1122-1127.

25. Novaes Junior AB, Vidigal Junior GM, Novaes AB, Grisi MF, Polloni S, Rosa A. Immediate implants placed into infected sites: a histomorphometric study in dogs. Int $\mathrm{J}$ Oral Maxillofac Implants. $1998 ; 13: 422-427$.

26. Degidi M, Piatelli A. Immediate functional and non-functional loading of dental implants: a 2- to 60-month follow up study of 646 titanium implants. J Periodontol. 2003;74:225-41.

27. Misch CE. Density of bone: effect on treatment planning, surgical approach, and healing. In: Misch CE. Contemporary Implant Dentistry. St. Louis: Mosby, 1993:469-485.

28. Donath K, Breuner G. A method for the study of undercalcified bones and teeth with attached soft tissue. J Oral Pathol 1982;11:318-326. 
29. Tarnow DP, Emtiaz S, Classi A. Immediate loading of threaded implants at stage 1 surgery in edentulous arches: ten consecutive case reports with 1- to 5-year data. Int J Oral Maxillofac Implants 1997:12:319-324.

30. Romanos GE. Surgical and prosthetic concepts for predictable immediate loading of oral implants. J Calif Dent Assoc. 2004;32:991-1001.

31. Engquist B, Astrand P, Anze'n B, Dahlgren S, Engquist E, Feldmann H, Karlsson U, Nord PG, Sahlholm S, Svärdström P. Simplified methods of implant treatment in the edentulous lower jaw. A controlled prospective study. Part II: Early loading. Clin Implant Dent Relat Res 2004:6:90-100.

32. Chiapasco M, Gatti C, Rossi E, Haefliger W, Markwalder TH. Implantretained mandibular overdentures with immediate loading. A retrospective multicenter study on 226 consecutive cases. Clin Oral Implants Res. 1997;8:48-57.

33. Ganeles J, Rosenberg MM, Holt RL, Reichman LH. Immediate loading of implants with fixed restorations in the completely edentulous mandible: report of 27 patients from a private practice. Int $\mathrm{J}$ Oral Maxillofac Implants. 2001;16:418-426.

34. Hönig JF, Merten HA. Subperiosteal versus epiperiosteal forehead augmentation with hydroxylapatite for aesthetic facial contouring: experimental animal investigation and clinical application. Aesthetic Plast Surg. 1993;17:93-98.

35. Norman TL, Wang Z. Microdamage of human cortical bone: incidence and morphology in long bones. Bone. 1997;20:375-379. 
36. van Oosterwyck H, Duyck J, Vander Sloten J, Van der Perre G, De Cooman M, Lievens S, Puers R, Naert I. The influence of bone mechanical properties and implant fixation upon bone loading around oral implants. Clin Oral Implants Res. 1998;9:407-418.

37. Tanck E, Homminga J, van Lenthe GH, Huiskes R. Increase in bone volume fraction precedes architectural adaptation in growing bone. Bone. 2001;28:650-654.

38. Hansson S. The implant neck: smooth or provided with retention elements. A biomechanical approach. Clin Oral Implants Res. 1999;10:394-405.

39. Hansson S. A conical implant-abutment interface at the level of the marginal bone improves the distribution of stresses in the supporting bone. An axisymmetric finite element analysis. Clin Oral Implants Res. 2003;14:286-293.

40. Hansson S, Werke $M$. The implant thread as a retention element in cortical bone: the effect of thread size and thread profile: a finite element study. J Biomech. 2003;36:1247-1258.

41. Turner $\mathrm{CH}$. Three rules for bone adaptation to mechanical stimuli. Bone. 1998;23:399-407. Review.

42. Berglundh T, Abrahamsson I, Lindhe J. Bone reactions to longstanding functional load at implants: an experimental study in dogs. J Clin Periodontol. 2005;32:925-932.

43. Testori T, Szmukler-Moncler S, Francetti L, Del Fabbro M, Scarano A, Piattelli A, Weinstein RL. Immediate loading of Osseotite implants: a 
case report and histologic analysis after 4 months of occlusal loading. Int J Periodontics Restorative Dent. 2001;21:451-459.

44. Romanos GE, Nentwig GH. Immediate loading using cross-arch fixed restorations in heavy smokers: nine consecutive case reports for edentulous arches. Int J Oral Maxillofac Implants. 2008;23:513-519.

45. Ostman PO, Hellman M, Sennerby L, Wennerberg A. Temporary implantsupported prosthesis for immediate loading according to a chair-side concept: technical note and results from 37 consecutive cases. Clin Implant Dent Relat Res. 2008;10:71-77.

46. Brunski JB. Avoid pitfalls of overloading and micromotion of intraosseous implants. Dent Implantol Update. 1993;4:77-81.

47. Salama H, Rose LF, Salama M, Betts NJ. Immediate loading of bilaterally splinted titanium root-form implants in fixed prosthodontics--a technique reexamined: two case reports. Int J Periodontics Restorative Dent. 1995;15:344-361.

48. Ivanoff CJ, Sennerby L, Lekholm U. Influence of initial implant mobility on the integration of titanium implants. An experimental study in rabbits. Clin Oral Implants Res. 1996;7:120-127.

49. Pilliar RM, Lee JM, Maniatopoulos C. Observations on the effect of movement on bone ingrowth into porous-surfaced implants. Clin Orthop Relat Res. 1986;208:108-113.

50. Brunski JB. Biomechanical factors affecting the bone-dental implant interface.Clin Mater. 1992;10:153-201. Review. 
51. Matsumoto H, Ochi M, Abiko Y, Hirose Y, Kaku T, Sakaguchi K. Pulsed electromagnetic fields promote bone formation around dental implants inserted into the femur of rabbits. Clin Oral Implants Res. 2000; 11: 354360.

52. Oh T-J, Yoon J, Misch CE, Wang H-L. The causes of early implant bone loss. Myth or science? J Periodontol. 2002;73:322333.

53. Isidor F. Histological evaluation of peri-implant bone at implants subjected to occlusal overload or plaque accumulation. Clin Oral Implants Res 1997;8:1-9.

54. Duyck J, Ronald H, Van Oosterwyck H, Naert I, Vander Solten J, Ellingsen JE. The influence of static and excessive dynamic loading on the marginal bone behaviour around implants: An animal experimental study. Clin Oral Implants Res 2001;12:207-218.

55. Hurzeler M, Quinones CR, Kohal R, Rohde M, Strub JR, Teuscher U, Caffesse RG. Changes in peri-implant tissues subjected to orthodontic forces and breakdown in monkeys. J Periodontol 1998;69:396-404.

56. Akin-Nergiz N, Nergiz I, Schulz A, Arpak N, Niedermeier W. Reactions of peri-implant tissues to continuous loading of osseointegrated implants. Am J Orthod Dentofacial Orthop 1998;114:292-298.

57. Hämmerle $\mathrm{CH}$, Brägger U, Bürgin W, Lang NP. The effect of subcrestal placement of the polished surface of ITI implants on marginal soft and hard tissues. Clin Oral Implants Res. 1996;7:111-9. 
58. Sagara M, Akagawa $Y$, Nikai $H$, Tsuru $H$. The effects of early occlusal loading on one stage titanium alloy implants in beagle dogs: A pilot study. J Prosthet Dent 1993;69:281-288.

59. Schnitman PA, Wöhrle PS, Rubenstein JE, DaSilva JD, Wang NH. Tenyear results for Brånemark implants immediately loaded with fixed prostheses at implant placement. Int $\mathrm{J}$ Oral Maxillofac Implants. 1997;12:495-503.

60. Tehemar SH. Factors affecting heat generation during implant site preparation: a review of biologic observations and future considerations. Int J Oral Maxillofac Implants. 1999;14:127-136. Review.

61. Donath K. Tissue reactions around loaded and unloaded titanium implants J. Hard Tissue Biol. 1993; 2: 37-47.

62. Esposito M, Grusovin MG, Willings M, Coulthard P, Worthington HV. The effectiveness of immediate, early, and conventional loading of dental implants: a Cochrane systematic review of randomized controlled clinical trials. Int J Oral Maxillofac Implants. 2007;22:893-904. Review.

63. De Smet E, Duyck J, Vander Sloten J, Jacobs R, Naert I. Timing of loading--immediate, early, or delayed--in the outcome of implants in the edentulous mandible: a prospective clinical trial. Int J Oral Maxillofac Implants. 2007;22:580-594. 
TABLES:

Table 1: Percentages of direct bone-to-implant contact around implants with different loading time:

\begin{tabular}{cccc}
\hline $\begin{array}{c}\text { BIC (\%) } \\
\text { dog }\end{array}$ & IL & EL & AEL \\
\hline 1 & 78.88 & 79.88 & 79.69 \\
2 & 77.11 & 76.57 & 78.23 \\
3 & 78.37 & 80.35 & 78.96 \\
4 & 78.12 & 75.75 & 79.12 \\
5 & 74.27 & 79.15 & 81.79 \\
6 & 79.04 & 81.60 & 77.43 \\
7 & 78.14 & 79.31 & 78.79 \\
8 & 79.95 & 81.40 & 81.39 \\
\hline Mean & 77.99 & 79.25 & 79.42 \\
SD & 1.71 & 2.11 & 1.49 \\
$P=0.817$ & $\mathrm{NS}$ & $\mathrm{NS}$ & $\mathrm{NS}$ \\
\hline
\end{tabular}

Significance of differences within ANOVA non-parametric test (ns: non significant) 
Table 2: Percentages of bone density around implants with different loading time:

\begin{tabular}{|c|c|c|c|}
\hline $\begin{array}{c}\text { BD (\%) } \\
\text { dog }\end{array}$ & IL & EL & AEL \\
\hline 1 & 65.79 & 68.34 & 65.21 \\
\hline 2 & 72.45 & 62.35 & 72.17 \\
\hline 3 & 68.70 & 75.56 & 68.69 \\
\hline 4 & 69.31 & 68.33 & 72.23 \\
\hline 5 & 65.47 & 61.99 & 68.48 \\
\hline 6 & 75.76 & 75.17 & 65.10 \\
\hline 7 & 68.02 & 66.39 & 69.84 \\
\hline 8 & 74.27 & 75.67 & 71.83 \\
\hline Mean & 69.97 & 69.23 & 69.19 \\
\hline SD & 3.81 & 5.68 & 2.90 \\
\hline$P=0.921$ & NS & NS & NS \\
\hline
\end{tabular}

Significance of differences within ANOVA non-parametric test (ns: non significant) 
Table 3: Crestal bone loss around implants with different loading time:

\begin{tabular}{|c|c|c|c|}
\hline $\begin{array}{c}\text { CBL (mm) } \\
\text { dog }\end{array}$ & IL & EL & AEL \\
\hline 1 & 1.55 & 1.36 & 1.28 \\
\hline 2 & 1.68 & 1.37 & 0.66 \\
\hline 3 & 1.20 & 0.82 & 0.74 \\
\hline 4 & 1.33 & 1.12 & 1.13 \\
\hline 5 & 1.68 & 1.20 & 1.42 \\
\hline 6 & 1.55 & 1.40 & 1.60 \\
\hline 7 & 1.64 & 1.36 & 1.30 \\
\hline 8 & 1.89 & 1.21 & 1.26 \\
\hline Mean & 1.57 & 1.23 & 1.17 \\
\hline SD & 0.22 & 0.19 & 0.32 \\
\hline$P=0.753$ & NS & NS & NS \\
\hline
\end{tabular}

Significance of differences within ANOVA non-parametric test (ns: non significant) 
FIGURES:

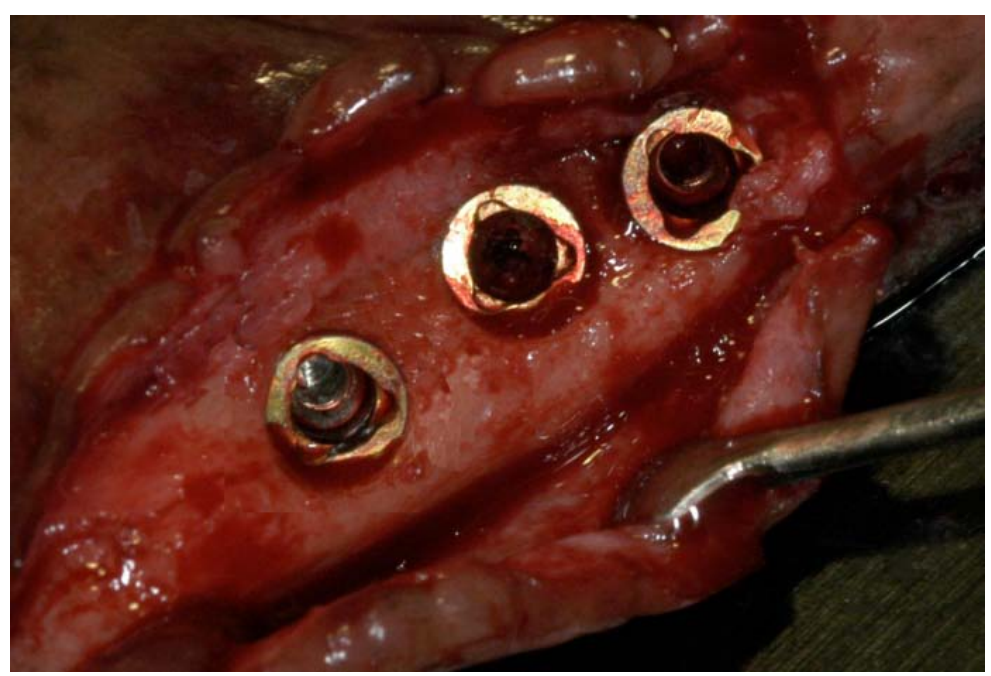

figure 1

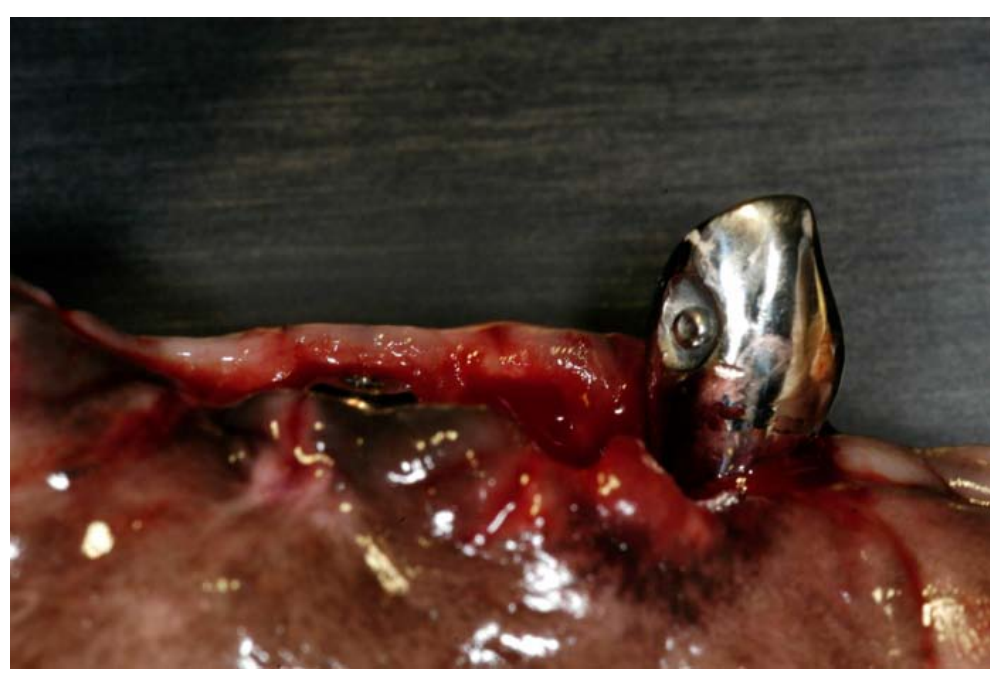

figure 2 


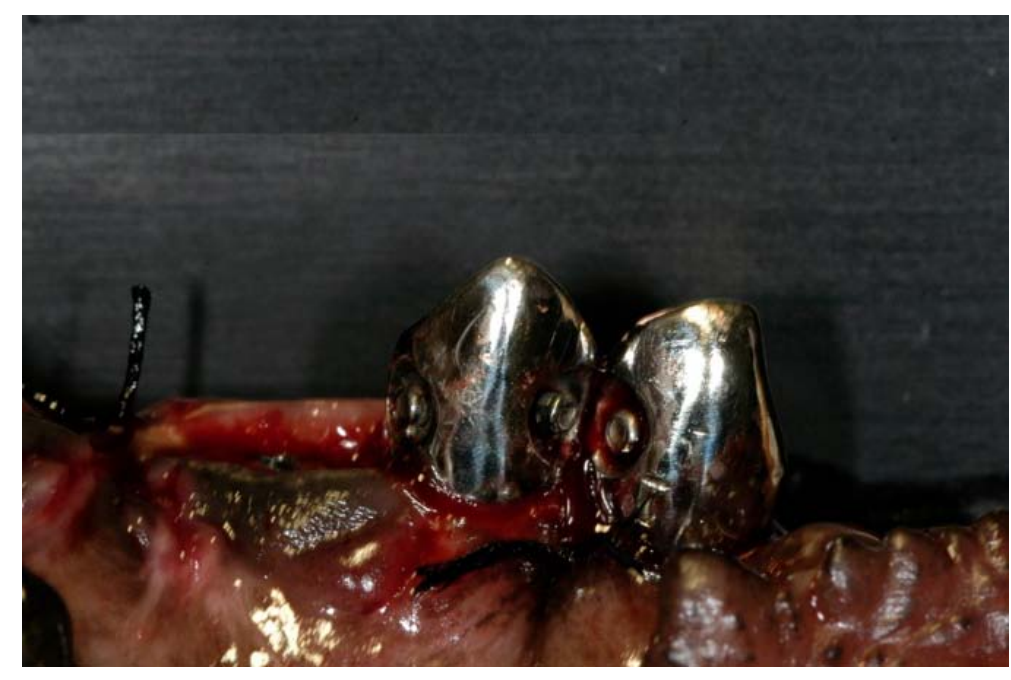

figure 3

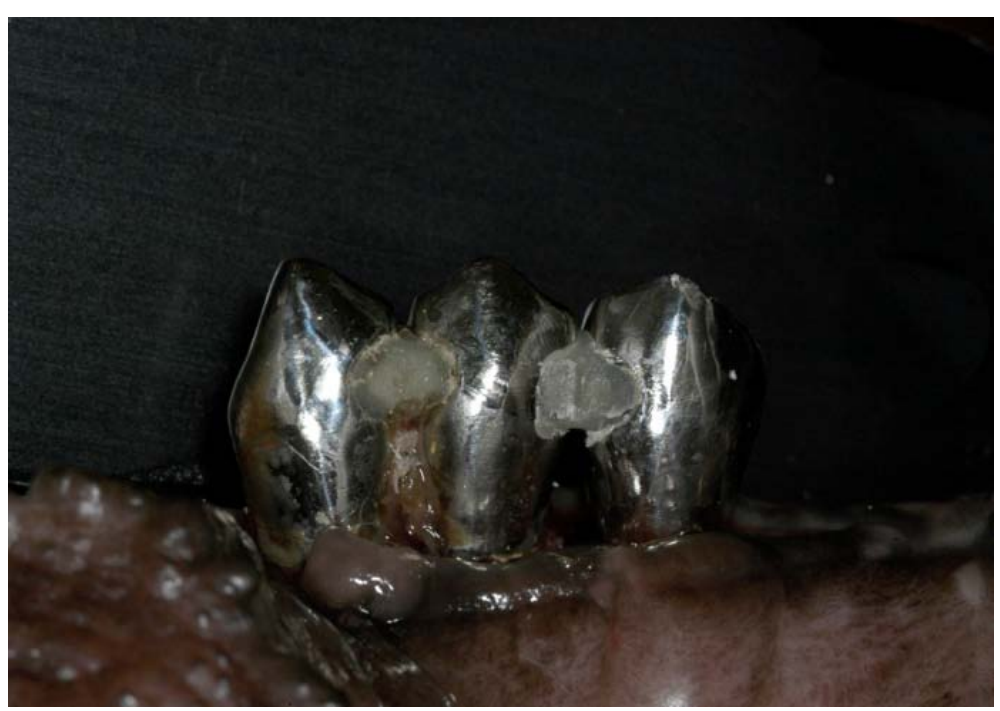

figure 4 


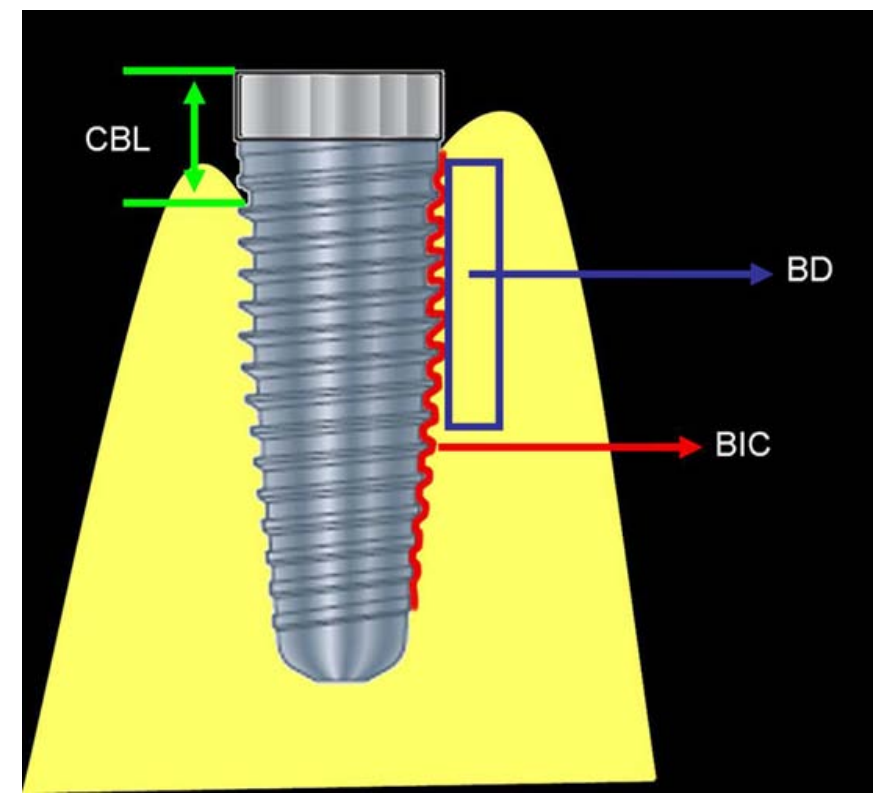

figure 5

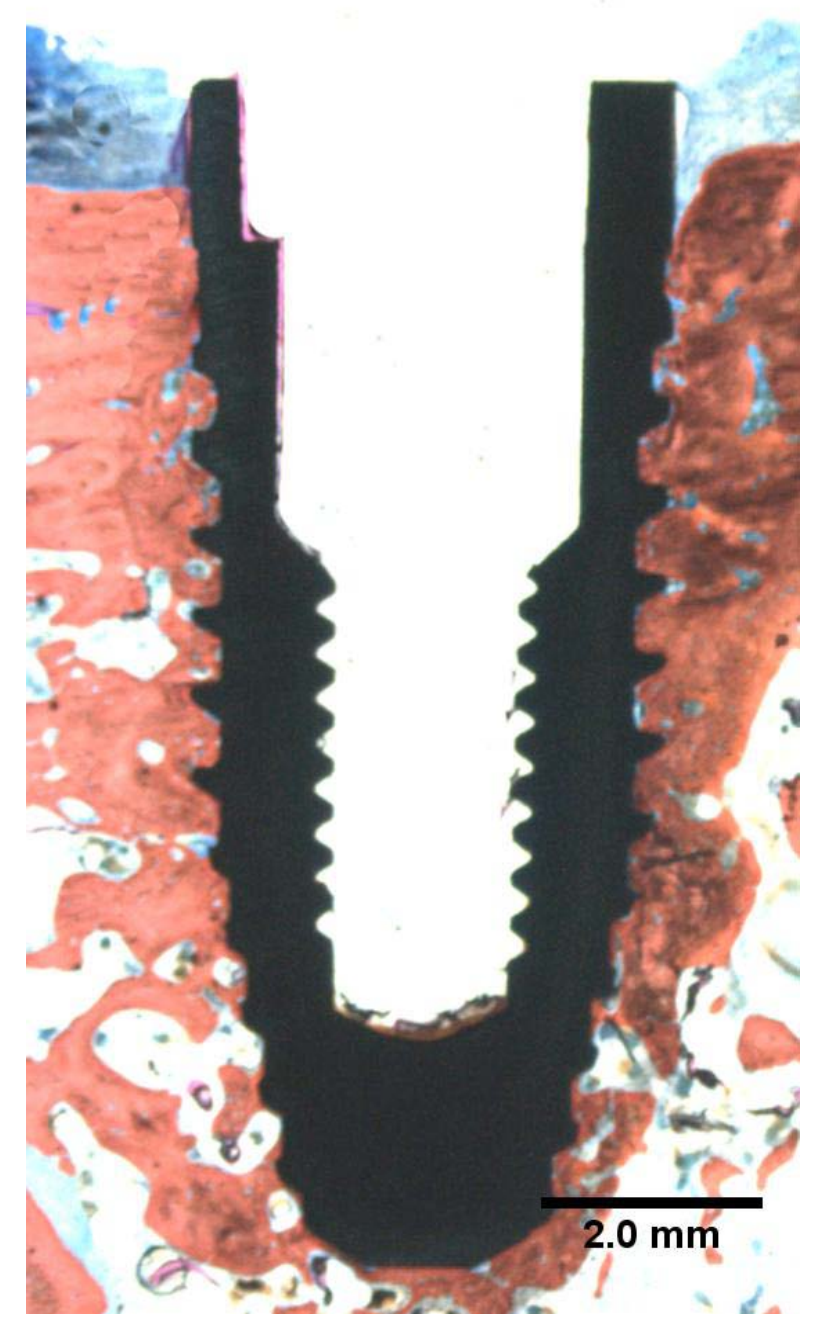

figure 6 


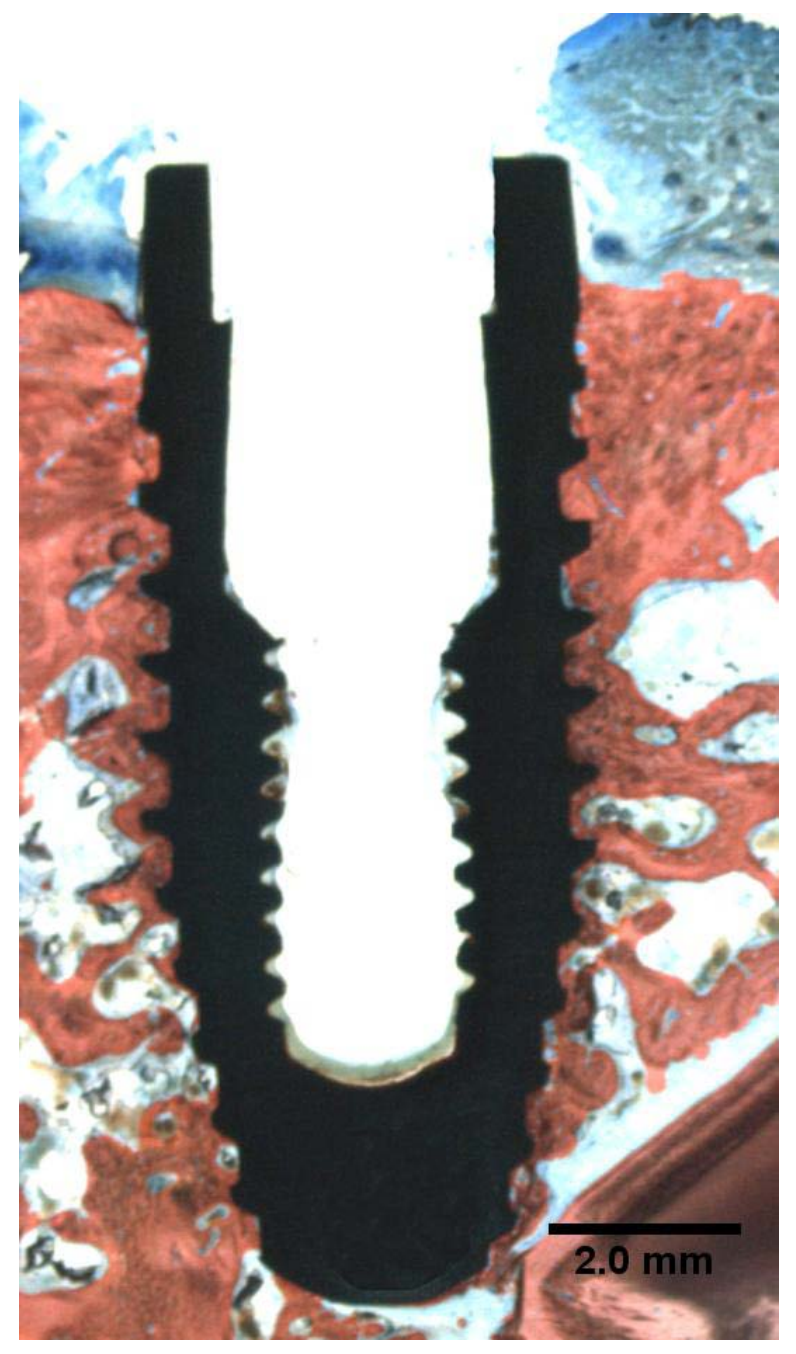

figure 7 


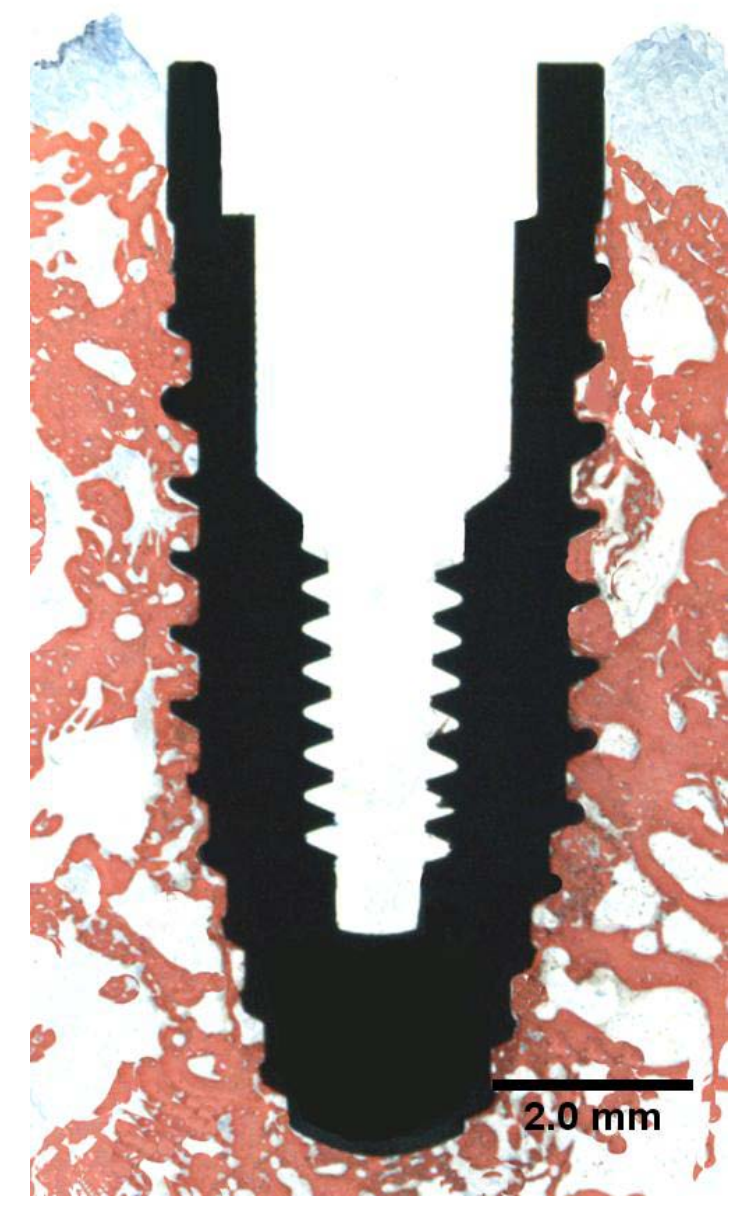

figure 8 


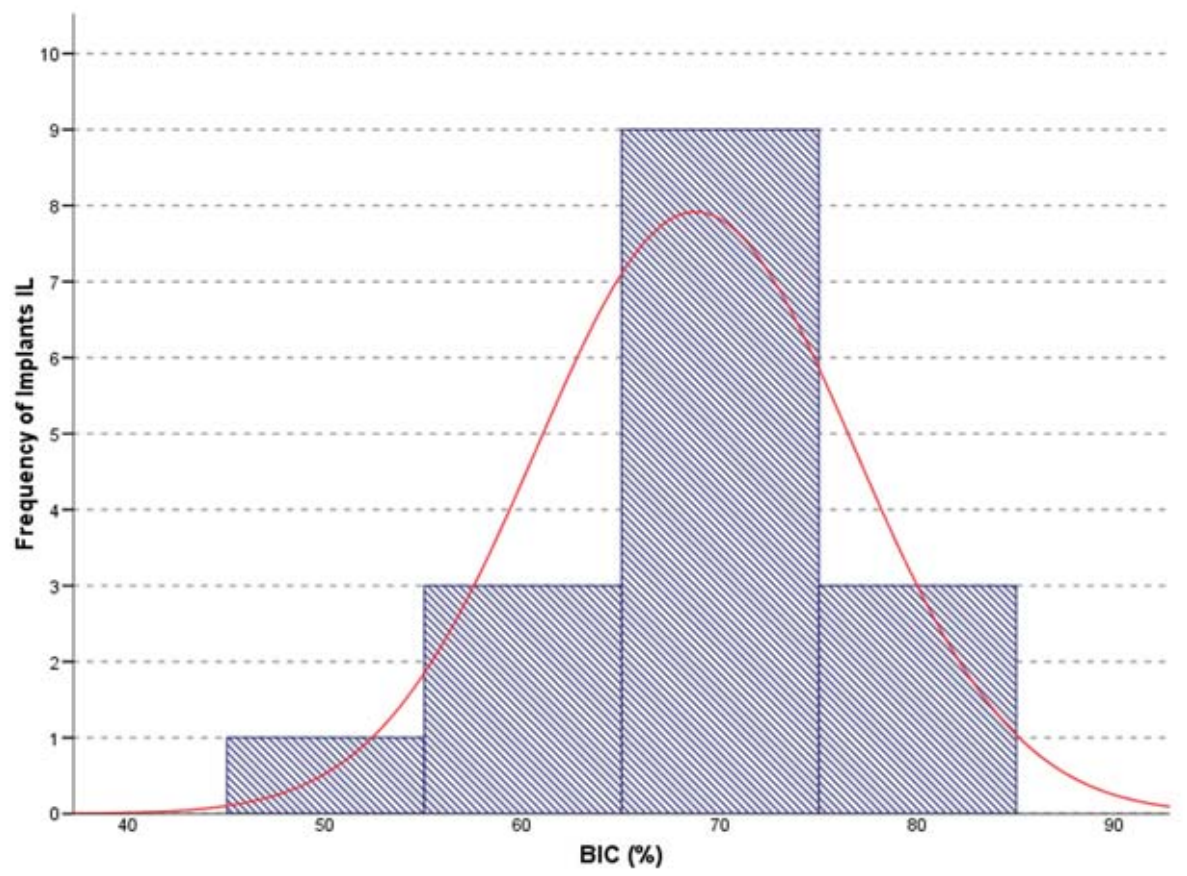

figure 9

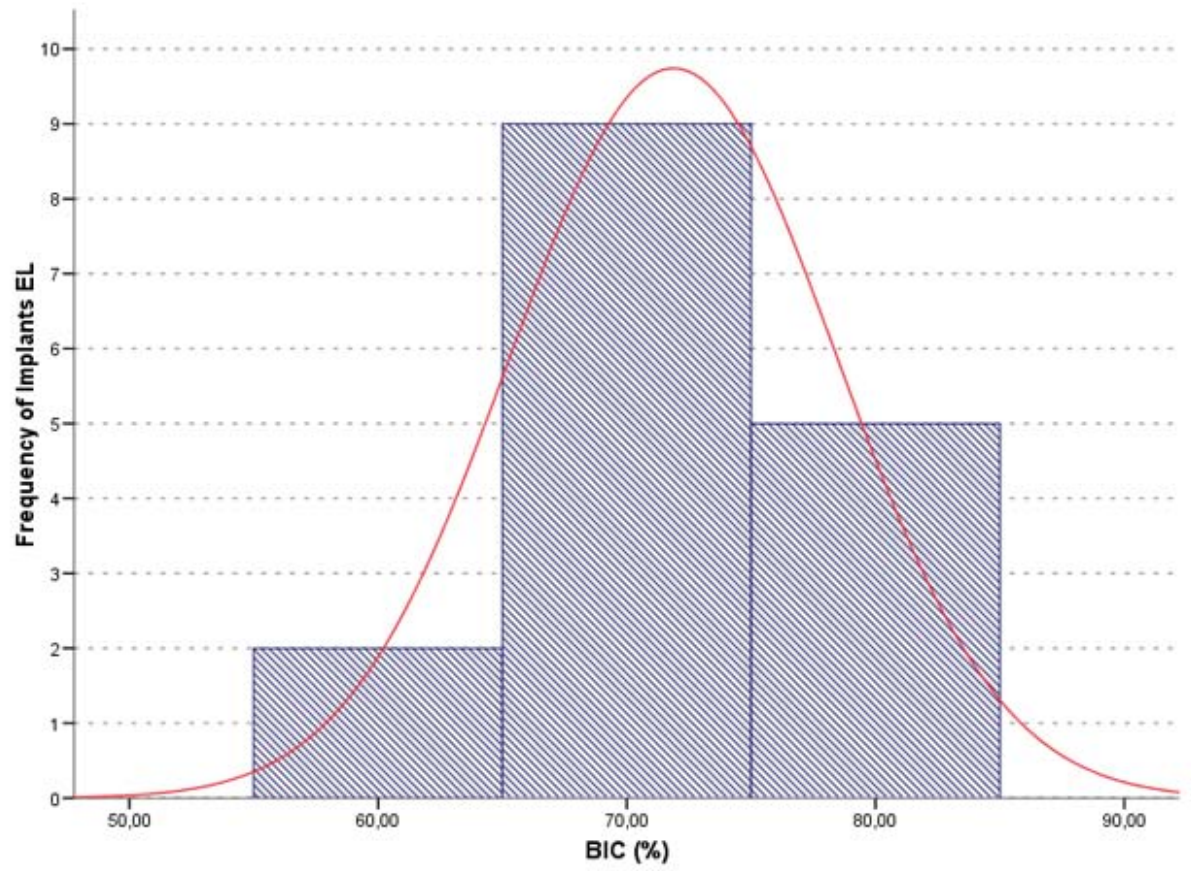

figure 10 


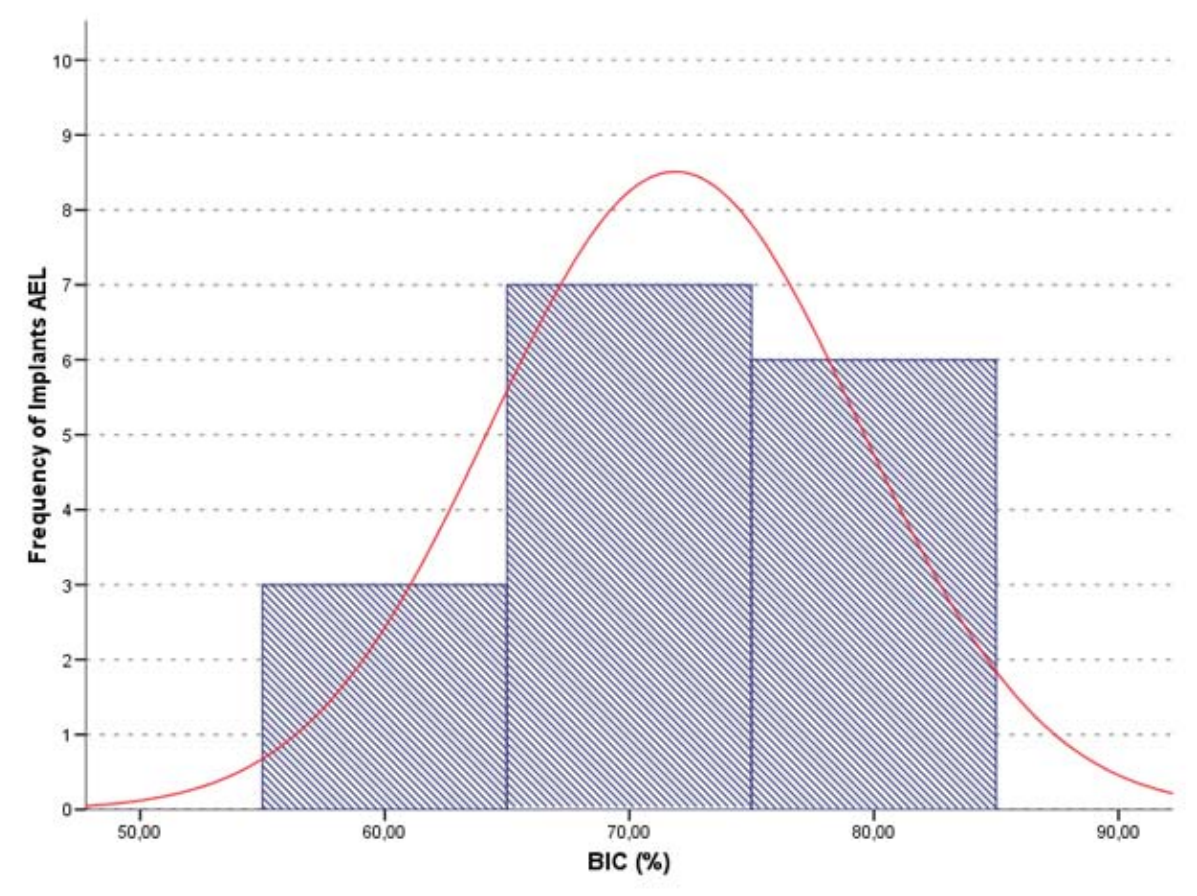

figure 11

\section{Crestal Bone Loss}

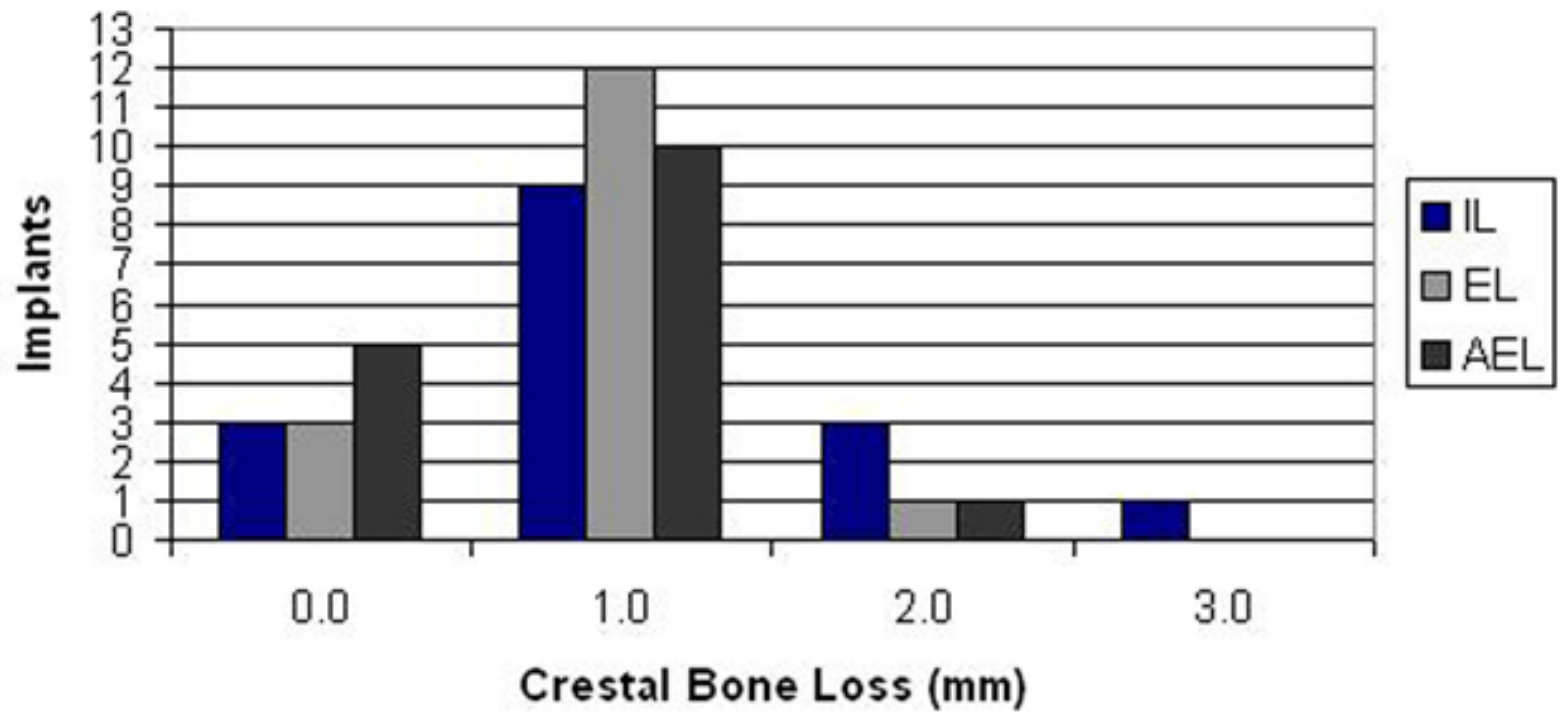

figure 12 


\section{FIGURE LEGENDS:}

Figure 1: Implants in position

Figure 2: Metallic crown placed on the implant selected for the immediate loading, the two remaining implants received healing abutments.

Figure 3: After seven days of implant placement the implant selected for the early loading received the prostheses. Note the gap for retention on the proximal surfaces.

Figure 4: After 14 days of implant placement the implant selected for advanced early loading received the prostheses. Note the crowns splinted with resin.

Figure 5: Schematic representation showing the histomorphometric analysis.

Figure 6: Representative histological section of immediate loading group. (Stevenel's blue and Alizarin red S, original magnification X1.5).

Figure 7: Representative histological section of early loading group. (Stevenel's blue and Alizarin red S, original magnification X1.5).

Figure 8: Representative histological section of advanced early loading group. (Stevenel's blue and Alizarin red S, original magnification X1.5).

Figure 9: The histogram shows a normal distribution with the majority of the values for the immediate loading group around the mean.

Figure 10: The histogram shows a normal distribution with the majority of the values for the early loading group around the mean.

Figure 11: The histogram shows a normal distribution with the majority of the values for the advanced early loading group around the mean. 
Figure 12: Frequency distribution of the number of implants in relation to the crestal bone loss. 


\section{APÊNDICE D}

Normas para publicação no periódico: The International Journal of Oral \& Maxilofacial Implants 
The International Journal of Oral \& Maxillofacial Implants

\section{Author Guidelines}

Submit manuscripts via JOMI's online submission service: www.manuscriptmanager.com/jomi

Manuscripts should be uploaded as a PC Word (doc) file with tables and figures preferably embedded at the end of the document. No paper version is required.

\section{Acceptable material.}

Original articles are considered for publication on the condition they have not been published or submitted for publication elsewhere (except at the discretion of the editors). Articles concerned with reports of basic or clinical research, clinical applications of implant research and technology, proceedings of pertinent symposia or conferences, quality review papers, and matters of education related to the implant field are invited.

\section{Number of authors.}

Authors listed in the byline should be limited to four. Secondary contributors can be acknowledged at the end of the article. (Special circumstances will be considered by the editorial chairman.)

\section{Review/editing of manuscripts.}

Manuscripts will be reviewed by the editorial chairman and will be subjected to blind review by the appropriate section editor and editorial staff consultants with expertise in the field that the article encompasses. The publisher reserves the right to edit accepted manuscripts to fit the space available and 
to ensure conciseness, clarity, and stylistic consistency, subject to the author's final approval.

\section{Adherence to guidelines.}

Manuscripts that are not prepared according to these guidelines will be returned to the author before review.

\section{MANUSCRIPT PREPARATION}

- The journal will follow as much as possible the recommendations of the International Committee of Medical Journal Editors (Vancouver Group) in regard to preparation of manuscripts and authorship (Uniform requirements for manuscripts submitted to biomedical journals. Ann Intern Med 1997;126:36-47).

- See www.icmje.org.

- Manuscripts should be double-spaced with at least a one-inch margin all around. Number all pages. Do not include author names as headers or footers on each page.

- Title page. Page 1 should include the title of the article and the name, degrees, title, professional affiliation, and full address of all authors. Phone, fax, and e-mail address must also be provided for the corresponding author, who will be assumed to be the first-listed author unless otherwise noted. If the paper was presented before an organized group, the name of the organization, location, and date should be included.

- Abstract/key words. Page 2 of the manuscript should include the article title, a maximum of 300-word abstract, and a list of key words 
not to exceed 6. Abstracts for basic and clinical research articles must be structured with the following sections: (1) Purpose, (2) Materials and Methods, (3) Results, and (4) Conclusions. Abstracts for all other types of articles (ie, literature reciews, clinical reports, technologies, and case reports) should not exceed 250 words and need not be structured.

- Introduction. Summarize the rationale and purpose of the study, giving only pertinent references. Clearly state the working hypothesis.

- Materials and Methods. Present materials and methods in sufficient detail to allow confirmation of the observations. Published methods should be referenced and discussed only briefly, unless modifications have been made. Indicate the statistical methods used, if applicable.

- Results. Present results in a logical sequence in the text, tables, and illustrations. Do not repeat in the text all the data in the tables or illustrations; emphasize only important observations.

- Discussion. Emphasize the new and important aspects of the study and the conclusions that follow from them. Do not repeat in detail data or other material given in the Introduction or Results section. Relate observations to other relevant studies and point out the implications of the findings and their limitations.

- Conclusions. Link the conclusions with the goals of the study but avoid unqualified statements and conclusions not adequately supported by the data. In particular, authors should avoid making statements on economic benefits and costs unless their manuscript 
includes the appropriate economic data and analyses. Avoid claiming priority and alluding to work that has not been completed. State new hypotheses when warranted, but clearly label them as such.

- Acknowledgments. Acknowledge persons who have made substantive contributions to the study. Specify grant or other financial support, citing the name of the supporting organization and grant number.

- Abbreviations. The full term for which an abbreviation stands should precede its first use in the text unless it is a standard unit of measurement.

- Trade names. Generic terms are to be used whenever possible, but trade names and manufacturer name, city, state, and country should be included parenthetically at first mention.

\section{REFERENCES}

- All references must be cited in the text, numbered in order of appearance.

- The reference list should appear at the end of the article in numeric sequence.

- Do not include unpublished data or personal communications in the reference list. Cite such references parenthetically in the text and include a date.

- Avoid using abstracts as references. 
- Provide complete information for each reference, including names of all authors (up to six). If the reference is to part of a book, also include title of the chapter and names of the book's editor(s).

\section{Journal reference style:}

1. Johansson C, Albrektsson T. Integration of screw implants in the rabbit: A 1-year follow-up of removal torque of titanium implants. Int J Oral Maxillofac Implants 1987;2:69-75.

\section{Book reference style:}

1. Skalak R. Aspects of biomechanical considerations. In: Brånemark P-I, Zarb GA, Albrektsson $\mathrm{T}$ (eds). Tissue-Integrated Prostheses: Osseointegration in Clinical Dentistry. Chicago: Quintessence, 1985:117-128.

\section{ILLUSTRATIONS AND TABLES}

- All illustrations must be numbered and cited in the text in order of appearance.

- Illustrations and tables should be embedded in a PC Word document.

- All illustrations and tables should be grouped at the end of the text.

- Original slides or high-resolution images must be sent to the Publisher's office upon acceptance of the article.

- Note that article acceptance is pending the receipt of acceptable original art.

Black \& white-Submit three sets of high-quality glossy prints. Should the quality prove inadequate, negatives will be requested as well. Photographs should be unmounted and untrimmed. 
Radiographs-Submit the original radiograph as well as two sets of prints.

Color-Color is used at the discretion of the publisher. No charge is made for such illustrations. Original slides (35-mm transparencies) must be submitted, plus two sets of prints made from them. When a series of clinical images is submitted, tonal values must be uniform. When instruments and appliances are photographed, a neutral background is best.

Drawings-Figures, charts, and graphs should be professionally drawn and lettered large enough to be read after reduction. High-resolution (at least 300 dpi) laser-printed art is acceptable (no photocopies, please); also provide electronic file if possible.

Electronic Files-May be accepted if original figures (as specified above) are unavailable. Resolution must be at least $300 \mathrm{dpi}$; files saved in .tiff or .eps format are preferred.

Legends-Figure legends should be grouped on a separate sheet and typed double-spaced.

MANDATORY SUBMISSION FORM

The Mandatory Submission Form (published in issues 1 and 4 and accessible at www.quintpub.com) must be signed by all authors and faxed to the JOMI Manuscript Editor (630 736 3634)

\section{PERMISSIONS AND WAIVERS}

- Permission of author and publisher must be obtained for the direct use of material (text, photos, drawings) under copyright that does not belong to the author. 
- Waivers must be obtained for photographs showing persons. When such waivers are not supplied, faces will be masked to prevent identification.

- Permissions and waivers should be faxed along with the Mandatory Submission Form to the JOMI Manuscript Editor (630 736 3634).

\section{REPRINTS}

If reprints are desired, they may be ordered from the publisher. Authors receive a discount of $40 \%$ on quantities of 100 or 200 reprints. 